\title{
Engineered biochar - a sustainable solution for the removal of antibiotics
}

\section{from water}

Patrycja Krasucka ${ }^{1}$, Bo Pan ${ }^{2,3}$, Yong Sik $\mathrm{Ok}^{4}$, Dinesh Mohan ${ }^{5}$, Binoy Sarkar ${ }^{6}$ and Patryk Oleszczuk $^{1^{*}}$

${ }^{1}$ Faculty of Chemistry, Department of Radiochemistry and Environmental Chemistry, Maria Curie-Sklodowska University, 3 M. Curie-Sklodowska Sq., 20-031 Lublin, Poland

${ }^{2}$ Faculty of Environmental Science and Engineering, Kunming University of Science and Technology, Kunming, 650500, People's Republic of China

${ }^{3}$ Yunnan Provincial Key Laboratory of Carbon Sequestration and Pollution Control in Soils, Kunming, 650500, People's Republic of China

${ }^{4}$ Korea Biochar Research Center, APRU Sustainable Waste Management \& Division of Environmental Science and Ecological Engineering, Korea University, Seoul, 02841, Republic of Korea

${ }^{5}$ School of Environmental Sciences, Jawaharlal Nehru University, New Delhi 110067, India

${ }^{6}$ Lancaster Environment Centre, Lancaster University, Lancaster, LA1 4YQ, United Kingdom

Corresponding Author* Patryk Oleszczuk, e-mail: patryk.oleszczuk@ poczta.umcs.lublin.pl 


\section{Highlights}

- Antibiotics global consumption and their environmental contamination were shown

- The use biochar for antibiotic sorption yields economic and environmental benefits

- Biochar-based materials are effective in removing antibiotics from water solutions

- Trends in the preparation and application of engineered biochar were described

- Mechanisms involved in the binding and removal of antibiotics were discussed

\section{Graphical abstract}

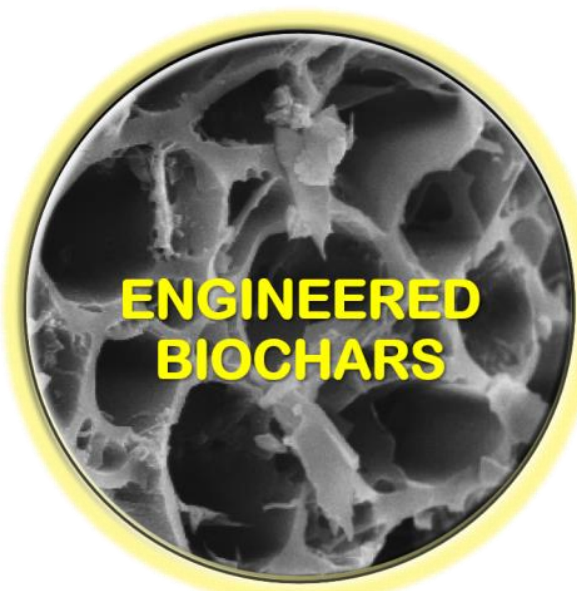

\section{ADSORPTION}

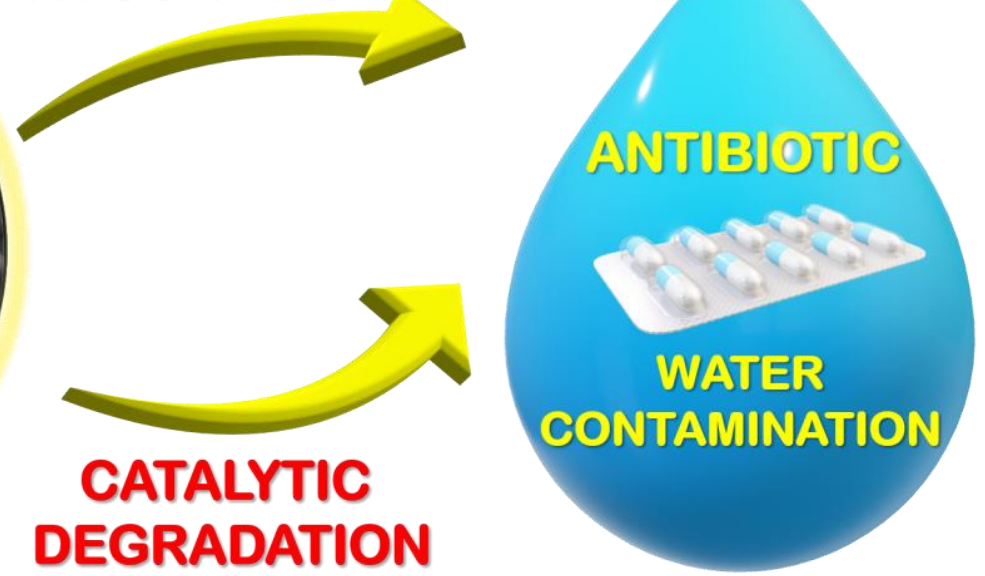




\section{ABSTRACT}

Antibiotic contamination and the spread of antimicrobial resistant bacteria are global environmental issues. Given the growing consumption of antibiotics, it is crucial to reduce their presence in the environment. Adsorption is one of the most efficient methods for removing contaminants from water and wastewater. For this process to be effective, it is of key importance to identify adsorption mechanisms that allow an efficient and selective adsorbent to be chosen. Carbon-based materials (including activated carbon, biochar and black carbon) are typically used for the adsorptive removal of antibiotics. To enhance the efficiency of adsorption of pharmaceuticals, engineered biochars (physically, chemically and biologically modified biochar) and their composites have attracted increasing interests. Biochar-based sorbents can be produced from various feedstocks, including waste products. The use of "green", low cost or sustainable biochar for contaminant sorption yields economic and environmental benefits. Moreover, this is in line with global trends in creating a circular economy and sustainable development. This paper collates the most recent data on the consumption of antibiotics, their related environmental contamination, and their removal using biochar-based materials. Special attention is paid to the newly emerging approaches of biochar modification and biochar composites in relation to the antibiotic removal from water.

Keywords: clean water, sustainable development, designer biochar, composite materials, circular economy 


\section{INTRODUCTION}

Without doubt, the penicillin discovery by Alexander Fleming in 1928 was not only the beginning of a new era in medicine but also a milestone in the history of mankind [1]. Subsequent research conducted by Howard Florey and Ernest Chain led to the commercialization of penicillin in 1945 [2]. This contributed to the intensive development of work on antibiotics, including their commercial application, during the period 1940-1970; this period was termed the "Golden Age" of antibiotic discovery [1-3]. Many lives were saved as a result of the use of this new group of drugs. However, with the wide dissemination of antibiotics, problems associated with their excessive use appeared. Penicillin was replaced with methicillin by 1959 , and with ampicillin in 1961 , due to the appearance of penicillin-resistant bacterial strains [1]. The phenomenon of antimicrobial resistance (AMR) in bacteria has forced the development of ever newer medicinal products; moreover, it also contributed to a continuous increase in the number and cost of antibiotics consumed. AMR is a serious problem, posing a threat to global health. Indeed, many organizations, including the WHO, have set themselves an overriding goal of combating this phenomenon. AMR is associated with the increased use of antibiotics and the associated contamination of the natural environment, which is another serious problem.

Population increases and the related increased demand for food have caused changes in antibiotic use trends. In recent decades (since 1950s) use of such medications on a massive scale in livestock and poultry production as well as in aquaculture has been started [4]. These have been used not as medicinal agents but predominantly as growth promoters and disease prevention additives [5]. In many countries (USA, Canada, Mexico, Israel), antibiotics are also used to grow and protect crops in order to increase yields [6]. Currently, much greater amounts of antibiotics are used to produce food of animal origin (approx. $70 \%$ global antibiotic consumption) versus human medicines (approx. 30\% global antibiotic consumption) [7]. In 
2010, global antibiotic production was 100,000 tons, of which 63,200 tons were drugs for farm animals [5]. By 2030, the usage of veterinary medicines is projected to rise to 105,600 tons per year [5]. These increases in antibiotic consumption are reflected in growing environmental contamination. This is linked to the fact that 30 to $90 \%$ of a drug taken by an organism is excreted, not having been metabolized [8]. Presently, many antibiotics are classified as emerging contaminants (ECs) or contaminants of emerging concern [9]. ECs are naturally occurring compounds or anthropogenically introduced compounds whose presence in the environment may pose a threat to flora and fauna, including humans [10,11]. Globally, residues of antibiotics belonging to various classes, characterized by different properties, biodegradability, or toxicity, are detected not only in wastewater [12,13], liquid manure [14], surface waters [15,16], groundwater [9], soil [8,17], and plants [18,19], but also in drinking water $[20,21]$ and food $[22,23]$. Many of these compounds are characterized by significant persistence and the ability to accumulate in soil and other solid matrices. Exposure of humans and other organisms to contact with antibiotics may affect their own microbiome, disturbing the microbiological balance of entire ecosystems, impairing resistance, and contributing to the development of antibiotic resistant bacteria (ARB) [15,24]. Therefore, it is essential to not only monitor and limit the use of antibiotics but also to effectively remove them from various environmental matrices, in particular water and soil.

Various methods have been used for the removal of organic contaminants from environmental matrices. These are typically classified as (i) destructive methods (biological approaches via microbial degradation, and chemical approaches via the processes of oxidation and precipitation, chlorination, ozonation and photocatalysis), and (ii) non-destructive physical methods including filtration, coagulation/flocculation, sedimentation, ion exchange, membrane processes, and adsorption [25,26]. Among the above-mentioned methods, adsorption is particularly common, especially in the context of antibiotics removal from the environment 
[13], as confirmed by the huge number of scientific publications in the SCOPUS database on "Antibiotic + Adsorption" ( $\approx 4170$ during last 20 years). The process of adsorption occurs at the interface of the liquid and solid (adsorbent) phases. The liquid phase (excretions, e.g., urine, wastewater) is usually the primary source of antibiotic pollution in the environment [26]. It is only due to their further cycling that antibiotics are transferred to solid matrices, e.g., soil, sediment, plants. As a process, adsorption is relatively cheap, simple, and efficient; therefore, it is possible to use it on a large scale in wastewater treatment plants [27-30].

Many types of adsorbents are currently available. These are classified as organic materials (e.g., polymers) and inorganic materials (e.g., silica, clay minerals), which can be of natural (e.g., zeolites, clay minerals) or synthetic (e.g., activated carbon, carbon nanotubes, graphene and graphene oxide, polymer resins, mesoporous silicas) origin [31-34]. It is extremely important to choose an appropriate adsorbent for removing contaminants from water. When an adsorbent's physicochemical properties, i.e., sorption parameters (specific surface area (SBET), pore size), chemical structure, functional groups are known, it can be matched to the contaminant type so that adsorption is as selective and effective as possible [35]. From a practical view point, it is also important for an adsorbent to be sustainable. Activated carbons (ACs) have shown effectiveness in removing inorganic and organic contaminant [36-38]. However, taking the economic factors into account coupled with wide modification possibilities, biochar (BC) based adsorbents have gained importance in recent years [39-43]. The number of scientific papers on "Biochar + Antibiotic" in the SCOPUS database witnessed a remarkable jump from only one in 2011 to $\approx 95$ in 2019 . Biochar $(B C)$ is a carbon-rich product obtained by heating biomass in presence of little or no air at a relatively low temperature $(<700$ ${ }^{\circ}$ C) [44]. BCs can be produced from various types of organic feedstocks, including wastes, e.g., waste biomass, municipal waste, agricultural and livestock waste, food production residues [45,46]. Moreover, BCs are much cheaper than ACs, which further enhances their 
attractiveness. For example, the price of $\mathrm{BCs}$ ranges from $\$ 350$ to $\$ 1,200$ per ton, whereas the price of ACs ranges from $\$ 1,100$ to $\$ 1,700$ per ton [47].

Owing to their appropriate physicochemical properties and thus adsorption properties, which can be additionally improved through various physical and chemical modifications [48,49], BCs have been applied to the adsorption of many contaminants [41,45,50,51]. New literature reports continuously appearing regarding the use of BCs of different origins, including engineered BCs (i.e., modified BCs and BC composites) for the adsorption of antibiotics $[32,52-55]$. This is evidence of the relevance of the production and application of new lowcost, but at the same time "green," adsorbents in the context of environmental pollution by this group of pharmaceuticals.

This paper is a critical review of the most recent literature data regarding the consumption of antibiotics and their associated environmental contamination. It also addresses the use of various $\mathrm{BC}$-based materials (pristine $\mathrm{BCs}$, modified $\mathrm{BCs}$, and $\mathrm{BC}$ composites) for the adsorption and removal of this type of contaminant, with special reference to the mechanisms responsible for their adsorption.

\section{ANTIBIOTICS}

\subsection{GENERAL INFORMATION, DEFINITIONS, AND CLASSIFICATIONS}

In 1941, Selman Waksman was the first to use the word antibiotic (antibiosis from Greek; anti-against, bios-life) to denote those substances produced by microorganisms that inhibit reproduction or kill other microorganisms [56]. Presently, antibiotics are primarily produced synthetically or semi-synthetically and may have a bactericidal effect (i.e., killing bacteria) or a bacteriostatic effect (i.e., inhibiting bacterial growth) [57]. Moreover, apart from their antibacterial activity, they are also used in the treatment of fungal infections and also as cytostatics in the treatment of cancers. In human and animal medicine, about 250 antibiotics 
(antibiotic entities) are available and they can be grouped according to different criteria [32]. The most popular division is based on their chemical structure and includes many types of compounds with different structural complexities, i.e., from simple compounds (sulfonamides) to multiple-ring compounds (glycopeptides). Therefore, classification of antibiotics is not easy. Table 1 presents the most common classes of antibiotics, including basic information and examples of medicinal substances [58]. Another division of antibiotics focuses on their mechanism of action against bacteria. As such, we can distinguish five main types of antibiotics based on their mode of action: inhibiting cell wall synthesis, causing the breakdown of cell membrane structure or function, inhibiting DNA repair and replication, blocking key metabolic pathways, and inhibiting protein synthesis in ribosomes [58,59].

Table 1. Classification of antibiotics according to chemical structure, including examples of compounds (structure figures are taken from ChemSpider http://www.chemspider.com) and mechanisms of action $[5,13,15,57,60-62]$.

The data collated in Table 1 show the variation in antibiotics in terms of their structures, properties, and spectrum of action. Owing to the issue of AMR, the most popular groups of medicines are becoming less efficient in diseases treatment; therefore, it is important to classify antibiotics in terms of their effectiveness and safety of use. According to estimates, $70 \%$ of disease-causing bacteria are resistant to most antibiotics available on the market [63]. The WHO's ranking published for 2018 classifies the following as "Highest Priority Critically Important Antimicrobials" used in human and veterinary medicines: quinolones, third and higher generation cephalosporins, macrolides and ketolides, glycopeptides, and polymyxins [64]. For this reason, in the near future it is expected to have an increase in (1) the antibiotic 
consumption belonging to these classes and (2) environmental contamination due to these compounds.

\subsection{ANTIBIOTICS CONSUMPTION}

To effectively combat environmental pollution by antibiotics, the sources of antibiotic contamination, together with their distribution pathways, need to be studied. It is equally important to monitor and predict the quantities of antibiotics consumed.

\subsubsection{HUMAN CONSUMPTION}

In 2010, antibiotics used in human medicine accounted for less than one-third of global output (about 27,000 tons) [65]. A 65\% increase in the consumption of antibiotics used in human medicine was recorded over the period 2000-2015, from 21.1 billion of defined daily doses (DDDs, i.e., a single antibiotic capsule or injection of antibiotics) to 34.8 billion DDDs [66]. In 2010, the USA, India, and China (in that order) had the highest consumption of antibiotics [65]. In 2015, the USA dropped to third position, ranking behind India and China. As regards the antibiotic consumption trend during the period 2000-2015, in the case of highincome countries (HICs), a 6\% rise in consumption was recorded, whereas the antibiotic consumption rate (expressed as DDDs per 1,000 inhabitants per day) declined by $4 \%$ [66]. This is attributable to policies aimed at the responsible use of antibiotics and the resultant public awareness of the problem of AMR. In the case of so-called low- and middle-income countries (LMICs), a 114\% increase in consumption was found. The antibiotic consumption rate rose by $77 \%$, which is related to the economic development of these countries. During the period studied (2000-2015), for the three largest consumers in LMICs, the increases in antibiotic consumption were $103 \%$ in India, $79 \%$ in China, and $65 \%$ in Pakistan, whereas among the consumption leaders in the group of HICs, i.e., the USA, France, and Italy, this increase was relatively low [66]. Disturbing is the fact that these authors [66] predict that the global 
consumption of antibiotics will increase by more than 200\% (128 billion DDDs) by 2030, as compared with 2015 (with the assumption that all countries will continue to increase their antibiotic consumption rates in keeping with their annual growth rates).

\subsubsection{ANIMAL CONSUMPTION}

Animals are the main "consumer" of antibiotics, accounting for two-thirds of their global usage. Within this group, antibiotics are predominantly used as growth promoters and disease prevention agents in livestock production and aquaculture. It is estimated that from 1992 to 2018 , the market value of veterinary drugs (including antibiotics) rose from $\$ 8.65$ billion to $\$ 42.9$ billion [67]. The role of antibiotics as animal growth promoters was noted in the 1940's. At that time, aureomycin was used as an additive to feeds for chickens, pigs, and calves in order to increase their weight and accelerate their growth. In 1951, the U.S. Food and Drug Administration approved the use of veterinary antibiotics without prescription as additives to animal feeds [68]. Subsequently, in the 1950's and 1960's, European countries such as France, Germany, and the United Kingdom started to use antibiotics on a large scale in animal husbandry. This caused the market share of antibiotics to rise to more than $40 \%$ [69]. In European Union countries post-2013, in accordance with Regulation (EC) No 1831/2003 of the European Parliament and of the Council on Additives for Use in Animal Nutrition, only substances used for medicinal purposes and supplied on veterinary prescription can be added to animal feeds [68]. Nonetheless, owing to the desire to increase food production, the use of antibiotics in order to intensify the livestock growth rate is becoming common. This trend is particularly found in developing countries. In 2010, the highest uses of antibiotics for livestock production were found in China (23\%), the USA (13\%), Brazil (9\%), India (3\%), and Germany (3\%) [70]. According to estimates, by 2030, global consumption of antibiotics the animal sector will increase by $67 \%$. In BRICS countries (a group of developing countries comprising Brazil, 
Russia, India, China, and the Republic of South Africa), this rise is estimated to be 99\% [5], with the highest increases predicted for Vietnam (157\%), Peru (160\%), Nigeria (163\%), Indonesia (202\%), and Myanmar (205\%). In China alone, antibiotic consumption in livestock production is forecast to reach about 35,000 tons in 2030 , which will account for about $30 \%$ of global antibiotic use [70]. The World Organisation for Animal Health (OIE) estimated (for 91 countries) the amounts of antimicrobial agents used in livestock production in 2015. According to these data, the global level of their use was $172 \mathrm{mg}$ of antimicrobial agents $/ \mathrm{kg}$ animal biomass. There were significant differences in this quantity between the world's regions: 297 $\mathrm{mg} / \mathrm{kg}$ in Asia, the Far East, and Oceania, $100 \mathrm{mg} / \mathrm{kg}$ in the Americas, $79 \mathrm{mg} / \mathrm{kg}$ in Europe, and $46 \mathrm{mg} / \mathrm{kg}$ in Africa [71].

Apart from livestock, aquaculture, which supplies $8 \%$ of animal protein consumed, plays an important role in building the antibiotic consumption data. The vast majority (90\%) of fish producers are now located in Asia; the largest producers are China (61\%), Indonesia (16\%), and India (6\%) [72]. In the European Union (EU), Norway, and the USA, the use of antibiotics in fish farming has been prohibited or limited, and is subject to strict controls based on relevant regulatory legislation [72]. However, in other countries, particularly in south-eastern Asia, such use is common. Unfortunately, there are no specific data regarding antibiotic usage in aquaculture in this region of the world, which may be due to the absence of appropriate legal regulations or non-compliance with existing regulations and international agreements [69]. There are reports concerning antibiotic residues in waters and aquatic organisms. In the case of China, 20 different antibiotics, including 12 prohibited for use in aquaculture, were detected in aquatic products (fish, mollusks, and crustaceans ) over the period 2008-2018 [72,73]. These compounds pose a special hazard since they can accumulate in fish and be consumed in successive links to the human food chain. Moreover, as much as $70-80 \%$ of an applied drug dose is excreted into water, thus affecting the entire ecosystem [7]. 


\subsubsection{ANTIBIOTIC USE IN PLANT AGRICULTURE}

Chemical antibiotic compounds are also used as plant protection products, albeit on a much smaller scale than in the groups described above. Only a few types of antibiotics are used in plant protection, and they account for about $0.4 \%$ of global production [7]. They are usually applied to crops in which diseases cause high economic losses, i.e., fruit and citrus orchards. Since 2016, EU countries and Switzerland have prohibited the use of antibiotics in plant crops. Nonetheless, such practices are allowed in other countries. For example, streptomycin (in the USA, Canada, Israel, Mexico, and New Zealand) and oxytetracycline (in the USA) are commonly used to control bacterial diseases (fire blight and bacterial spot) in growing apples, pears, peaches, and others. In 2019, extensive spraying with both of these compounds was allowed in citrus groves in California and Florida in an attempt to fight a disease called citrus greening [74]. It is estimated that 18-19.8 tons of streptomycin and 12.5-14 tons of oxytetracycline were used in the USA in 2015 [6,75]. In Latin America, oxytetracycline and gentamycin are used not only for fruit tree protection but also in rice crops and vegetable crops (e.g., garlic, onion, potato, tomato, and tobacco). However, there are no specific data regarding the usage of these compounds in agriculture. In Israel, oxolinic acid is used to protect peach trees against fire blight, whereas in Japan it is applied in rice crops [75]. In the case of popular antibiotics, e.g., streptomycin, bacterial strains resistant to their action have appeared [76]. In addition, the spraying of antibiotics used in human and veterinary medicine may result in the development of resistance genes in soil microorganisms that can be transferred to human pathogens. Antifungal chemicals belonging to the azoles group (e.g., triazoles, imidazoles) are commonly used in plant protection, and although these are not identical to those compounds used in human medicine, their high chemical similarity to medical azoles carries the risk of the cross-resistance of human pathogens [75]. 


\subsection{SOURCE AND DISTRIBUTION OF ANTIBIOTICS IN ENVIRONMENT}

Antibiotics enter the environment as a result of a diverse range of human activities. To identify the potential risks to humans associated with the antibiotic presence in the environment, it is necessary to accurately determine sources and pathways of contamination as well as to establish their mutual correlations (Fig. 1). The main consumers of antibiotics are animals and humans; as such, these are the primary sources of environmental pollution by antibiotics. After being administered, an antibiotic is metabolized in the body and its residue is excreted, mainly in feces (up to 75\%) and/or urine (up to 90\%) [5]. These pollutants are further transported with sewage to wastewater treatment plants where they can accumulate in sewage sludge that may be used as a soil amendment. As a consequence of pipeline failures, such pollutants can also directly enter the soil as well as surface and ground waters. Industrial plants manufacturing pharmaceuticals can also become a source of antibiotics in the environment. In 2008, in Hyderabad (India), water was analyzed from nearby lakes, wells, and a treatment plant processing the wastewater from 100 antibiotic manufacturing plants operating in the vicinity. High levels of antibiotics were found in all samples examined. In one lake, the concentrations of ciprofloxacin and cetirizin were even higher than their recommended therapeutic doses [5].

The use of manures as plant nutrient sources is the main pathway for the distribution of veterinary antibiotic residues. Antibiotics in manure-applied soils can further enter waters and plants $[8,77]$. Tetracyclines are the most frequently detected antibiotics in manures [78]. It is estimated that on average, the tetracycline (TC) concentration in manures exceeds $100 \mathrm{mg} / \mathrm{kg}$, and in extreme cases can reach up to $764 \mathrm{mg} / \mathrm{kg}$ [24]. Sulfonamides are the second most popular class of antibiotics present in manures. Sulfonamide concentrations determined in manures range from $20 \mathrm{mg} / \mathrm{kg}$ for sulfadimidine to $91 \mathrm{mg} / \mathrm{kg}$ for sulfadiazine [79]. However, the concentrations of antibiotics in manures can be lowered via appropriate methods. According to laboratory studies, more than $99 \%$ of nine veterinary antibiotics was removed from manures 
during composting over a period of 40 days [77]. The effectiveness of antibiotic degradation strictly depends on the composting conditions such as temperature, humidity or amount of oxygen [80].

Animal sources of antibiotic contaminants also include those used in aquaculture. Compounds used in fish farming are excreted into the water, and can further accumulate in the bottom sediments as well as in plants and aquatic organisms [7]. As such, a certain portion can be transported to larger water bodies (seas and oceans). In sea water, the most frequently detected antibiotic compounds include sulfonamides $(1.42-71.32 \mu \mathrm{g} / \mathrm{L})$ and TCs $(2.11-9.23$ ng/L) [81]. It has been shown that sulfonamide drugs are toxic to algae, impair chloroplast activity, and disturb the photosynthesis process, thus affecting the balance of aquatic ecosystems [82].

Plant protection activities are another potential pathway for environmental contamination by antibiotics. During spraying operations, chemical compounds can directly enter soils and surface waters, or they can become washed off from plant surfaces during precipitation events. Having contaminated soil and water, antibiotics further circulate, and are absorbed by plants and animals, which are links in the human food chain. Antibiotic residues have been detected in food products such as fruit [24], vegetables $[83,84]$, meat $[22,85]$, fish and seafood [86,87], milk [88], eggs [89], and even in drinking water [20,90]. As such, humans have become "secondary consumers" of antibiotics via consumption of contaminated foods.

It should be stressed that antibiotic concentrations in the environment vary significantly, ranging from $\mathrm{ng} / \mathrm{kg}$ or $\mathrm{ng} / \mathrm{L}$ levels in the case of food products and drinking water to $\mathrm{mg} / \mathrm{kg}$ for manures and soils [91]. This is largely determined by the type of matrix in which a contaminant is present. As a result of adsorption and interactions with solid particles, the concentrations of antibiotics are higher in soils and bottom sediments than in water. Antibiotics introduced into the environment are characterized by varying levels of persistence, which depends on their and 
matrix physicochemical properties (chemical structure, solubility, sorption ability, etc.), and on ambient conditions ( $\mathrm{pH}$, humidity, temperature, etc.) $[79,81,92]$. A lower temperature and the absence of light result in an extension of the half-life of antibiotic compounds. For example, the measured half-life of oxytetracycline in marine sediments was more than 300 days, whereas in seawater it was 16 days [93]. It was shown that the content of antibiotic residues in environmental samples (water, sediment and soil) is seasonal, in the autumn the amounts of tested drugs were higher than in the summer. This was due to higher temperatures causing degradation of the drug and frequent rainfall which increases the dilution during the summer [92]. As a result of bioaccumulation, most antibiotic contaminants (particularly antibiotics belonging to the tetracyclines and fluoroquinolones groups) are characterized by high persistence, i.e., they do not biodegrade for several months or even years [94,95]. In a certain contaminated region of Mexico, for instance, sequestered forms of sulfamethoxazole and ciprofloxacin were observed in the soil for 20 years as a result of their accumulation [95].

Although the description of the sources and distribution of antibiotic residues in the natural environment has been simplified here, it demonstrates that antibiotic pollution affects not only inanimate elements (mainly soils and surface/groundwater) but also living organisms. The presence of antibiotics in the environment has an impact on all organisms present in an ecosystem. The greatest danger arising from such pollution relates to the spread of ARB and the disruption of the natural microbiome of living organisms [96]. It is therefore important to monitor and remove antibiotic residues from the natural environment. 


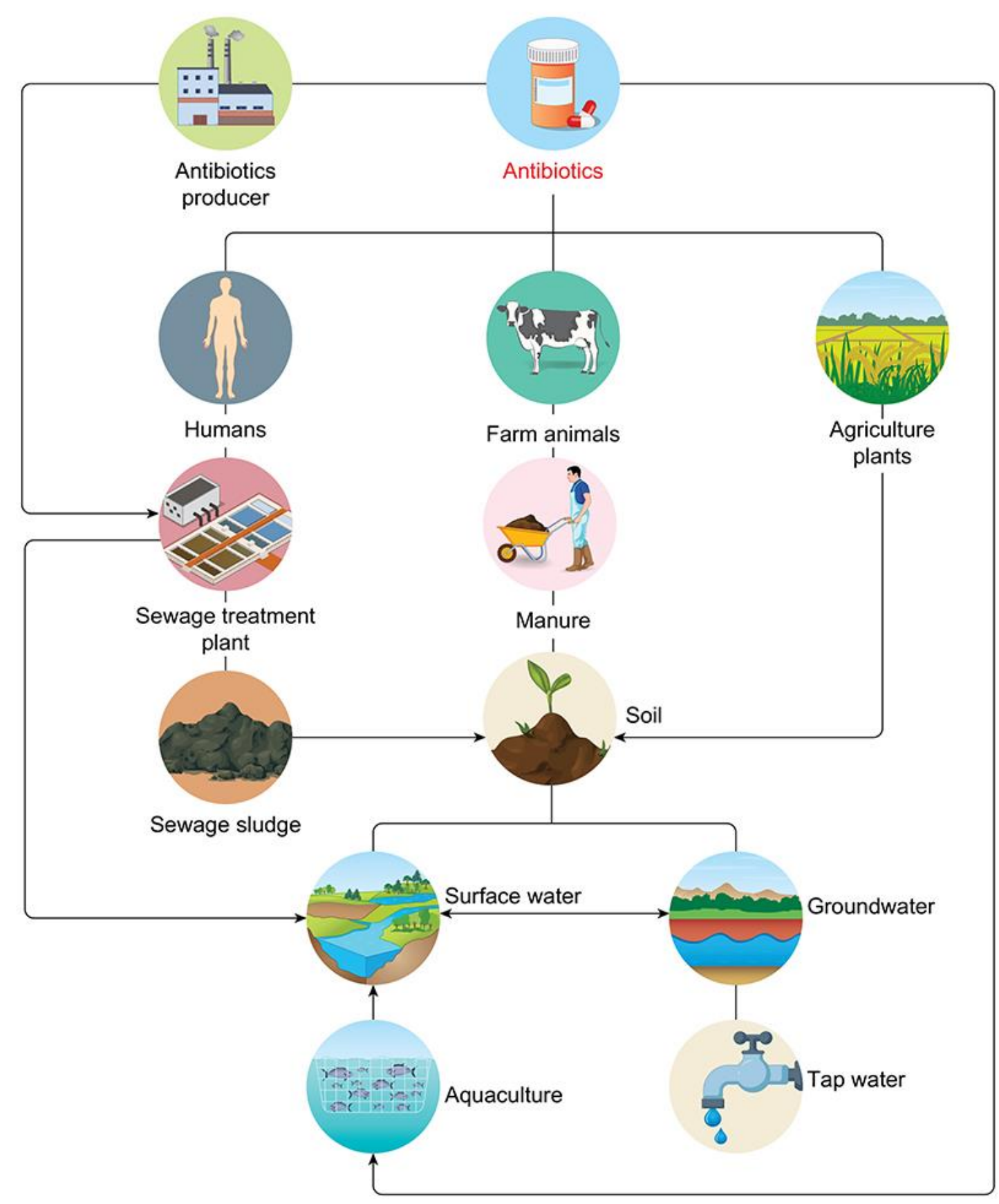

Fig. 1. Sources and distribution of antibiotics in the environment based on reviewed literature [24,94,97]. 


\section{BIOCHAR-BASED MATERIALS FOR ANTIBIOTICS REMOVAL}

\section{FROM WATER}

Growing interest in BCs has been observed for more than 20 years [98]. Research on BCs is multidisciplinary, and primarily focuses on the production of such materials and their practical applications. In recent years, attention has also been drawn to risks arising from their introduction into the natural environment $[99,100]$. An undoubted advantage of BCs is the possibility of using them across the life and science fields. The main areas of BC application include improvement of soil properties, waste management, climate change mitigation, and energy production [44,101]. However, continued reports on new applications of BCs, for instance in the production of supercapacitors, electrodes [102-104], animal husbandry [105], and construction materials [106] are common. Sustainable BC materials, which are sometimes termed "green" owing to their ubiquitous origin and low-cost $[40,107]$, are largely used for the adsorption, immobilization, and removal of environmental contaminants; as such, they are replacing ACs $[41,45,98,108]$. Owing to their porous structure, significant $S_{\text {BET, }}$ presence of functional groups, and wide modification possibilities, BCs are used for the removal of compounds of different origins, i.e., inorganic (e.g., phosphate and nitrate anions, heavy metal cations) and organic (e.g., dyes; polycyclic aromatic hydrocarbons (PAHs); volatile organic compounds (VOCs); pesticides; and drugs belonging to various classes, including antibiotics) [109]. With the increasing consumption of antibiotics, the issue of environmental contamination is growing. This produces the need to seek new methods and effective adsorbents for efficiently removing such compounds from environmental matrices. In many studies, carbon adsorbents, chiefly ACs, have exhibited the highest efficiency in removing antibiotics (> 90\%) [26]. From an economic point of view, replacing ACs with BCs appears to offer advantages in that BCs are cheaper than ACs but offer similar physiochemical properties. As a result, a significant interest in BC-based adsorbents has been observed in recent years in the context of antibiotic 
contaminants removal. This trend is shown in Fig. 2, which presents the number of papers published during the period 2010-2019 that contain the keywords "antibiotics and biochar," "antibiotics, biochar, and sorption" and "antibiotics, biochar and catalytic degradation".

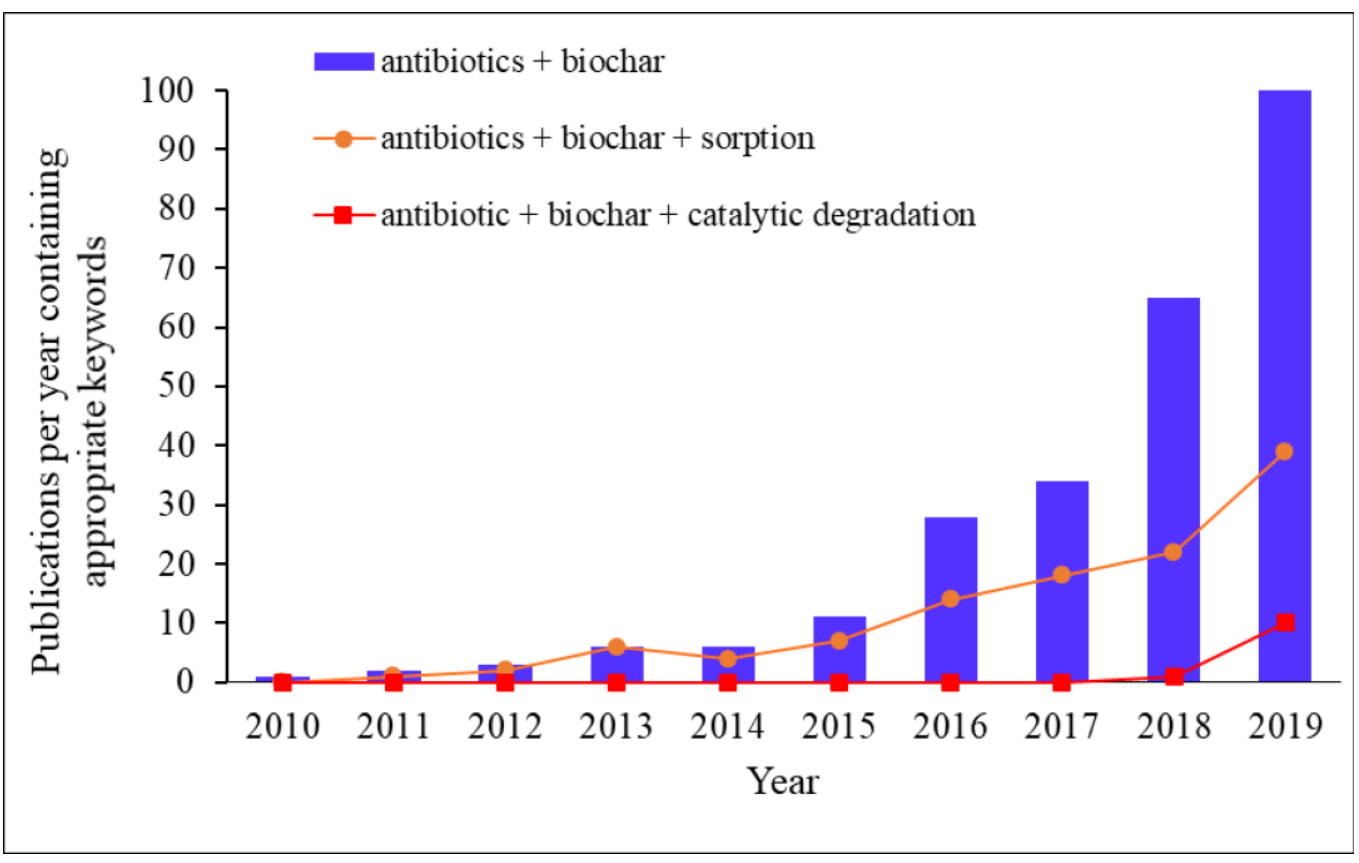

Fig. 2. Number of publications containing the keywords: "antibiotics and biochar" or "antibiotics, biochar and sorption" or "antibiotics, biochar and catalytic degradation" in indexed journals published between 2010 and 2019. The data are based on the search results from Web of Science (11.05.2020).

\subsection{ADSORPTION ON BIOCHARS}

In simple terms, the process of adsorption on a porous solid such as $\mathrm{BC}$ can be divided into four stages: (1) transport of adsorbate molecules from the solution to the BC; (2) diffusion of the adsorbate through the liquid film surrounding the $\mathrm{BC}$ molecule; (3) diffusion of the liquid in the pores, i.e., transport of adsorbate molecules from the surface of BC particles along the solid pore surface to active sites; and (4) adsorption as a result of adsorbate-BC interactions $[26,52]$. 
The adsorption mechanism depends on the adsorbent-adsorbate interaction. Various interactions are involved in the adsorption of antibiotics onto BC (schematically shown in Fig. 3). Among them, the following are distinguished: electrostatic interactions; hydrophobic interactions; $\pi$ interactions, mainly $\pi-\pi$ EDA (electron-donor-acceptor) interactions; and dipole interactions, i.e., hydrogen bonding (dipole-dipole interactions, dipole-induced dipole interactions, charge-dipole interactions, and fluctuating dipoles) [110][110]. The process of surface complexation or pore filling with the adsorbate may also occur [32,109]. Obviously, not all of the above-mentioned interactions take place in every antibiotic-BC system because this is determined by the chemical structures of the adsorbate and adsorbent as well as the adsorption/desorption conditions.

The mechanism and capacity of adsorption are influenced by many factors, among which the following can be highlighted as the most important ones: physicochemical properties of the adsorbent (pore structure, $\mathrm{S}_{\mathrm{BET}}$, presence of functional groups); type and nature of the adsorbate (pKa, presence of functional groups, polarity, solubility, molecule size, etc.); related affinity of the adsorbate for the adsorbent; and process conditions (solution $\mathrm{pH}$ and ionic strength, temperature, presence of other substances, etc.) [111,112]. In theory, an optimal selection of system components (adsorbent and adsorbate) and adsorption conditions allows this process to be carried out with the best possible efficiency. However, in the case of antibiotics removal from the environment (water, wastewater), it is often difficult to control the type of contaminants occurring in a matrix (adsorbate) and/or the adsorption parameters $(\mathrm{pH}$, ionic strength, temperature, etc.). Therefore, it is of key importance to select an adsorbent that is highly selective to the targeted antibiotics. An increasing interest in new BCs, so-called engineered BCs (modified/functionalized and composites), has therefore been observed for some time. 


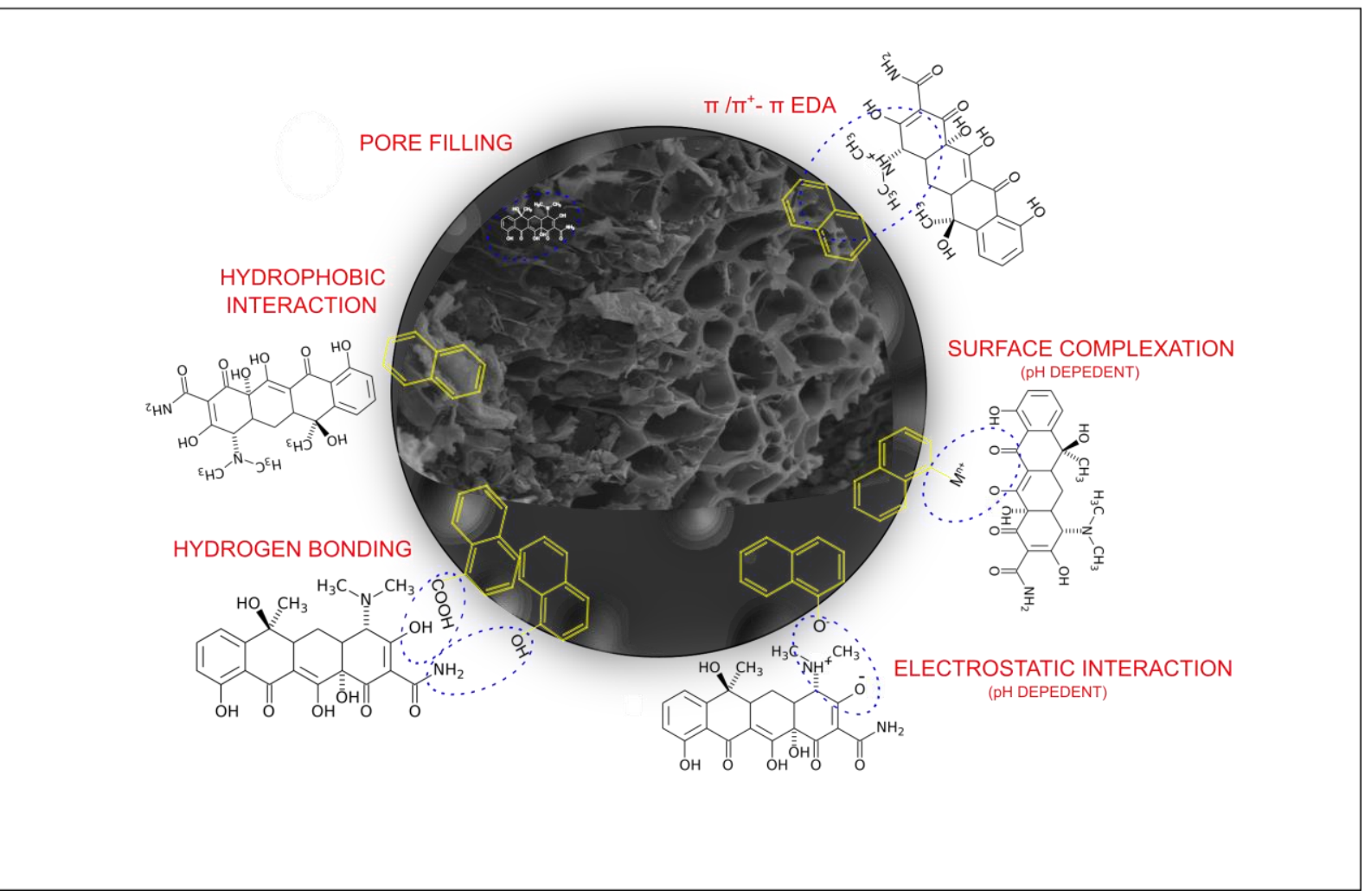

Fig. 3. Simplified scheme of mechanisms involved in sorption of tetracycline (serving as a model antibiotic molecule) on a biochar particle [45,52,113-116].

\subsection{BIOCHAR-BASED ADSORBENTS OF ANTIBIOTICS}

In the case of $\mathrm{BC}$ adsorbents, there are many ways to manipulate their properties so that they exhibit the best possible parameters for adsorption. Depending on the procedure and "advancement" of the synthesis and modification methods, the derived materials can be conventionally divided into pristine BCs and engineered BCs. The latter could be separated as modified BCs and BC composites (Fig. 4). 


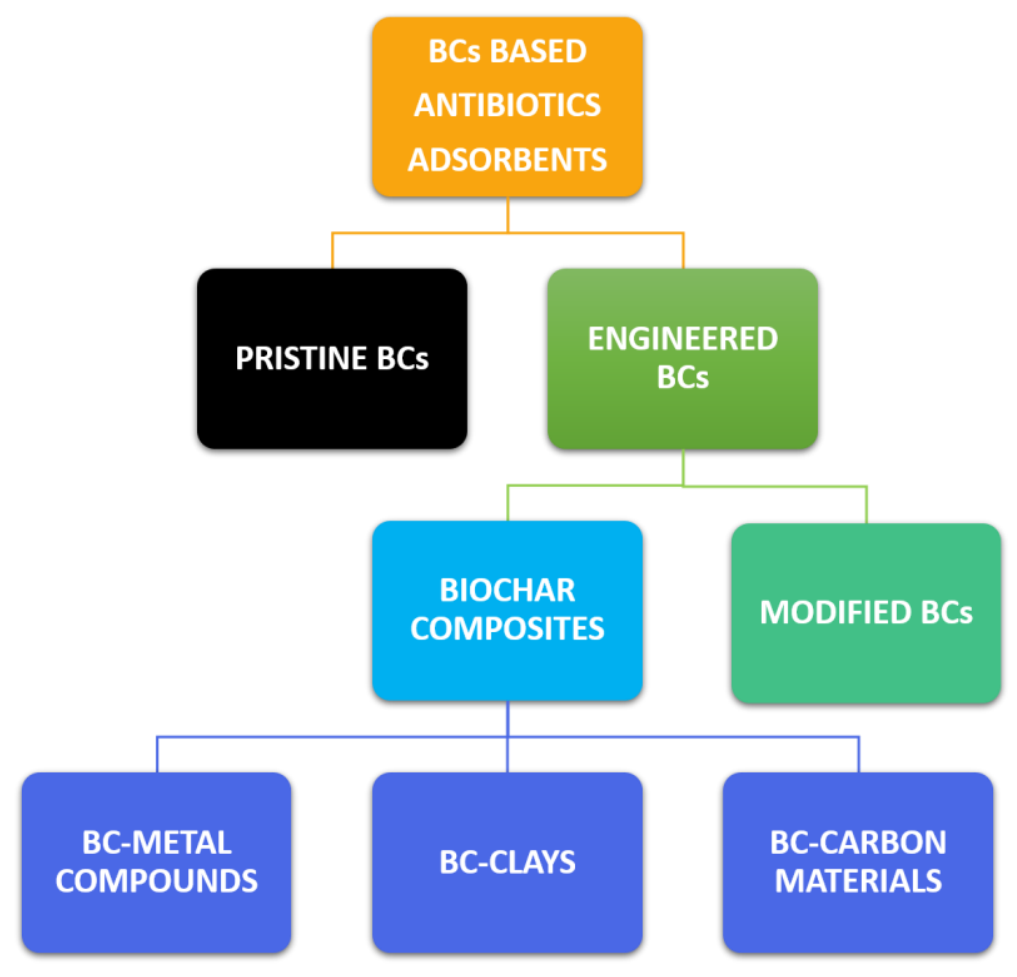

Fig. 4. Types of biochar-based antibiotics adsorbents.

\subsubsection{PRISTINE BCs}

Pristine BCs are produced via biomass slow pyrolysis at a temperature of up to $700{ }^{\circ} \mathrm{C}$ with or no oxygen $(\leq 2 \%)[32,44,117]$. In relation to antibiotics adsorption, the characteristics of the $\mathrm{BC}$ produced, in particular its sorption parameters ( $\mathrm{S}_{\mathrm{BET}}$, pore diameter and volume) as well as its aromaticity (H/C molar ratio), hydrophilicity, and density of surface oxygen functional groups (often expressed as $\mathrm{O} / \mathrm{C},(\mathrm{O}+\mathrm{N}) / \mathrm{C}$ molar ratio) or ash content, all play an essential role [109]. The properties of the BC obtained depend on the feedstock and pyrolysis process conditions (temperature, heating rate, carrier gas type, and pyrolysis time) [118-120], as shown in Fig. 5. To date, many studies have been conducted on the adsorption of antibiotics onto BCs produced under varying conditions and from different feedstocks (Table 2). 


\section{EFFECT OF PYROLYSIS CONDITIONS AND FEEDSTOCK TYPE ON PROPERTIES OF PRISTINE BIOCHAR}
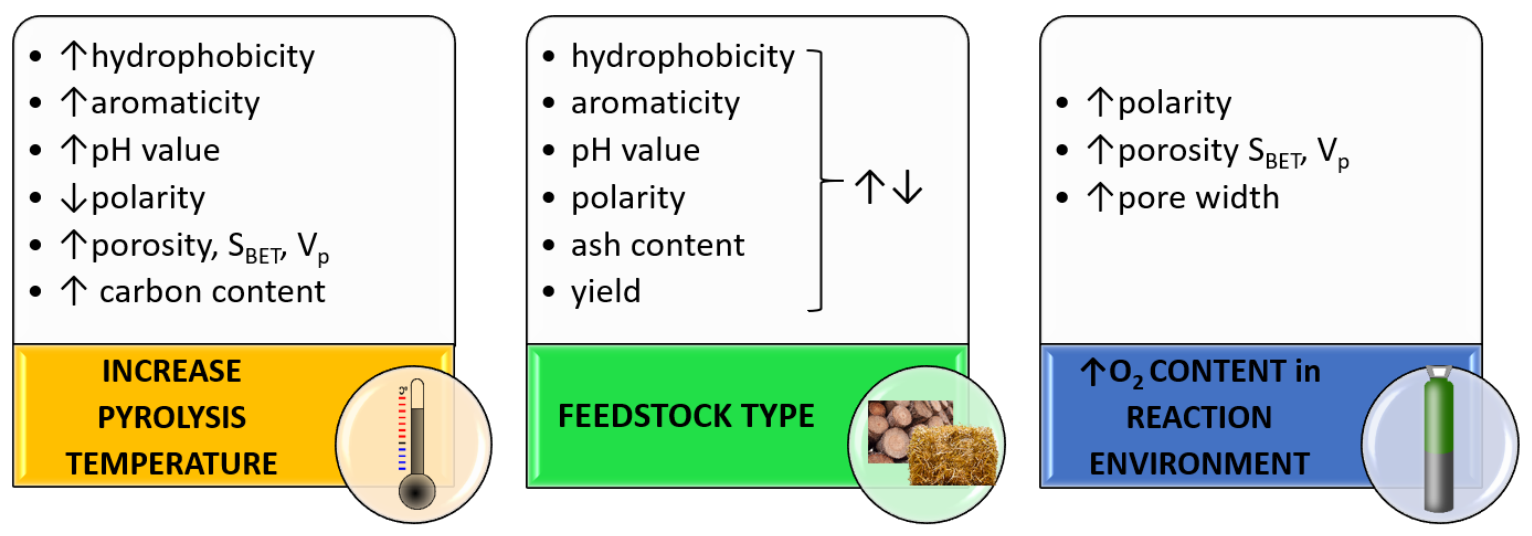

Fig. 5. Simplified illustration showing the effects of pyrolysis conditions and feedstock type on properties of pristine biochar.

\subsubsection{EFFECT OF PYROLYSIS CONDITIONS}

Appropriate selection of pyrolysis conditions like: temperature and time pyrolysis, heating rate and carrier gas, allows to the adjustment of the yield and properties of BCs [119]. Slow pyrolysis characterized by heating rate $\left(<10^{\circ} \mathrm{C} / \mathrm{min}\right)$ provides to receive biochar as main product (over 30\% yield) [41]. As opposed to fast pyrolysis where the heating rate is very fast $\left(>10{ }^{\circ} \mathrm{C} / \mathrm{s}\right.$ ) favors the production of bio-oil (over 50\% yield) [121]. Besides improving efficiency (in case of slow pyrolysis), higher heating rate affects the properties of BCs. It can decrease the porosity and surface area by destruction of the cell structure [121]. The increase of residence time at the same temperature impacts the efficiency of the carbonization process decreases the yield and enlarges porosity $[119,121,122]$. However, some reports prolonged the residence time can decrease biochar surface area and caused destruction and defects in biochar structure [123]. Undoubtedly a key parameter affecting BC properties is pyrolysis temperature [124-127]. A higher process temperature results in a higher degree of $\mathrm{BC}$ carbonization (increase carbon content, decrease oxygen and hydrogen content), which is conducive to the 
development of $\mathrm{S}_{\mathrm{BET}}$ and increased pore volume $\left(\mathrm{V}_{\mathrm{p}}\right)$. BCs produced at a higher temperature are usually characterized by higher hydrophobicity, aromaticity, $\mathrm{pH}$ values, as well as lower polarity $[127,128]$. Research reveals [129-132] that increasing pyrolysis temperature promotes the higher adsorption capacity of BCs toward various antibiotics.

Regardless of the feedstock used, the adsorption of tetracycline (TC) was more effective onto BCs produced at higher temperatures, as compared with analogous materials obtained at lower temperatures. This trend was reported for BCs derived from rice straw [129] (an increase from $300{ }^{\circ} \mathrm{C}$ to $700{ }^{\circ} \mathrm{C}$ enhanced TC adsorption by $250 \%$ ), waste Auricularia auricula dregs (an increase from $300{ }^{\circ} \mathrm{C}$ to $700{ }^{\circ} \mathrm{C}$ enhanced TC adsorption by 65\%) [130], pinewood (an increase from $600{ }^{\circ} \mathrm{C}$ to $800{ }^{\circ} \mathrm{C}$ enhanced TC adsorption by 56\%) [133], or swine manure (an increase from $400{ }^{\circ} \mathrm{C}$ to $600{ }^{\circ} \mathrm{C}$ enhanced TC adsorption by 25\%) [132]. This was associated with an increase in the porosity parameters $\left(\mathrm{S}_{\mathrm{BET}}, \mathrm{V}_{\mathrm{p}}\right)$ of the $\mathrm{BC}$ as a result of pyrolysis at higher temperature and with the TC adsorption mechanism onto the BC. The ring structure of the drug molecule (structures given in Table 1 ) promotes $\pi-\pi$ EDA interactions, which are predominantly responsible for $\mathrm{TC}$ adsorption onto $\mathrm{BC}$ [132]. With increasing synthesis temperature, $\mathrm{BC}$ increases the degree of graphitization on its surface, the number of arene rings participating in the binding of $\pi-\pi$ EDA to the TC molecule, and hence the dominant proportion of this type of interaction in the adsorption process. In addition, hydrophobic interactions, hydrogen bonding, and electrostatic interactions (Fig. 3) [134] may participate in the binding of TC with BC. With increasing pyrolysis temperature, $\mathrm{BC}$ polarity and thus the number of surface functional groups taking part in hydrogen bonding are observed to decrease [126]. Therefore, an increase in biomass pyrolysis temperature results into the reduction of hydrogen bonding contribution to the adsorption of $\mathrm{TC}$ on $\mathrm{BC}$. In turn, the presence of electrostatic interactions taking part in the binding of the drug is strongly dependent on solution $\mathrm{pH}$ because $\mathrm{BC}$ surface charge is also $\mathrm{pH}$ dependent. At $\mathrm{pH}<\mathrm{pHPZC}(\mathrm{pH}$ at point of zero charge), the BC surface is positively charged, 
whereas at $\mathrm{pH}>\mathrm{pH}$ pzc, it is negatively charged. TC, on the other hand, is an amphoteric molecule with three $\mathrm{pKa}$ values, i.e., at $3.3<\mathrm{pH}>9.7$, it has a positive or negative charge, whereas at $\mathrm{pH}$ in the range of 3.3-7.7, the drug is a neutral molecule and does not interact with the BC surface through electrostatic attraction/repulsion [130]. Similar results were obtained for ciprofloxacin (CIP) with respect to Astragalus mongholicus-derived BCs. In this case, an increase in pyrolysis temperature also resulted in higher adsorption parameters in relation to CIP. Owing to the structure of the CIP molecule, the dominated adsorption mechanism was also $\pi-\pi$ EDA interactions. The presence of aromatic rings and electron acceptor atoms, i.e., fluorine and nitrogen, in the CIP molecule (structure shown in Table 1) is conducive to the formation of $\pi-\pi$ EDA bonds with a BC surface rich in arene structures [135]. In relation to the adsorption of CIP and doxycycline (DOX) onto BCs produced from rice straw at various temperatures (300, 500, and $700^{\circ} \mathrm{C}$ ), researchers have drawn similar conclusions regarding the adsorption mechanisms (the dominance of $\pi-\pi$ EDA bonding), and the effect of BC porosity (increasing pyrolysis temperature increases BC porosity and hence drug adsorption). Furthermore, a variation in adsorption capacity was observed depending on the compound tested. The adsorption of DOX was higher than that of CIP, which resulted from differences in the structures of the compounds. The DOX molecule is characterized by greater hydrophobicity than CIP; hence, it exhibits a higher affinity for BC, which usually has a hydrophobic surface [131].

The type of carrier gas used and access to oxygen are other pyrolysis parameters affecting the properties and adsorption ability of a produced BC material $[133,136]$. Li et al. [133] studied the effect of pyrolysis conditions, i.e., temperature $(200,400,500,600,700$, and $800{ }^{\circ} \mathrm{C}$ ) and carrier gas composition (v/v air/ $\mathrm{N}_{2}$ 1:10 and 1:5), on the properties of BCs in the context of their adsorption of TC and sulfadiazine (SD). An increase in temperature and the addition of air to the nitrogen during pyrolysis developed greater porosity in the material. The 
proportion of mesopores in the produced BC increased particularly significantly (the pores had expanded) [133]. Thus, a key parameter in the adsorption of larger mass/size molecules (such as antibiotics) is to consider it in terms of the sorbent pore size to avoid the size-exclusion effect [137]. The adsorption of TC and SD onto the BCs increased with increase in temperature and increasing proportion of air in the carrier gas during BC preparation. Air ( $\mathrm{v} / \mathrm{v}$ air/ $\mathrm{N}_{2}$ 1:5) addition during $\mathrm{BC}$ synthesis at $800{ }^{\circ} \mathrm{C}$ caused more than 30 -fold and 32 -fold increases in adsorption for TC and SD, respectively, versus the BC produced in $\mathrm{N}_{2}$ alone. Similar to TC, $\mathrm{SD}$ is an amphoteric molecule and its adsorption depends on solution $\mathrm{pH}$. At a $\mathrm{pH}$ of 5, SD has zero charge and its molecule is stable. Under these conditions, $\pi-\pi$ EDA interactions mainly participate in the adsorption. In the case of $\mathrm{TC}$, apart from $\pi-\pi$ interactions, hydrogen bonding also takes part in the adsorption due to the presence of hydroxyl groups in the molecule (structure shown in Table 1 and Fig. 3)[133]. Xie et al. [136] studied the adsorption of sulfamethoxazole (SMX) and sulfapyridine (SPY) onto BCs produced from red pine at temperatures of $400{ }^{\circ} \mathrm{C}$ and $500{ }^{\circ} \mathrm{C}$. The process was carried out under aerobic conditions. The adsorption capacities toward SMX and SPY were greater than those of the materials produced at a higher temperature. It should be noted that an increase in temperature of only $100{ }^{\circ} \mathrm{C}$ resulted in an over 10-fold increase in the adsorption capacity of both the antibiotics. However, such a significant increase in adsorption capacity was not observed for BCs obtained through anaerobic pyrolysis [136]. The greater adsorption onto $\mathrm{BC}$ produced at $500{ }^{\circ} \mathrm{C}$ was associated with the higher degree of $\mathrm{BC}$ graphitization, whose increase contributes to enhanced $\pi-\pi$ EDA interactions with drug molecules [136].

\subsubsection{EFFECT OF FEEDSTOCK TYPE}

Another parameter that may have a significant impact on antibiotic adsorption in the context of $\mathrm{BC}$ use is the type of feedstock used to produce the $\mathrm{BC}$. The chemical composition including cellulose, hemicellulose, and lignin of the original feedstock materials used for BC 
production primarily affects the pyrolysis yield as well as the elemental composition and ash content of the material produced $[119,138,139]$.

Liu et al. [140] studied the adsorption of the antibiotic lincomycin (LIN) onto BCs derived from manure of various origins: bulls $(\mathrm{BM}-\mathrm{BC})$, dairy $(\mathrm{DM}-\mathrm{BC})$, and poultry $(\mathrm{PM}-$ BC). PM-BC adsorbed $20 \%$ and $43 \%$ more LIN than did DM-BC and BM-BC, respectively. Interestingly, $\mathrm{PM}-\mathrm{BC}$ showed the highest $\mathrm{Q}_{\max }$ (maximum adsorption capacity), with simultaneously the lowest $\mathrm{S}_{\mathrm{BET}}$. This BC was also characterized by the highest polarity (molar ratio $(\mathrm{O}+\mathrm{N}) / \mathrm{C}$ for $\mathrm{PM}-\mathrm{BC}=0.4$ vs. $\mathrm{BM}-\mathrm{BC}=0.15$ and $\mathrm{DM}-\mathrm{BC}=0.13)$, and ash content $(\mathrm{PM}-$ $\mathrm{BC}=56 \%$ vs. $\mathrm{BM}-\mathrm{BC}=11 \%$ and $\mathrm{DM}-\mathrm{BC}=13 \%)$. This may suggest that the adsorption was not determined by the porosity parameters of the BCs, such as the $\mathrm{S}_{\mathrm{BET}}$, but by specific adsorbate-adsorbent interactions. In the case of LIN, which does not have aromatic rings in its structure (structure shown in Table 1), the adsorption mechanism may be based on electrostatic, hydrogen, and dipole interactions. Therefore, the polarity of the BC and the presence of functional groups on its surface are very important. Additionally, metal as exchangeable cations $\left(\mathrm{Ca}^{2+} \mathrm{Mg}^{2+}, \mathrm{Na}^{+}, \mathrm{K}^{+}\right)$contained in the inorganic portion of $\mathrm{BC}$ may be involved in the binding and complexation of molecules of this antibiotic.

Jang and Kan [134] found more varied results with respect to the feedstock used for BC production. In the case of $\mathrm{TC}$ adsorption onto $\mathrm{BCs}$ derived from alfalfa (AF-BC) and bermudagrass (BG-BC), TC adsorption capacity onto the former was 8.5 times higher than that onto the latter. Both BCs had similar $S_{\mathrm{BET}}$ values, but they differed significantly in their aromaticity $(\mathrm{H} / \mathrm{C}$ for $\mathrm{AF}-\mathrm{BC}=0.279$ vs. $\mathrm{BG}-\mathrm{BC}=0.429)$, hydrophilicity $(\mathrm{O} / \mathrm{C}$ for $\mathrm{AF}-\mathrm{BC}=$ 0.112 vs. $\mathrm{BG}-\mathrm{BC}=0.268)$, and ash content $(\mathrm{AF}-\mathrm{BC}=31 \%$ vs. $\mathrm{BG}-\mathrm{BC}=12 \%)$ [134]. Similar to the case for $\mathrm{LIN}$, TC adsorption onto the $\mathrm{BCs}$ was dependent on the drug compound-BC interactions. The high adsorption onto $\mathrm{AF}-\mathrm{BC}$ was associated with the complexation of $\mathrm{TC}$ functional groups by the ions present in the ash (including iron, calcium, and magnesium), 
although the adsorption also resulted from electrostatic interactions and hydrogen bonding [134].

Zhang et al. [141] compared the adsorption of chlortetracycline (CTC) onto BCs produced from corncob $(\mathrm{BC}-\mathrm{CC})$ and sugarcane bagasse $(\mathrm{BC}-\mathrm{SB})$. These $\mathrm{BC}$ s showed a large difference in porosity. The $\mathrm{S}_{\mathrm{BET}}$ value for $\mathrm{BC}-\mathrm{SB}$ was 85 times more than that for $\mathrm{BC}-\mathrm{CC}$. The adsorbed CTC amount onto BC-SB was $\sim 30 \%$ more that onto BC-SS; likewise, it depended on solution $\mathrm{pH}$ due to the amphoteric structure of the CTC molecule. The $\mathrm{Q}_{\max }$ values were found in the $\mathrm{pH}$ range $4-5$, at which the CTC molecule is not charged, i.e., where there were no electrostatic interactions between the drug and the BC surface [141]. Under such conditions, analogous to the case for TC (characterized by a similar molecular structure), one can expect the dominance of $\pi-\pi$ EDA interactions and the presence of hydrogen bonds $[133,134]$.

In summary, antibiotic adsorption efficiency onto BC adsorbents is dependent on the properties and chemical structure of the drug molecule as well as the adsorption process conditions; however, it is primarily dependent on $\mathrm{BC}$ physicochemical properties. $\mathrm{BC}$ properties are predominantly determined by the feedstock type used and pyrolysis temperature, residence time and carrier gas. An increase in temperature and the presence of oxygen during pyrolysis usually improves BC adsorption properties toward antibiotics. This is linked to the higher degree of graphitization of the BC surface and elevated hydrophobicity, which cause increased $\pi-\pi$ interactions with aromatic drug molecules. Moreover, a high pyrolysis temperature promotes $S_{\text {BET }}$ development and pore expansion (particularly in an oxygen atmosphere) in BCs, which is important in the case where pore filling with the drug dominates. The type of feedstock used for $\mathrm{BC}$ production impacts the process efficiency, chemical composition, hydrophobicity/polarity, and ash content of BC produced. The above-mentioned properties are of key importance in binding antibiotics through polar functional groups (electrostatic interactions, hydrogen bonding) or complexation with metals occurring in the ash. 
To obtain an efficient and selective BC adsorbent, it is essential to select an appropriate feedstocks and production conditions.

Table 2. Antibiotic adsorption capacities on pristine BCs derived from different feedstocks at various conditions.

Where: $\mathrm{S}_{\mathrm{BET}}-$ the specific surface area determined from $\mathrm{N}_{2}$ sorption measurements according to the BET equation, $\mathrm{t}$ - adsorption time, $\mathrm{pH}$ - adsorption $\mathrm{pH}, \mathrm{T}$ - adsorption temperature, $\mathrm{BC}$-adsorbent dose, $\mathrm{c}_{\mathrm{ant}}-$ initial antibiotic concentration, $\mathrm{Q}_{\max }-$ the maximum adsorption capacity

\subsubsection{ENGINEERED BCs}

\subsubsection{MODIFIED BCs}

Pristine BC-based adsorbents show unsatisfactory adsorption capacities for various antibiotics (Table 2). This is usually associated with the lack of affinity between a drug and an adsorbent, which is influenced by BC aromaticity, polarity, and the absence/presence of required/not required surface functional groups. In systems where the adsorption mechanism is based on pore filling, weak adsorption is due to low porosity parameter values including $\mathrm{S}_{\mathrm{BET}}$, $\mathrm{V}_{\mathrm{p}}$, and/or a too narrow pore diameter in relation to the size of the antibiotic molecule. To improve the BCs properties, especially in the context of the adsorption of various compounds, including antibiotics, BCs are subjected to modifications. The most general division of such modifications is based on physical and chemical methods (Fig. 6). Table 3 contains data concerning the adsorption of antibiotics using modified BCs. 


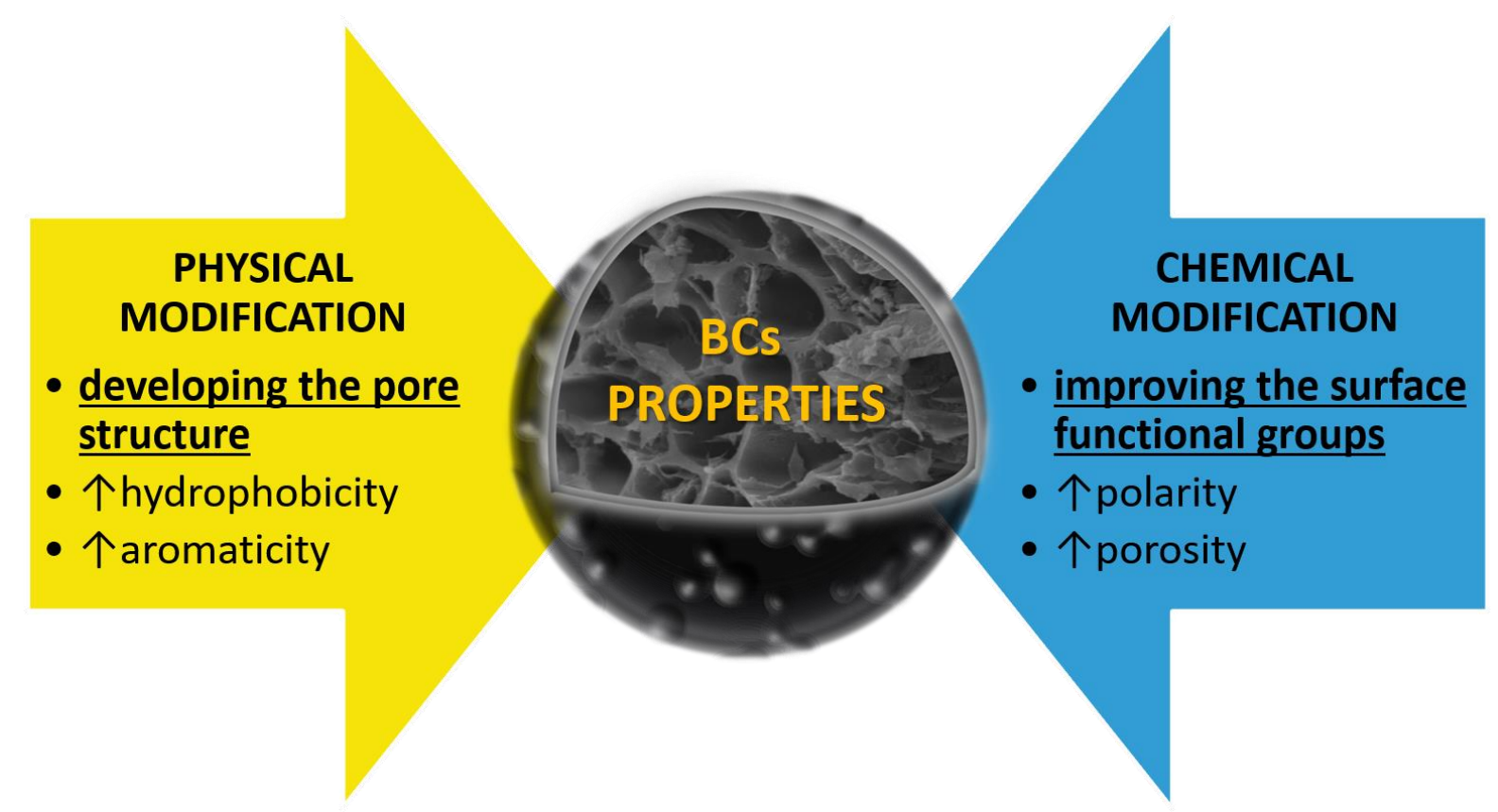

Fig. 6. Main changes in biochar properties resulting from various modifications.

\subsection{PHYSICAL MODIFICATION}

Physical BC modification methods include: steam/gas activation (air, $\mathrm{CO}_{2}$ ), ball milling, and microwave modification (also called microwave pyrolysis) $[142,143]$. The first two methods belong to the so-called post-synthesis methods, wherein modification is carried out on previously synthesized BCs. The third type of modification involves the use of microwaves as a source of heating in the course of pyrolysis, during which BC is produced as a result of the action of microwaves, modifying its structure and properties [142,143]. Essentially, the BC structure pores is improved (increased $\mathrm{S}_{\mathrm{BET}}, \mathrm{V}_{\mathrm{p}}$, and proportion of micro- and mesopores) as a result of physical modifications, particularly in the case of gas modification. This is related to the removal of trapped incomplete combustion products, degasification, and BC pore unblocking being altered during the modification process [119]. The advantages of applying these methods include their low-cost, purity (elimination of the product and reduced environment contamination), and the potential for controlling the process [142]. 
Rajapaksha et al. [144-146] investigated the effect of steam modification of BCs produced from burcucumber (BBC) and tea waste (TBC) at $300{ }^{\circ} \mathrm{C}$ and $700{ }^{\circ} \mathrm{C}$ on the adsorption of sulfamethazine (SMT). Adsorbents produced at $700{ }^{\circ} \mathrm{C}$ showed much higher porosity parameter values $\left(\mathrm{S}_{\mathrm{BET}}, \mathrm{V}_{\mathrm{p}}\right.$ ) and $\mathrm{Q}_{\max }$ for the tested antibiotic versus $\mathrm{BCs}$ obtained at $300{ }^{\circ} \mathrm{C}$. Steam modification of the materials resulted in decreased hydrophobicity with a simultaneous increase in their polarity (a rise in \% O) and the development of the SBET, with an increase in pore diameter and volume. The SBET values for TBC (original $=342 \mathrm{~m}^{2} / \mathrm{g}$ ) and TBC-S (steam modified $=576 \mathrm{~m}^{2} / \mathrm{g}$ ) were much higher than those for BCs derived from burcucumber (original $\mathrm{BBC}=2.3 \mathrm{~m}^{2} / \mathrm{g}$ and modified $\mathrm{BBC}-\mathrm{S}=7.1 \mathrm{~m}^{2} / \mathrm{g}$ ) [144-146]. Adsorption capacity were much higher for both $\mathrm{BBC}$ and $\mathrm{BBC}-\mathrm{S}$, as compared with the tea waste-derived materials. This was due to the differences in the chemical composition and BC properties, to which the SMT adsorption mechanism is linked. The largest variations were related to ash content $(\mathrm{BBC}=44 \%$ and $\mathrm{BBC}-\mathrm{S}=71 \%$ vs. $\mathrm{TBC}=11 \%$ and $\mathrm{TBC}-\mathrm{S}=16 \%)$ and polarity $(\mathrm{O} / \mathrm{C}$ molar ratio, $\mathrm{BBC}=$ 0.26 and $\mathrm{BBC}-\mathrm{S}=0.67$ vs. $\mathrm{TBC}=0.08$ and $\mathrm{TBC}-\mathrm{S}=0.11)$. It is accepted that hydrophilic groups including hydrogen bonding and electrostatic bonding and ash content (complexation with metals) are dominant in the adsorption of SMT onto BCs. The latter parameter is particularly important for materials with low porosity because the contribution of pore filling with the adsorbate is lower (other drug binding mechanisms predominate). In the case of BCs characterized by high porosity parameters, similar polarity, as well as a similar ash content and composition (as in the case of TBC and TBC-S), it can be assumed that differences in porosity determine the adsorption capacity. In the case of TBC-S, an increase in SBET from 342 to 576 $\mathrm{m}^{2} / \mathrm{g}$, and a five-fold increase in $\mathrm{V}_{\mathrm{p}}$ after modification resulted in a five-fold rise in SMT adsorption compared with the original TBC. However, for BBC-S, which exhibited low porosity after modification $\left(\mathrm{S}_{\mathrm{BET}}=7.1 \mathrm{~m}^{2} / \mathrm{g}\right.$ only), a less than two-fold increase in the adsorption of the antibiotic was observed compared with the original BBC. SMT adsorption 
was dependent on solution $\mathrm{pH}$, decreasing with increasing $\mathrm{pH}$. The highest adsorption values were found at a pH of 3, at which SMT occurs as a cation. This was related to the presence of $\pi-\pi^{+}$EDA interactions between the protonated amine group found in the ring of the SMT molecule and the electron-rich graphene rings on the BC surface (analogous mechanism of interaction between BC and TC molecule is presented on Fig. 3) [144,145].

In another study on TC adsorption, thermal treatment in a stream of mixed air and nitrogen was used to modify BC[147]. BC derived from Pinus radiata sawdust was heated at $700{ }^{\circ} \mathrm{C}$ under nitrogen environment with an admixture of air at different flow rates. The presence of air in the gas used for modification promoted SBET development and mesopore formation. An increase in the number of oxygen functional groups on the $\mathrm{BC}$ was reported. It was also observed that increasing the proportion of air in the gas mixture caused a simultaneous rise in $\mathrm{BC}$ porosity and $\% \mathrm{O}$ content, which led $\mathrm{TC}$ adsorption capacity to an enhancement. In BC modified with using air supply, the sorption capacity was more than nine times higher than the BC modified without air [147]. It can be inferred that for this type of material (high porosity), the process of $\mathrm{TC}$ adsorption is related to the pore filling mechanism, which is also linked to interactions involving oxygen functional groups, i.e., hydrogen bonding or electrostatic interactions.

\subsection{CHEMICAL MODIFICATION}

Chemical modification methods involve the action of chemical compounds, usually with oxidizing/reducing properties, on pristine BCs (in the case of the post-synthesis method) which can then undergo simple drying [48] or more advanced microwave treatment [148]. In the presynthesis method, a feedstock is subjected to the action of chemical compounds, and is subsequently pyrolyzed [48]. Chemicals including $\mathrm{H}_{3} \mathrm{PO}_{4}, \mathrm{H}_{2} \mathrm{SO}_{4}, \mathrm{HNO}_{3}, \mathrm{HCl}, \mathrm{H}_{2} \mathrm{O}_{2}$, and $\mathrm{KMnO}_{4}$ are commonly used as oxidants in both pre- and post-synthesis methods. The action of these types of reagents on BCs leads to oxidation of surface groups (hydroxyl and aldehyde 
groups) and the formation of carboxyl moieties capable of binding cations, as well as promoting the development of SBET and microporosity $[50,119,149]$. The reducer (bases such as $\mathrm{NaOH}$, $\mathrm{KOH}, \mathrm{NH}_{4} \mathrm{OH}$ ) activity usually leads to a decline in the amount of hydroxyl functional groups on the $\mathrm{BC}$ surface; as a consequence, hydrophilicity decreases and the porosity of the $\mathrm{BC}$ modified using this method increases substantially owing to the removal of non-calcined residues from the $\mathrm{BC}$ [119]. Unlike physical modifications, whose main purpose is to develop the porosity of $\mathrm{BCs}$, chemical modifications chiefly cause changes in the chemical nature of BCs, especially in surface oxygen functional groups [50]. This type of modification is of special significance in relation to antibiotics adsorption. However, in comparison with physical methods, the application of chemical methods entails the need to use generally environmentally unfriendly and sometimes costly chemical reagents.

Chen et al. [132] demonstrated that $\mathrm{H}_{3} \mathrm{PO}_{4}$ modification of $\mathrm{BCs}$ derived from rice straw and swine manure increases the adsorption of TC. In both BC types, post-synthesis treatment with acid resulted in an increase in $\mathrm{S}_{\mathrm{BET}}$ and $\mathrm{V}_{\mathrm{p}}$, with a reduction in the percentage contents of oxygen and ash. The highest adsorption capacity for TC was observed for modified BC obtained from manure (TC adsorption was $25 \%$ greater than that for pristine $\mathrm{BC}$ ), which was attributable to its higher $\mathrm{S}_{\mathrm{BET}}$ value and high hydrophobicity. It was confirmed that electrostatic interactions, cation exchange, metal complexation, $\pi-\pi$ EDA interactions, and hydrogen bonding were responsible for the mechanism of TC adsorption onto pristine BC. However, after acid modification (as a result of which, metal cations $\left(\mathrm{Ca}^{2+}, \mathrm{Mg}^{2+}, \mathrm{Na}^{+)}\right.$were removed), $\pi-\pi$ EDA interactions and hydrogen bonding were mainly responsible for the adsorption. The effect of solution $\mathrm{pH}$ on $\mathrm{TC}$ adsorption was also investigated. The adsorption was observed to significantly increase with increasing $\mathrm{pH}$ from 5 to 9 , which was explained by the larger contribution of electrostatic interactions to TC binding [132]. 
Liu et al. [150] investigated the adsorption of TC onto rice husk $\mathrm{BC}$ modified with $\mathrm{H}_{2} \mathrm{SO}_{4}$ (BC-A) or $\mathrm{KOH}(\mathrm{BC}-\mathrm{B})$. In comparison with pristine $\mathrm{BC}$, the adsorption capacity toward TC increased for both the modified materials: acid modification caused a 35\% increase in TC adsorption, whereas $\mathrm{KOH}$ modification proved to be more efficient, providing a $250 \%$ increase. These variations were due to the different properties of the obtained adsorbents. BC subjected to the action of the base (BC-B) had a two-three times higher $\mathrm{S}_{\text {BET }}$ and $\mathrm{V}_{\mathrm{p}}$, a higher \%C content, the lowest $\% \mathrm{O}$ content, and a significantly reduced ash content relative to pristine $\mathrm{BC}$ and acidmodified $\mathrm{BC}(\mathrm{BC}-\mathrm{A})$. This indicates that the $\mathrm{TC}$ adsorption capacity was dependent on $\mathrm{BC}$ porosity, and was also linked to the occurrence of $\pi-\pi$ interactions of the TC molecule rings with the graphene layers of the $\mathrm{BC}$. The content of surface oxygen-containing functional groups was also found to be of significance since they take part in the adsorption of TC through hydrogen bonding [150].

Fan et al. [151] investigated the adsorption of chloramphenicol (CAP) onto bamboo-derived BC as well as $\mathrm{BC}$ modified with $\mathrm{H}_{2} \mathrm{SO}_{4}(\mathrm{BC}-\mathrm{A})$ and $\mathrm{KOH}(\mathrm{BC}-\mathrm{B}) . \mathrm{BC}-\mathrm{B}$ exhibited the highest adsorption capacity toward $\mathrm{CAP}\left(\mathrm{Q}_{\max }>3\right.$ times higher than that for pristine $\mathrm{BC}$, and 1.6 times higher than that for $\mathrm{BC}-\mathrm{A})$. This was related to the changes in chemical composition and the functional group types in this BC. BC-B had the highest oxygen content as well as the highest percentage of $\mathrm{C}=\mathrm{O}$ surface groups and graphite structures compared with the other two $\mathrm{BCs}$ (pristine $\mathrm{BC}$ and $\mathrm{BC}-\mathrm{A})$. Fourier transformed infrared (FT-IR) spectra confirmed the removal of phenolic groups and the formation of lactone moieties during the modification. Acidmodified $\mathrm{BC}$ exhibited properties similar to those of pristine $\mathrm{BC}$, apart from having the lowest content of COO- groups. Chemical modification did not affect the structure and porosity of the materials tested since all the BCs were characterized by a very low SBET value $\left(<1 \mathrm{~m}^{2} / \mathrm{g}\right)$. It can therefore be concluded that CAP adsorption was not dependent on the material porosity but rather on interactions between CAP and the surface groups. The presence of electron- 
donor/acceptor functional groups in the CAP molecule (structure in Table 1) favors $\pi-\pi$ EDA interactions and hydrogen bonding, with base-modified $\mathrm{BC}$ containing the most oxygen moieties [151].

In another study that involved pre-synthesis modification of sewage sludge-derived BC using $\mathrm{NaOH}$, the $\mathrm{TC} \mathrm{Q}_{\max }$ was found to increase more than four times. $\mathrm{NaOH}$ modification also caused an over four-fold increase in $\mathrm{S}_{\mathrm{BET}}$ and micropore volume, as well as an eight-fold increase in the $\mathrm{V}_{\mathrm{p}}$ value of $\mathrm{BC}$ mesopores. In this case, the enhanced $\mathrm{TC}$ adsorption was associated with an increase in porosity parameters and with the pore filling mechanism (and to a lesser extent this was related to interactions with functional groups located on the BC surface). The change in the $\mathrm{BC}$ chemical properties after modification, i.e., an increase in $\mathrm{pH}$ value and oxygen content as well as a decrease in carbon and hydrogen contents, may have also increased the contribution of $\pi-\pi$ EDA interactions and/or hydrogen bonding between the TC molecule and the BC after modification [152].

Jang et al. $[153,154]$ studied the adsorption of TC and SMX onto chemically-modified BCs. The process of post-synthesis modification involved mixing pristine $\mathrm{BC}$ (produced from Pinus taeda at $300{ }^{\circ} \mathrm{C}$ ) with $\mathrm{NaOH}$ before the sample was pyrolyzed again at $800{ }^{\circ} \mathrm{C}(\mathrm{BCB})$. In comparison with pristine $\mathrm{BC}, \mathrm{NaOH}$-modified $\mathrm{BC}$ was characterized by a more developed pore structure $\left(S_{\text {BET }}=959.6 \mathrm{~m}^{2} / \mathrm{g}, V_{\mathrm{p}}=0.4 \mathrm{~cm}^{3} / \mathrm{g}\right.$ for $\mathrm{BCB}$ vs. $1.4 \mathrm{~m}^{2} / \mathrm{g}$ and $0.008 \mathrm{~cm}^{3} / \mathrm{g}$, respectively, for $\mathrm{BC}$ ), a higher carbon content ( $85.8 \%$ vs. $56.4 \%$, respectively), and lower oxygen and hydrogen contents, which resulted in its decreased polarity[153]. Despite this, the number of surface oxygen functional groups in BCB was slightly increased. The effect of such marked changes in the physicochemical properties of this BC after modification was a more than nine-fold increase in its adsorption capacity toward TC, and a more than seven-fold increase in the case of SMX, as compared with pristine BC. The adsorption of both TC and SMX was dependent on solution $\mathrm{pH}$, and was most effective at $\mathrm{pH} 6$ and 4, respectively, for 
TC and SMX. At these values, the adsorbent surface and the molecules of these compounds were neutral; hydrophobic interactions, $\pi-\pi$ EDA interactions, and hydrogen bonding were responsible for the binding of the drugs with the $\mathrm{BC}[153,154]$.

Jang at al. [155] studied the sorption of TC onto BCs produced from alfalfa at a temperature of $300{ }^{\circ} \mathrm{C}$. Three $\mathrm{BCs}$ were tested: pristine $\mathrm{BC}(\mathrm{BC})$, pristine $\mathrm{BC}$ carbonized at $800{ }^{\circ} \mathrm{C}(\mathrm{BC}-$ $800)$, and pristine $\mathrm{BC}$ subjected to the action of $\mathrm{NaOH}$ and carbonized at $800{ }^{\circ} \mathrm{C}(\mathrm{BCB}-800)$. The best results for TC adsorption were obtained for BCB-800. The $\mathrm{Q}_{\max }$ values determined for BCB-800 were five and ten times greater than those for BC-800 and pristine $\mathrm{BC}$, respectively. Moreover, BCB-800 exhibited more than 1000 times higher SBET than that for pristine BC. BCB-800 was also characterized by the lowest polarity as well as the highest aromaticity and carbon content. The adsorption isotherms and the TC binding energies with the individual BCs indicated different binding mechanisms depending on the $\mathrm{BC}$ type. In the case of pristine $\mathrm{BC}$ and $\mathrm{BC}-800$, the data showed that TC was bound through physisorption, whereas in the case of BCB-800 it was bound via chemisorption [155].

Slightly different results regarding TC adsorption were obtained for BCs derived from poplar sawdust and pyrolyzed at 300, 500 and $700{ }^{\circ} \mathrm{C}$ (BC-300, BC-500, and BC-700), and subsequently modified with $\mathrm{KOH}$ (BCB-300, BCB-500, and BCB-700)[156]. The TC adsorption capacity was increased only for BCB-300 (a four-fold rise in comparison with BC$300)$, in spite of its very low porosity parameters. Modification under the other conditions decreased the $\mathrm{Q}_{\max }$ values by about $40 \%$ relative to pristine $\mathrm{BC}$, despite the fact that these $\mathrm{BCs}$ (BCB-500 and BCB-700) were characterized by much larger $S_{\mathrm{BET}}$ and $\mathrm{V}_{\mathrm{p}}$ than were found for the pristine $\mathrm{BC}$. This effect was attributable to differences in the surface oxygen functional group contents between the materials tested. $\mathrm{KOH}$ was shown to cause an increase in the number of acidic and basic oxygen functional groups only in the case of BCB-300. As far as BCB-500 and BCB-700 were concerned, the numbers of these groups were observed to 
decrease in relation to pristine $\mathrm{BC}$. Based on these observations, the authors found that for TC adsorption onto BCB-300, the main role is played by hydroxyl moieties $(-\mathrm{OH})$ or ionized moieties $(-\mathrm{O})$ on the $\mathrm{BC}$ acting as n-electron donors and interacting with the drug molecule through $n-\pi$ EDA interactions [156]. In the case of the other BCs, $\pi-\pi$ EDA interactions, hydrophobic interactions, hydrogen bonding, and pore filling were likely predominant, particularly in the case of $\mathrm{BCs}$ produced at $700{ }^{\circ} \mathrm{C}$, which were characterized by the highest porosity parameters.

TC adsorption was also investigated on rice husk-derived BC modified with acid methanol [157]. The use of an acidified alcohol solution causes esterification of carboxyl groups, thus changing the properties of surface oxygen groups participating in the binding of the antibiotic [158]. Modified BC was characterized by a reduced number of carbonyl functional groups and an increased number of ester and hydroxyl groups (in comparison with pristine BC). A $25 \%$ increase in the $\mathrm{S}_{\mathrm{BET}}$ of the BC was also recorded after acid methanol modification. Hydroxyl groups $(-\mathrm{OH})$ or ionized moieties $\left(-\mathrm{O}^{-}\right)$present on the $\mathrm{BC}$ surface can act as electron donors promoting $n-\pi$ EDA interactions with the TC molecule. adsorption phase (after $12 \mathrm{~h}$ ), this process was fast on the modified material, which resulted in an increase in TC adsorption capacity by $46 \%$ versus pristine $\mathrm{BC}$; however, adsorption equilibrium had been reached after 13 days, this difference was $17 \%$ [157].

Hydrogen peroxide $\left(\mathrm{H}_{2} \mathrm{O}_{2}\right)$ was also used to modify BC for antibiotic adsorption [159]. Using rape stalk for pyrolysis, Tan et al. [159] produced three types of pristine BC at 300, 450, and $600{ }^{\circ} \mathrm{C}$ (BC-300, BC-450, and BC-600, respectively). These BCs were subsequently modified by a post-synthesis method using $30 \% \mathrm{H}_{2} \mathrm{O}_{2}$ (BCM-300, BCM-450, BCM-600). For the pristine $\mathrm{BCs}$, that produced at the lowest temperature exhibited the highest TC adsorption. Interestingly, BC-300 had the lowest porosity parameters ( $\mathrm{S}_{\mathrm{BET}}$ was $3.87 \mathrm{~m}^{2} / \mathrm{g}$ ) relative to the other BCs tested. The high TC adsorption onto this BC was explained by the presence of 
numerous functional groups on its surface and by residues of non-carbonized organic matter that interacted with the TC. Nevertheless, in the case of the two other unmodified BCs, the porosity parameter values rose substantially with increasing pyrolysis temperature (the $S_{\text {BET }}$ value was 16 times higher for BC-600 than BC-450); however, the differences in $\mathrm{Q}_{\max }$ were less significant, i.e., about $23 \%$. This suggests that in this treatment, adsorption was largely dependent on the presence of functional groups. $\mathrm{H}_{2} \mathrm{O}_{2}$ modification did not markedly improve the porosity of the materials. In the case of BCM-300 and BCM-450, a decrease in the porosity parameters was even observed, which was probably related to the removal of organic matter residues by $\mathrm{H}_{2} \mathrm{O}_{2}$. In the case of modified $\mathrm{BCs}$ produced at higher temperatures, the amount of adsorbed TC increased by $30 \%$, reaching a maximum for BCM-600. This arises from the oxidative activity of $\mathrm{H}_{2} \mathrm{O}_{2}$, which causes an increase in the number of oxygen functional groups participating in the adsorption of TC molecules through hydrogen bonding and $\pi-\pi$ EDA interactions [159].

Table 3. Antibiotic adsorption on modified BCs.

Where: $S_{\mathrm{BET}}-$ the specific surface area determined from $\mathrm{N}_{2}$ sorption measurements according to the BET equation, $\mathrm{t}$ - adsorption time, $\mathrm{pH}$ - adsorption $\mathrm{pH}, \mathrm{T}$ - adsorption temperature, $\mathrm{BC}$-adsorbent dose, $\mathrm{c}_{\text {ant }}-$ initial antibiotic concentration, $\mathrm{Q}_{\max }-$ the maximum adsorption capacity

\subsubsection{BIOCHAR COMPOSITES}

Composites are the most complex BC group adsorbents used for the antibiotic removal. According to the definition of the International Union of Pure and Applied Chemistry (IUPAC), a composite is a multicomponent material comprising multiple, different (non-gaseous) phase domains in which at least one type of phase domain is a continuous phase, whereas in the case 
where one of the phases has nanoparticle dimensions, it is termed a nanocomposite [160]. Being a continuous phase, $\mathrm{BC}$ can be combined with various components; most frequently, these are metal oxides and hydroxides, clay minerals, carbon materials (carbon nanotubes (CNTs), graphene, graphene oxide (GO), and polymers [50,161]. Generally, BC composites can be produced in two ways, as in the case of modified BCs. In the first method, composite components, not being a continuous phase, can be incorporated into a feedstock before pyrolysis (pre-treatment) (e.g., saturation with metal salts), whereas in the second method, composite components are added to the finished $\mathrm{BC}$ after pyrolysis (e.g., through precipitation of oxides, impregnation with ready-made nanoparticles, and coatings) (post-treatment) [161]. An advantage of such approaches (which is at the same time the underlying idea of composites based not only on $\mathrm{BC}$ but also on other matrices) is the fact that they combine the characteristics of the initial components; therefore, the material obtained exhibits new qualities $[162,163]$. In the case of $\mathrm{BC}$ composites, the $\mathrm{BC}$ matrix may be responsible for the hydrophobic nature of a composite or the adsorption properties associated with high porosity, whereas the addition of, e.g., clay minerals or metal oxides/hydroxides may increase the percentage of oxygen functional groups in the final product, improving its polarity/hydrophilic nature. Finally, entirely new properties can be passed to the derived composite, e.g., catalytic $\left(\mathrm{TiO}_{2}\right)$ or magnetic (iron compounds) properties. The addition of carbon materials (CNTs, GO) can promote increased porosity and thermal resistance [161]. Obviously, it should be taken into account that certain properties may also deteriorate, e.g., a reduction in porosity as a result of physical blocking of pores owing to the incorporation of a new component [109]. Nevertheless, owing to the possibility of the changing physicochemical properties and developing completely new functionalities in BC composites, coupled with the simplicity of synthesis and the multitude of components available, materials of this type have been tested in many studies for the adsorption and removal of antibiotics from water in recent years (Table 4). Figure 7 presents 
the effects of the most frequently used additions (metal compounds, carbon materials, and clay minerals) on the properties of produced BC composites used for the antibiotic removal.

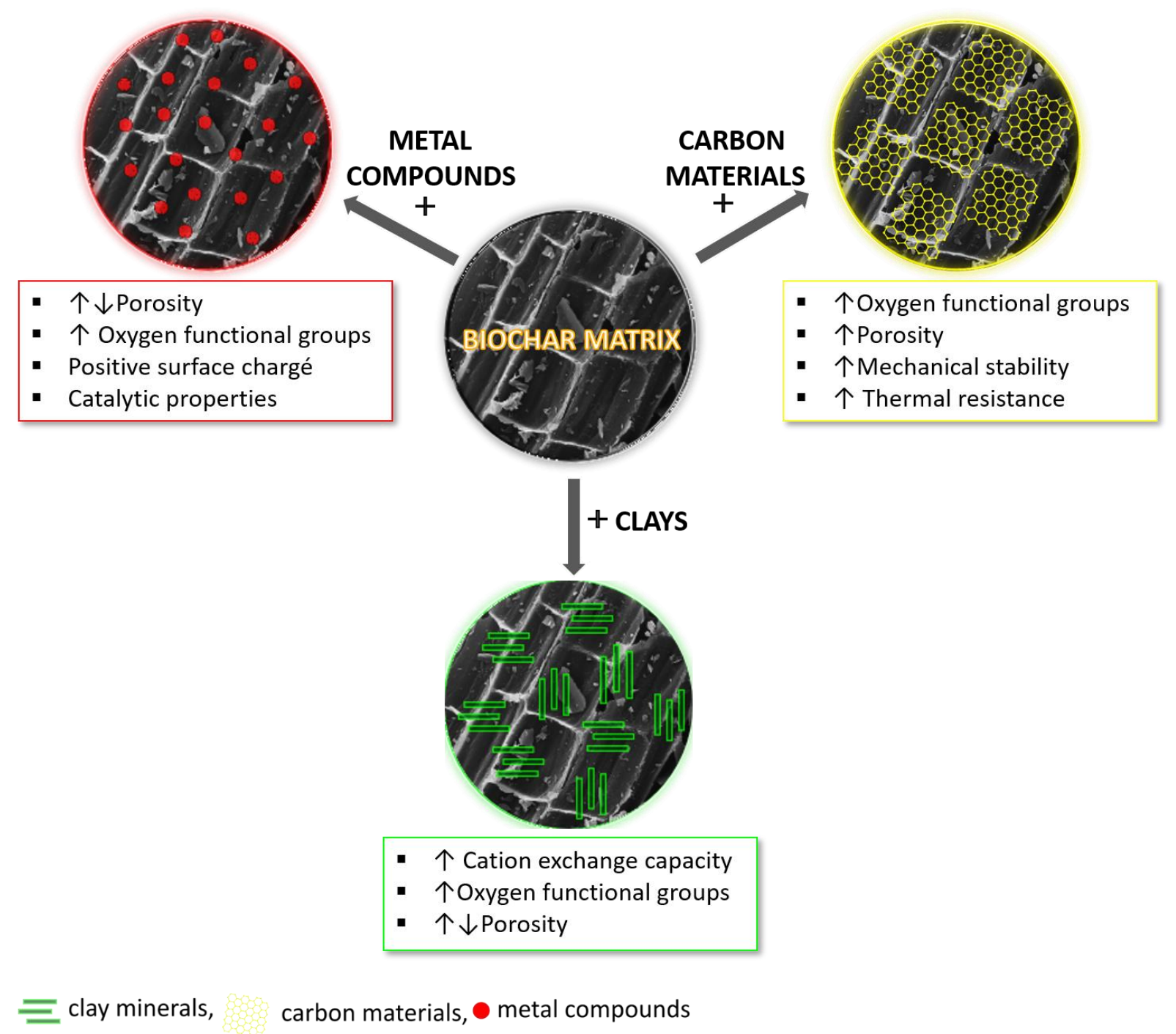

Fig. 7. Effect of commonly used additives (metal compounds, carbon materials, and clay minerals) on the properties of biochar-based composites.

\subsection{BIOCHAR-CLAY COMPOSITES}


Owing to their layered structure, high $\mathrm{S}_{\mathrm{BET}}$, and high ion exchange capacity, clay minerals (e.g., montmorillonite, kaolinite, and palygorskite) have huge potential to remove various contaminant including dyes, heavy metals, and organic compounds $[164,165]$. Additionally, they are abundantly available and low-cost materials. However, clay minerals are generally tiny particles (often of the nano- order in one or more dimensions), which hinders their application, e.g., in fixed-bed adsorption substrates [166]. Another limitation of using clay minerals in a fixed-bed system is the poor water flowability of some clay minerals, especially in case of the swellable 2:1 type (one alumina octahedron is sandwiched between two silica tetrahedral structures) clay minerals such as montmorillonite $[167,168]$. Therefore, it seems advisable to combine them in composites with other materials having a porous structure that can perform the function of a support or host, e.g., polymers or BCs [166,169-172].

Premarathna et al. [173] used two clay minerals, montmorillonite (MMT) and red earth clay (RE), and municipal solid waste to produce BC composites (via a pre-treatment method) [173]. The produced composites were termed $\mathrm{BC}-\mathrm{MMT}$ and $\mathrm{BC}-\mathrm{RE}$, respectively, and were used together with pristine $\mathrm{BC}$ for $\mathrm{TC}$ adsorption in a $\mathrm{pH}$ range of 3 to 9 . The addition of both clay minerals caused a nearly two-fold increase in the $\mathrm{S}_{\mathrm{BET}}$ of the obtained composites, which is an evidence for the absence of pore blocking phenomenon after the incorporation of the porous particles of the minerals into the BC. Nevertheless, the TC adsorption capacity did not differ significantly between $\mathrm{BC}-\mathrm{RE}$ and the pristine $\mathrm{BC}$. It was demonstrated that $\mathrm{TC}$ is primarily adsorbed via chemisorption, in which $\pi-\pi$ interactions, hydrogen bonding, electrostatic interactions, and ion exchange participate [173]. Adsorption was dependent on solution pH. For $\mathrm{BC}-\mathrm{RE}$ and pristine $\mathrm{BC}$, the adsorption of $\mathrm{TC}$ was low at low $\mathrm{pH}$ values, which was a result of electrostatic repulsion between positively charged (at this $\mathrm{pH}$ ) $\mathrm{TC}$ molecules and the positively charged surface of the adsorbents. The maximum values of TC adsorption onto the BCs were obtained at a pH between 5 and 7 , at which the drug molecule is neutral. The similar values of 
the $\mathrm{TC}$ adsorption capacities onto pristine $\mathrm{BC}$ and $\mathrm{BC}-\mathrm{RE}$ are evidence that in the case of the above-mentioned composite, the BC matrix is chiefly responsible for the adsorption, whereas the presence of RE does not have a significant impact on the amount and mechanism of adsorption. The composite with MMT exhibited a much larger (by about 20 times) TC adsorption capacity compared with the other two materials. This was attributable to the layered structure of MMT, which RE does not possess. The structure of MMT enabled intercalation of the drug between the layers of the adsorbent, coupled with pore filling. For BC-MMT, adsorption was also effective at low $\mathrm{pH}$ values (high $\mathrm{Q}_{\max }$ at $\mathrm{pH}<4$ ). The authors [173] linked this effect to the mechanism of ion exchange of positively charged ions of the drug with ions $\left(\mathrm{Na}^{+}, \mathrm{Ca}^{2+}\right)$ present between the layers of the clay mineral. For the other composite, the contribution of ion exchange to the adsorption was much smaller owing to the different chemical composition and low cation exchange capacity of RE clay.

Enhanced norfloxacin (NOR) sorption (a 140\% increase) onto a BC-MMT composite as compared with pristine BC was reported [174]. Owing to the composite high porosity values, the adsorption mechanism was associated with pore filling. Hydrogen bonding and electrostatic interactions also participated in the adsorption process, which was related to an increase in the number of surface oxygen groups in the MMT-containing material and the amphoteric structure of the NOR molecule. The highest adsorption occurred in solutions having $\mathrm{pH}$ between 5 and 11, at which values the drug molecule is neutral. The presence of $\mathrm{Cu}^{2+}$ ions and dissolved humic acid in the solution reduced the adsorption of NOR as a result of competition.

Ashiq et al. [175] investigated the ciprofloxacin (CPX) adsorption onto a biocomposite derived from municipal solid waste with the addition of bentonite clay. A $40 \%$ increase in CPX adsorption onto the composite, as compared with pristine BC was reported [175]. This increase was associated with the enhanced porosity of the adsorbent and the presence of electrostatic 
interactions between functional groups present on the composite surface and the CPX molecule, as well as with the intercalation of CPX in the bentonite layers.

\subsection{BIOCHAR-CARBON COMPOSITES}

Apart from the addition of clay minerals, combinations of $\mathrm{BC}$ with other carbon materials (including graphene, GO, reduced GO and carbon nanotubes) are also used [50,176-178]. The purpose of adding a carbon material to BC is to increase a composite's $S_{\text {BET, }}$ mechanical stability, or thermal resistance $[175,177][174,176][173,175][172,174]$. Additionally, the socalled grafting of the surface of added nanocarbons with functional groups (carboxyl, hydroxyl, amine, fluorine ones, etc.) is commonly used in order to improve the adsorption properties of a developed composite $[180,181]$. BC-carbon composites find applications in the removal of various types of contaminants, e.g., heavy metals, PAHs, dyes, pesticides, and drugs $[176,177,182,183]$.

As far as antibiotics are concerned, studies to date have addressed composite materials containing GO [183] and CNTs [184]. Huang et al. [183] investigated the adsorption of sulfamethazine (SMT) onto BC derived from bamboo sawdust and its composite with the addition of GO. The composite was obtained by pre-treatment ( $0.2 \mathrm{~g} \mathrm{GO}: 10 \mathrm{~g}$ feedstock ratio, $600{ }^{\circ} \mathrm{C}$ for $1 \mathrm{~h}$ in $\mathrm{N}_{2}$ ). It was characterized by more than double the SMT adsorption capacity relative to pristine $\mathrm{BC}$. The addition of $\mathrm{GO}$ increased the $\mathrm{S}_{\mathrm{BET}}$ and the amount of oxygen functional groups on the composite surface by $90 \%$, which was reflected in the increase in SMT adsorption. SMT was shown to undergo chemisorption, with the greatest contribution of $\pi-\pi$ EDA interactions. Adsorption was investigated in solutions with different $\mathrm{pHs}$ and ionic strengths. Antibiotic adsorption increased with decreasing solution ionic strength and was highest for solutions in the $\mathrm{pH}$ range of 3 to 6, at which the SMT molecule is electrically neutral. 
The effect of chemical aging of the adsorbents (subjected to the action of a mixture of $\mathrm{H}_{2} \mathrm{SO}_{4}$ and $\mathrm{HNO}_{3}$ ) on their adsorption ability was also investigated. Aging increased SMT adsorption by $30 \%$, both for pristine $\mathrm{BC}$ and the $\mathrm{BC}-\mathrm{GO}$ composite. This was associated with an increase in the proportion of acidic functional groups, and an increase in the S SET of the materials, as affected by the acids [183].

Inyang et al. [184] conducted a study on the adsorption of SMT onto BC composites with CNTs. To prepare BC composites, hickory chips (HC) and sugarcane bagasse (SB) were used in two pre-treatment options: (1) with a CNT suspension, or (2) with a CNT suspension containing a surfactant (sodium dodecylbenzenesulfonate; SDBS). Nanotube addition significantly increased the SMT adsorption ability of both the HC and SB BCs. Maximum SMT removal was achieved with the composites prepared in the presence of the surfactant, i.e., $86 \%$ and $56 \%$, respectively, for $\mathrm{HC}$ and SB. At the same time, the composites for which the highest efficiency was obtained were characterized by the lowest $\mathrm{pH}$, which is evidence of the high contribution/better exposure of acidic groups that may have participated in the binding of SMT. In both the case of the composites derived from SB and the CNT suspension, as well as with the CNT suspension with SDBS addition, a more than 40-fold increase in SBET was found relative to pristine $\mathrm{BC}-\mathrm{SB}$. A similar effect was not observed for the HC-based composites. Investigation of the kinetics and isotherms of SMT adsorption onto the composites confirmed the binding of the antibiotic via chemisorption, primarily through $\pi-\pi$ EDA interactions. The study also evaluated the $\mathrm{Pb}^{2+}$ impact on STM adsorption effectiveness. The adsorption efficiency did not decrease, which may suggest that the $\mathrm{Pb}^{2+}$ adsorption mechanism onto the tested BCs was different to that of SMT [184].

\subsection{BIOCHAR-METAL COMPOSITES}


Metals $\left(\mathrm{Fe}^{0}, \mathrm{Ag}^{0}, \mathrm{Cu}^{0}, \mathrm{Ni}^{0}\right)$ and their compounds, usually oxides $\left(\mathrm{MgO}, \mathrm{MnO}, \mathrm{Al}_{2} \mathrm{O}_{3}, \mathrm{Fe}_{2} \mathrm{O}_{3}\right.$, $\mathrm{CaO})$ and hydroxides $\left(\mathrm{AlOOH}, \mathrm{Mg}(\mathrm{OH})_{2}\right)$, are commonly used in the $\mathrm{BC}$ composites synthesis [185-187]. BC modification with metal oxides/hydroxides is designed to increase the porosity, and change the physicochemical properties of an obtained composite; in particular, by changing the surface charge from negative (characteristic of $\mathrm{BCs}$ ) to positive (characteristic of metal oxides). This type of composite can find application in the adsorption of negatively charged compounds from water, particularly oxyanions $\mathrm{AsO}_{4}{ }^{3-}, \mathrm{AsO}_{3}{ }^{3-}, \mathrm{CrO}_{4}{ }^{2-}, \mathrm{NO}^{3-}$, and $\mathrm{PO}_{4}{ }^{3-}$, which are hazardous to health and the environment, and exhibit only weak affinity for pristine BCs $[186,188]$. Moreover, these composites can successfully adsorb cations, e.g., heavy metals $\mathrm{Pb}^{2+}, \mathrm{Cu}^{2+}, \mathrm{As}^{5+}$, and $\mathrm{Cr}^{6+}$. Adsorption results are sometimes much better than for pristine $\mathrm{BCs}$ owing to the greater porosity parameters of the composites and the presence of functional groups (mainly hydroxyl groups) capable of complexing ions $[189,190]$. The use of BCs support improves the properties of incorporated metal compounds, increases dispersion, protects them against oxidation, or as in the case of nZVI, increases the electron transfer ability [191]. BCs can also serve as carriers and stabilizers of catalysts, e.g., aluminum compounds $\left[\mathrm{Al}_{2} \mathrm{O}_{3}\right.$, $\left.\mathrm{Al}(\mathrm{OH})_{3}, \mathrm{AlO}(\mathrm{OH})\right]$ in the process of glucose isomerization to fructose in biorefineries [192], or metals $\left(\mathrm{Ni}^{0}, \mathrm{Fe}^{0}\right)$ catalyzing tar decomposition in biogas plants [185].

Yang ${ }^{159}$ et al. [193] studied the TC adsorption onto pristine BC derived from sewage sludge and onto a composite (BC-Fe) made from sewage sludge and iron compounds. The feedstock was impregnated with iron sulfate $\left[\mathrm{Fe}_{2}\left(\mathrm{SO}_{4}\right)_{3}\right]$ before pyrolysis (pre-treatment). X-ray photoelectron spectroscopy (XPS) analysis confirmed the presence of $\mathrm{Fe}_{2} \mathrm{O}_{3}, \mathrm{Fe}_{3} \mathrm{O}_{4}$, and $\mathrm{FeS}$ in the composite. The composite prepared with the $\mathrm{Fe}_{2}\left(\mathrm{SO}_{4}\right)_{3}$ addition was characterized by higher hydrophilicity (O/C ratio) and porosity (a 55-fold increase in SBET and a 16-fold increase in $\mathrm{V}_{\mathrm{p}}$ ), as compared with pristine BC. A consequence of the presence of iron compounds in the composite was a $300 \%$ increase in TC adsorption capacity compared with unmodified BC. The 
study revealed that hydrogen bonding with $\mathrm{Fe}-\mathrm{O}$ groups and metal complexation may have made substantial contributions to the binding of $\mathrm{TC}$ in the $\mathrm{BC}-\mathrm{Fe}$ material, as opposed to pristine BC [193].

Zhou et. al [194] derived similar results and conclusions regarding TC adsorption for a sawdust-based BC composite with the addition of zinc and iron chloride salts. The composite materials with iron and zinc compounds showed an almost three-fold higher adsorption capacity in relation to $\mathrm{TC}$ than did pristine $\mathrm{BC}$. Moreover, the material produced by subjecting the feedstock to the action of a mixture of both salts exhibited a four-fold increase in Qmax value versus original BC [194].

Chen et al. [195] studied the effect of the type of synthesis of BC composites with iron oxides on their adsorption ability towards TC and levofloxacin (LEV). The synthesis of the BC composites involved impregnation of the feedstock with iron salt before pyrolysis (IP-BCFe) (pre-treatment) or after pyrolysis (PI-BCFe) (post-treatment). The prepared composites differed in their chemical composition and properties. The PI-BCFe composite was shown to contain hydrated amorphous iron oxides, whereas crystalline $\gamma-\mathrm{Fe}_{2} \mathrm{O}_{3}$ was predominant in the IP-BCFe composite. It was found [195] that the PI-BCFe composite, in spite of its lower SBET and iron content, showed much higher values of $\mathrm{Q}_{\max }$ for the drugs examined (by about $50 \%$ for TC and $400 \%$ for LEV) than the IP-BCFe composite. This resulted from the presence of numerous hydroxyl moieties in PI-BCFe which participated in the adsorption. The adsorption mechanisms revealed that (1) electrostatic attraction, (2) hydrogen bonding, (3) complexation, and additionally in the case of LEV (4) F-replacement with - OH groups participated in the binding of the drugs with the composites. Hydroxyl groups participated in the last three abovementioned mechanisms, which would explain the greater adsorption ability toward LEV. Furthermore, the regeneration ability of both composites after five adsorption cycles was tested. 
The reduction in adsorption for both composites did not exceed $20 \%$, as compared with the newly obtained adsorbents, which confirmed their practical usefulness [195].

Composites derived from potato stems and leaves as well as from magnetic manganese oxide (BC-FeMn) were tested as adsorbents of three antibiotics belonging to the quinolone class, i.e., norfloxacin (NOR), ciprofloxacin (CIP), and enrofloxacin (ENR) [196]. Plant biomass including potato stems and leaves was impregnated with a solution of $\mathrm{FeCl}_{3} \cdot 6 \mathrm{H}_{2} \mathrm{O}$, and subsequently dried and impregnated with a solution of $\mathrm{KMnO}_{4}$ before pyrolysis. The results were compared with BC made only from potato stems and leaves. The obtained composite was characterized by 1.5 times larger $\mathrm{S}_{\mathrm{BET}}, 2$ times larger $\mathrm{V}_{\mathrm{p}}$, and a pHpZC that was lower by 3.3 units, as compared with the pristine BC. XPS analysis confirmed the presence of iron and manganese oxides on the surface of $\mathrm{BC}-\mathrm{FeMn}$. In comparison with pristine $\mathrm{BC}$, the $\mathrm{BC}$ composite exhibited a higher adsorption capacity of 20 to $63 \%$ for all the antibiotics tested. The adsorption increased in the following order: NOR $<$ CIP $<$ ENR. The observed variations in the effect of modification on the adsorption of the individual antibiotics were due to the slightly different structures and properties of the drug molecules. The authors suggest that the higher porosity parameters and the presence of additional oxygen groups on the adsorbent surface increased adsorption onto the composite relative to pristine BC. Oxygen groups originating from the metal oxides and $\pi-\pi$ interactions participated in the binding of the drug. The adsorption of all the antibiotics increased with decreasing $\mathrm{pH}$ and ionic strength of the solution. It was demonstrated that after three reuse cycles, $\mathrm{BC}-\mathrm{FeMn}$ maintained almost $100 \%$ of the original adsorption capacity toward all the antibiotics tested [196].

Another multicomponent BC-based calcined-Mg/Al layered double hydroxide composite was used to investigate TC adsorption [197]. This study revealed that over twice the amount of drug was adsorbed onto the composite than onto pristine $\mathrm{BC}$. This was attributable to the presence of numerous hydroxide and alkoxide groups in the composite structure, which 
participated in hydrogen bonding with the TC molecule. Moreover, electrostatic interactions (dependent on solution $\mathrm{pH}$ ) and $\pi-\pi$ interactions were suggested among the mechanisms responsible for binding $\mathrm{TC}$ to the composite. The $\mathrm{TC}$ adsorption capacity was shown to be dependent on solution $\mathrm{pH}\left(\mathrm{Q}_{\max }\right.$ was highest at $\left.\mathrm{pH} 4\right)$, ionic strength $\left(\mathrm{Q}_{\max }\right.$ decreased with increasing ionic strength), adsorbent dose ( $\mathrm{Q}_{\max }$ increased with increasing adsorbent), and temperature $\left(\mathrm{Q}_{\max }\right.$ increased with increasing temperature). The achieved desorption efficiency was $70 \%$, whereas adsorption decreased with each successive reuse cycle. However, after five cycles, adsorption remained higher than that found for pristine BC [197].

Using a post-treatment method, Heo et al. [198] prepared a magnetic composite composed of $\mathrm{BC}$ and $\mathrm{CuZnFe}_{2} \mathrm{O}_{4}$ (BC-CZF). The composite's efficiency in the removal of sulfamethoxazole (SMX) from a solution was studied [198]. The composite was characterized by a $65 \%$ higher SMX adsorption capacity compared with pristine BC. This was due to the higher porosity parameters of the $\mathrm{BC}-\mathrm{CZF}$ material than those of the original $\mathrm{BC}\left(\mathrm{S}_{\mathrm{BET}}\right.$ and $\mathrm{V}_{\mathrm{p}}$ were higher by about 2.5 times relative to pristine BC). Furthermore, the increase in SMX adsorption onto the composite was linked to the adsorption mechanism. It was shown that groups of metal-bound atoms, e.g., Me-O, participated in the binding of the antibiotic via hydrogen bonding or complexation. The authors did not also exclude hydrophobic and $\pi-\pi$ EDA interactions originating from the $\mathrm{BC}$ structure from being important in the process of SMX adsorption by the investigated BC composites. The usefulness and regeneration ability of the produced composite were also tested. After four cycles, the adsorbent still showed a $90 \%$ SMX adsorption performance compared with its value for the fresh composite.

The removal of antibiotics from the water using BC composites with the addition of metals and their compounds can be carried out not only via adsorption but can also be linked to composite's catalytic properties, which lead to the degradation of an antibiotic. For example, Zhang et al. [199] produced a composite consisting of BC coated with titanium oxide (BC- 
$\mathrm{TiO}_{2}$ ) as a photocatalyst for the degradation of SMX. This study investigated the simultaneous adsorption and photocatalytic degradation of the antibiotic onto the produced composite. The SMX adsorption capacity of the composite was 3.5 times lower than for the original BC. This resulted from a decrease in the composite's adsorption parameters. Following the incorporation of $\mathrm{TiO}_{2}$ into the $\mathrm{BC}$, the number of oxygen functional groups participating in the binding of the drug was found to decrease. However, in spite of the BC's reduced adsorption ability, the efficiency of photocatalytic SMX degradation was observed to be higher for $\mathrm{BC}-\mathrm{TiO}_{2}(91 \%)$ than for pure titanium oxide $(59 \%)$. A high degree of $\mathrm{TiO}_{2}$ dispersion in the composite was confirmed. The use of a porous $\mathrm{BC}$ carrier prevented the agglomeration of $\mathrm{TiO}_{2}$ molecules, which enhanced the photodegradation efficiency, thus preventing the recombination of electrons $\left(\mathrm{e}^{-}\right)$and holes $\left(\mathrm{h}^{+}\right)$. The composite's performance was also investigated in the presence of $\mathrm{SO}_{4}{ }^{2-}, \mathrm{Cl}^{-}$, and $\mathrm{NO}_{3}{ }^{-}$ions in river water. The SMX degradation efficiency was observed to decline (66\%), which was explained by competition of the ions with the composite surface and by inhibition of the photocatalysis as a result of the reaction of their $\bullet \mathrm{OH}$ and $\left(\mathrm{h}^{+}\right)$ radicals. After five cycles, the SMX degradation performance remained unchanged (86\%) [199].

In addition to photocatalytic processes promoting the degradation of antibiotics, such compounds can also be degraded due to the action of free radicals formed with the participation of oxidizing agents (e.g., oxygen $\left(\mathrm{O}_{2}\right)$, sodium thiosulfate $\left(\mathrm{Na}_{2} \mathrm{~S}_{2} \mathrm{O}_{3}\right)$, or hydrogen peroxide $\left.\left(\mathrm{H}_{2} \mathrm{O}_{2}\right)\right)$ as activators. Redox systems composed of metals and/or their oxides with an oxidant are commonly used to generate free radicals. For instance, Fu et al. [200] tested a composite consisting of $\mathrm{BC}$ and copper nanoparticles $(\mathrm{BC}-\mathrm{nCu})$ in the removal of $\mathrm{TC}$ from an aqueous solution. Assessment of the removal of this antibiotic was performed both in the presence and absence of $\mathrm{H}_{2} \mathrm{O}_{2}$ for the composite, as well as for pristine $\mathrm{BC}$ and copper nanoparticles (nCu) for the purpose of comparison. In the systems without $\mathrm{H}_{2} \mathrm{O}_{2}$, the amounts of $\mathrm{TC}$ removed were much lower than that in the systems with $\mathrm{H}_{2} \mathrm{O}_{2}$. In the case of the composite without $\mathrm{H}_{2} \mathrm{O}_{2}$ 
addition, more than $30 \%$ of the drug was removed from the solution over $6 \mathrm{~h}$, which can be linked to the mechanism of adsorptive binding of $\mathrm{TC}$ onto $\mathrm{BC}-\mathrm{nCu}$. For $\mathrm{BC}-\mathrm{nCu}$, the study found high adsorption parameter values $\left(\mathrm{S}_{\mathrm{BET}}=135 \mathrm{~m}^{2} / \mathrm{g}, \mathrm{V}_{\mathrm{p}}=0.1 \mathrm{~cm}^{3} / \mathrm{g}\right)$, and confirmed the presence of oxygen functional groups such as $\mathrm{C}-\mathrm{O}, \mathrm{C}=\mathrm{O}, \mathrm{Cu}-\mathrm{O}$, and- $\mathrm{OH}$, which can participate in the binding of the drug due to hydrogen, electrostatic, or $\pi-\pi$ EDA interactions. The $\mathrm{H}_{2} \mathrm{O}_{2}$ addition caused a significant increase in the amount of $\mathrm{TC}$ removed. It was found that $\mathrm{BC}-\mathrm{nCu}$ with $\mathrm{H}_{2} \mathrm{O}_{2}$ resulted in $98 \%$ TC removal, whereas unmodified $\mathrm{BC}$ and $\mathrm{nCu}$ resulted in $31 \%$ and $48 \%$ removal, respectively. These observations confirm the oxidative mechanism of TC degradation with the participation of formed hydroxyl free radicals. $\mathrm{Cu}$ performs the function of an activator and participates in the degradation of $\mathrm{H}_{2} \mathrm{O}_{2}$ through redox reactions; hence, an improved performance was observed for the materials containing this element. For the BC composite, the highest percentage of TC removed may have resulted from the combination of its adsorption properties and the high dispersion of $\mathrm{Cu}$ nanoparticles. These factors have an effect on increasing active redox reaction sites. The results obtained for pristine $\mathrm{BC}$ not containing $\mathrm{nCu}$ confirmed the occurrence of free radicals participating in electron transfer in the BC. At the same time, these radicals can have contributed to enhanced TC degradation performance in the case of the composite material [200].

A composite prepared from BC and nanoscale zero-valent iron (nZVI) was tested by Deng et al. [201] for the purpose of oxidative degradation of SMT in the presence of hydrogen peroxide (Fenton's reaction). The study investigated SMT removal efficiency in the presence and absence of $\mathrm{H}_{2} \mathrm{O}_{2}$ for three materials: pristine $\mathrm{BC}$, the composite, and ZVI nanoparticles. In the absence of $\mathrm{H}_{2} \mathrm{O}_{2}$ in the solution, most SMT was removed using pristine $\mathrm{BC}(31 \%)$ and the composite $(25 \%)$. In the case of ZVI nanoparticles, removal was just $7 \%$. The higher values found for the first two materials are related to the adsorption of SMT by pristine BC and the $\mathrm{BC}$ composite. Pristine $\mathrm{BC}$ was characterized by the highest adsorption parameters, which 
yielded its highest SMT removal efficiency. In the case of the composite, which was characterized by lower porosity than that of the pristine BC, the removal of SMT was probably linked to the presence of oxygen functional groups, including those originating from the metal and participating in the binding of the antibiotic. The addition of $\mathrm{H}_{2} \mathrm{O}_{2}$ to this system caused an increase in the amount of SMT removed for all the materials tested. The achieved removal levels were $37 \%$ for pristine $\mathrm{BC}, 74 \%$ for $\mathrm{BC}-\mathrm{nZVI}$, and $57 \%$ for the nanoparticles (nZVI). Such a substantial increase in the case of the composite and nanoparticles (nZVI) is evidence of the catalytic activity of iron nanoparticles and the activation of hydrogen peroxide in Fenton's reaction, leading to the generation of hydroxyl free radicals participating in the degradation of the antibiotic. The improved results for pristine $\mathrm{BC}$ confirm its ability to activate $\mathrm{H}_{2} \mathrm{O}_{2}$. In the composite material, $\mathrm{BC}$ performs the role of not only a catalyst carrier, preventing the aggregation of its molecules (protecting it against passivation), but also of binding SMT through adsorption and activation of $\mathrm{H}_{2} \mathrm{O}_{2}$. The researchers also determined the optimal operating conditions for the composite, and verified its performance after regeneration. After three cycles, the efficiency of SMT removal by BC-nZVI decreased by $38 \%$ owing to the loss of the catalytic ability by the nZVI particles.

Nguyen et al. [202] conducted a study on the oxidative removal of TC using a composite composed of BC and magnetite. Spent coffee grounds impregnated with iron chloride (III) $\left(\mathrm{FeCl}_{3}\right)$ were used to prepare the composite, whereas sodium thiosulfate $\left(\mathrm{Na}_{2} \mathrm{~S}_{2} \mathrm{O}_{3}\right)$ was applied to generate reactive free radicals. Acting as a catalyst, the iron (III) present in the composite, caused activation of the thiosulfate ions, which resulted in the generation of thiosulfate and sulfate radicals (in an acidic environment) or hydroxyl radicals (in a basic environment). Subsequently, these radicals participated in the degradation of TC. After optimization of the process conditions, the authors [202] achieved TC degradation of 96\%. A similar result was obtained for a composite produced via post-synthesis of BC (derived from peanut shells) with 
an admixture of $\mathrm{Cu}$-doped $\mathrm{FeOOH}$ clasts in relation to sodium thiosulfate [203]. The amount of TC removed was the sum of two processes: adsorption and catalytic oxidation using the thiosulfate. The researchers tested the composite's regeneration ability; after five cycles, the TC removal efficiency remained at a high level of $90 \%$.

In summary, the use of engineered BCs is aimed to improve the efficiency of removal of aqueous antibiotic residues. This is strictly dependent on the physicochemical properties of both the adsorbent and the adsorbate (antibiotic) and the sorption conditions.

The physical modification usually leads to an improvement of the $\mathrm{BC}$ porous structure as well as an increase of aromaticity/hydrophobicity. Hence, it can be successfully used in the BCdrug system, where the adsorption is based on the pore filling process, hydrophobic interactions, and $\pi-\pi$ interactions. However, when sorption is based on interactions involving polar functional groups, such as the electrostatic interactions, hydrogen bonding, $n-\pi$ EDA, usually dependent on $\mathrm{pH}$, physical modification is not sufficient. Thus, it is advisable to chemically modify the BCs, leading mostly to increase the polarity by changes within surface functional groups and biochar pHpzc value, as well as enlarge BCs porosity. That enables occurring the above-mentioned BC-antibiotic interactions.

In the case of $\mathrm{BC}$ composites, the presence of an additional component may change the properties and/or give completely new ones, influencing the process and mechanisms of antibiotic adsorption and removal. Depending on the type of clay, its addition to the BC matrix can increase porosity, change the surface charge, and provide oxygen polar functional groups or cations. Hence, in addition to the typical adsorption mechanisms for $\mathrm{BC}$, the contribution of interactions involving polar groups or pore filing can be increasing. Additionally, the ion exchange as well as drug intercalation between the clay layers can take place.

The combination of carbon nanomaterials with a biochar matrix usually results in an increase of the porosity parameters, or in the case of $\mathrm{GO}$, the introduction of oxygen functional 
groups. As a consequence, among the mechanisms responsible for the adsorption of antibiotics on this type composites, the greatest contributors may be pore filing, interactions with oxygen groups, as well as hydrophobic and $\pi-\pi$ interactions resulting from the structure both carbon materials.

Metal compounds present in biochar-metal composites are responsible for changing the surface charge and provide functional groups, mainly oxygen. The electrostatic attraction, hydrogen bonding, and metal complexation can be also distinguished. Furthermore, some metal compounds exhibit photocatalytic/catalytic activity, so BC acts not only as an antibiotic adsorbent but also as a carrier for such a catalyst. In the presence of an activator such as light or a free radical generating oxidant, the antibiotic can be catalytically degraded.

Table 4. Antibiotic adsorption/degradation on biochar composites.

Where: $\mathrm{S}_{\mathrm{BET}}-$ the specific surface area determined from $\mathrm{N}_{2}$ sorption measurements according to the BET equation, $\mathrm{t}$ - adsorption time, $\mathrm{pH}$ - adsorption $\mathrm{pH}, \mathrm{T}$-adsorption temperature, $\mathrm{BC}$-adsorbent dose, $\mathrm{c}_{\text {ant }}-$ initial antibiotic concentration, $\mathrm{c}_{\mathrm{H} 2 \mathrm{O} 2}-\mathrm{H}_{2} \mathrm{O}_{2}$ concentration, $\mathrm{Q}_{\max }-$ the maximum adsorption capacity, \%removal - the maximum percentage of antibiotic removal

\section{CHALLENGES AND PROSPECTS IN ADSORPTIVE REMOVAL OF ANTIBIOTICS RESIDUES BY BIOCHAR-BASED ADSORBENTS}

\subsection{CHALLENGES}

Based on the available information, it can be concluded that the potential of the commercial application of $\mathrm{BC}$ materials for the removal of antibiotic residues is enormous. Nonetheless, it should be taken into account that the research topic is new (this review primarily 
includes papers from the last several years); therefore, it is necessary to conduct research designed to fill the research gaps and to expand the existing knowledge on the subject, which will promote the practical applications of these materials. The most important challenges include the following:

- Study of antibiotic binding mechanisms depending on the antibiotic-adsorbent system used, considering adsorption process conditions and the properties of the $\mathrm{BC}$, as dependent on its production conditions (temperature, gas, feedstock);

- Synthesis of functionalized BC materials characterized by the highest possible ability to remove antibiotics and/or "matched" to a particular type of antibiotic/drug;

- Study on biologically aged BCs and biologically modified BCs in consider antibiotic and other environmental pollutants removal;

- Monitoring of the consumption of specific groups of antibiotics and their associated environmental contamination, which will help to focus research on the most frequently found and/or hazardous drugs;

- Economic analysis of the use of $\mathrm{BC}$ materials, taking into account their production/modification costs and regeneration ability;

- Estimation of environmental costs (carbon foot print, secondary pollution potential) resulting from the production of $\mathrm{BC}$ materials using harmful chemical compounds (BC composites and materials subjected to chemical modification);

- Ecotoxicological analysis of BC materials before their application, including an assessment of their introduction into the environment, which poses a potential environmental risk; 
- Taking account of matrix effects, particularly in complex environmental matrices that are frequently contaminated with antibiotics, e.g., river water, liquid manure, and municipal wastewater;

- For BC production, the use of wastes (sewage sludge, agricultural and food wastes, biogas digestate, etc.) that may be characterized by high contaminant binding potential, and whose management will allow for their recycling;

- Management of spent biochar-based adsorbents coupling with seeking the new environment-friendly way of utilization and reuse exhausted adsorbents.

\subsubsection{MANAGEMENT OF SPENT BIOCHAR-BASED ADSORBENTS}

As with any adsorbent, spent biochar-based adsorbents provide a challenge, which needs proper management. Depending on the cost of material, type of pollutants, spent (exhausted) adsorbents are usually regenerated or became waste disposed of landfills and/or incinerated [204,205]. As a result of adsorption, the contaminants are immobilized by the adsorbent, but the process is usually reversible, especially in the case of physic-sorption. Hence, the disposal of adsorbents with adsorbed pollutants in landfills carries the risk of environmental contamination of soil, surface water, and groundwater and also generates additional cost [204]. The incineration of exhausted adsorbents leads to the release toxic gases, generates ash possibly with hazardous constituents and also requires money [206]. Recovery and regeneration of the adsorbent can reduce the cost and the amount of deposited waste. The thermal regeneration, microwave irradiation regeneration, chemical regeneration with a solvent (organic or inorganic) or supercritical fluid regeneration are the methods usually used in biochar regeneration[207]. However, in non-thermal methods, taking place in the solution, the adsorbate can desorb without decomposing, so there is a further problem of its removal [205]. Hence, the new approach to the regeneration of biochar is based on catalytic oxidation (e.g. Fenton reaction) 
leading to the degradation of the adsorbate [208]. The effectiveness of all of these methods depends on many factors of which the most important are the type of adsorbent and interactions between adsorbent and adsorbate (e.g. for chemisorption some regeneration processes are not efficient) [204,209]. The regeneration by high temperature and chemicals impact the biochar properties and change the structure and porosity of adsorbent, including the destruction of functional groups, etc. This can lead to change sorption capacity and/or catalytic functionality of adsorbent and in the consequence loss of their usefulness [201]. This is especially essential for engineered $\mathrm{BCs}$ regeneration, which are mostly characterized by the presence of functional groups or some additives like catalytic compounds in composites. Therefore, it is important to have a case-by-case approach depending on the type of biochar-adsorbate system tested. An interesting alternative of exhausted biochar utilization is the reuse of adsorbents with a bound adsorbate in other various areas of life. Biochar-based adsorbents used for the removal of phosphate ions can be used as a soil fertilizer [187,210]. Biochar with adsorbed trace metals, which are also microelements, can be used as feed additives or catalysts [204]. Research shows that BCs can be used in energy, e.g. as a solid fuel [211,212] or as an additive in the production of biogas [213,214], hence the use of spent BCs-based adsorbent for this purposes seems to be possible. However, there are no relevant data about this topic, which should be investigated more deeply in near future.

\subsection{ECONOMIC AND ENVIRONMENTAL BENEFITS OF USE BIOCHAR- BASED ADSORBENTS}

The use of BCs as adsorbents in the sorption of pollutants, as well as in the other life areas, may have a positive economic aspect. As mentioned earlier, BCs can be used as "cheaper replacements" for ACs due to the average lower cost of production $(\$ 350$ - $\$ 1,200$ per ton BCs vs. $\$ 1,100$ - $\$ 1,700$ per ton ACs) [47]. In the case of biochar-based products, their price mostly 
depends on costs of: feedstocks (collection, transport, storage and pre-processing), pyrolysis, storage and transport BCs [215]. For example, in 2013, the average world price of BCs was \$ 2,650 per ton, with the lowest value of $\$ 90$ per ton in the Philippines and the highest in the UK $\$ 8,850$ per ton [216]. From an economic point of view, the cost-effectiveness of BCs production is crucial. Some data reports that the net present value for biochar production in Selangor showed positive results of economic feasibility of biochar, the total revenue from biochar sale was $\$ 8,012$ per year [217]. To reduce the cost of BCs, it is important to improve and use the new production technologies and the selection of cheaper and more suitable feedstocks [217]. Hence the economic advantage is the use of various types of waste including yard waste, livestock, manures etc. as feedstock [216,217]. The use of waste products to produce BCs provides also an environmental benefit. Moreover, it is in line with the current trends of sustainable development and circular economy. In 2015, all United Nations members adopted "The 2030 Agenda for Sustainable Development"[218]. One of the seventeen main goals of the Agenda is to ensure responsible consumption and production through sustainable waste management including their reduction, recycling and reuse [218]. However, it should be considered the possible threats and limitations resulting from the use of these type of feedstocks. Additionally, in the case of engineered BCs, an increase in production costs is possible due to the used modifications and additional components. Regarding other environmental advantages, carbon sequestration is equally essential, resulting in the mitigation of greenhouse gases $\left(\mathrm{CO}_{2}\right.$ and $\mathrm{CH}_{4}$ ) emissions from feedstocks [207,219]. Data shows that storing carbon in BC limits the emission of $0.1-0.3$ billion tons of $\mathrm{CO}_{2}$ per year [220], which economically may result in a reduction of cost for $\mathrm{CO}_{2}$ offset [221]. However the Kyoto Protocol under the United Nations Framework on Climate Change (UNFCCC) is not eligible biochar soil addition for carbon sequestration purpose [221]. Finally, with no doubt the use of biochar-based adsorbents to remove water contaminants in water treatment affects a positive effect on the environment. It 
is essential to ensure the safety and reproducibility of the adsorbent application. Hence, commonly used for water treatment ACs must meet specific standards depending on the application, such as European EN 12915-1:2009 (Products used for the treatment of water intended for human consumption) or EN 15799:2010 (Products used for the treatment of swimming pool water) [222]. Due to the novelty approach of the application of biochar-based adsorbents for water treatment, to date, there are no regulations regarding their commercial use. For the most common and promising use of BCs, i.e. as fertilizer and soil additives, standards and guidelines for the production and properties of BCs and recommended analytical methods have been developed and issued by the International Biochar Initiative's, European Biochar Certificate (Europe), The Biochar Quality Mandate (United Kingdom)[223]. Although the guidelines of the European Union regarding the application of BCs in agriculture (soil) are not clear and do not explicitly prohibit the use of BCs, some countries such as Switzerland, Italy, Austria or Germany under their own legislation allow the application of BCs to soil [223]. Nevertheless, research and projects of the European Union like the REFERTIL (Reducing mineral fertilizers and chemicals use in agriculture by recycling treated organic waste as compost and bio-char products) project provide policy support for the European Commission (DG Industry \& Enterprise) in the novelization of the Fertilizer Regulation (Reg. EC No 2003/2003), and the possible application of biochar as organic fertilizer and soil additive [224]. Expanding the knowledge about BCs, give new possibilities of its application and increase its economic importance. What can ultimately influencing the policy regarding its local or even global use. On the other hand, legislation and politics can both stimulate or inhibit the development of research in the field it covers. 


\section{CONCLUSIONS}

Natural environment contamination with antibiotics creates many potential threats to the health and life of organisms. Global consumption of such drugs increases year on year, which only aggravates the problem and increases the scale of contamination. Therefore, the best possible methods and/or materials designed to eliminate antibiotic residues from the environment are sought. Results demonstrate that BC-based adsorbents, i.e., pristine BCs produced under different conditions, physically and chemically modified BCs, and BC composites, can be effective in removing antibiotics. Their mode of action can be based on adsorption or the combination of adsorption with catalytic oxidation, leading to degradation of the antibiotics. The type and efficiency of a specific process depends on many factors, predominantly on the composition and physicochemical properties of the adsorbent and antibiotic, as well as on the application conditions. All of these factors determine the mechanisms involved in the adsorption process. In the case of adsorbates/antibiotics with an aromatic structure and in the presence of functional groups having the nature of electron donors-acceptors, $\pi-\pi$ EDA interactions with the BC surface and hydrophobic interactions are predominant. The presence of functional groups capable of dissociation promotes the formation of electrostatic interactions dependent on environment $\mathrm{pH}$, whereas groups containing hydrogen atoms and/or electronegative atoms having free electron pairs participate in hydrogen bonding. The manner in which an antibiotic becomes bound to the surface of a BC adsorbent depends on the presence of functional groups, $\mathrm{pH}_{\mathrm{pzc}}$, and the degree of graphitization of the $\mathrm{BC}$. Additionally, an adsorbate can be bound/trapped as a result of pore filling in the $\mathrm{BC} /$ composite or complexation with metals present in the composite, ash, or non-carbonized residues. Despite the fact that the adsorption of a particular antibiotic is specific for a given $\mathrm{BC}$ material, there are common relationships and mechanisms involved in this process, as demonstrated in this review. Therefore, it is of key importance to conduct further research aimed at identifying the 
binding mechanisms for various antibiotics. On the basis of such knowledge, it will be possible to "match" as best as possible an adsorbent with an antibiotic, and to create so-called "tailored" materials with enhanced performance. Furthermore, most of the adsorption studies were restricted to lab only. Results are not available if these materials will be successful in presence of many ions. Life cycle assessment is also recommended. Thus, research designed to optimize adsorption conditions, complemented using environmental samples as well as economic and ecotoxicological analysis, is particularly important in this area. Performance demonstrations of $\mathrm{BC}$ materials in removing antibiotic contaminants under real world contamination conditions are also a need of the hour.

\section{Competing interests}

The authors declare no competing interests.

\section{Acknowledgments}

This work was supported by National Science Centre (Poland) in the frame of SHENG 1 grant (UMO-2018/30/Q/ST10/00060).

\section{References:}

[1] K. Gould, Antibiotics: from prehistory to the present day, J. Antimicrob. Chemother. 71 (2016) 572-575. https://doi.org/10.1093/jac/dkv484.

[2] R.I. Aminov, A brief history of the antibiotic era: lessons learned and challenges for the future, Front. Microbiol. 1 (2010). https://doi.org/10.3389/fmicb.2010.00134.

[3] Guillaume André Durand, D. Raoult, G. Dubourg, Antibiotic discovery: history, methods and perspectives, Int. J. Antimicrob. Agents. 53 (2019) 371-382. https://doi.org/10.1016/j.ijantimicag.2018.11.010.

[4] L.E. Robles Jimenez, J.C. Angeles Hernandez, J. Osorio Avalos, X. Li, E.R. Atwill, O. Castelan Ortega, M. Gonzalez Ronquillo, Veterinary antibiotics in animal diet: effects on waste/environmet, in: J.-M. Mérillon, K.G. Ramawat (Eds.), Bioact. Mol. Food, Springer International Publishing, Cham, 2019: pp. 1775-1792. http://link.springer.com/10.1007/9783-319-78030-6_41 (accessed August 13, 2019). 
[5] H. Gelband, M. Miller-Petrie, S. Pant, S. Gandra, J. Levinson, D. Barter, A. White, R. Laxminarayan, N. Ganguly, S. Kariuki, L. Ndegwa, E. Wesangula, B. Sigauque, E. Sevene, B. Basnynat, P. Pokharel, S. Dixit, S. Giri, A. Duse, N. Do, The state of the world's antibiotics 2015, Wound Heal. South. Afr. 8 (2015).

[6] V.O. Stockwell, B. Duffy, Use of antibiotics in plant agriculture, Rev. Sci. Tech. OIE. 31 (2012) 199-210. https://doi.org/10.20506/rst.31.1.2104.

[7] J. O'Neill, The review on antimicrobial resistance (2015). antimicrobials in agriculture and the environment: reducing unnecessary use and waste, 2015. http://amrreview.org/sites/default/files/Antimicrobials\%20in\%20agriculture\%20and\%20the\%20environ ment\%20-\%20Reducing\%20unnecessary\%20use\%20and\%20waste.pdf.

[8] X. Hu, Q. Zhou, Y. Luo, Occurrence and source analysis of typical veterinary antibiotics in manure, soil, vegetables and groundwater from organic vegetable bases, northern China, Environ. Pollut. 158 (2010) 2992-2998. https://doi.org/10.1016/j.envpol.2010.05.023.

[9] D.J. Lapworth, N. Baran, M.E. Stuart, R.S. Ward, Emerging organic contaminants in groundwater: A review of sources, fate and occurrence, Environ. Pollut. 163 (2012) 287-303. https://doi.org/10.1016/j.envpol.2011.12.034.

[10] E. Archer, B. Petrie, B. Kasprzyk-Hordern, G.M. Wolfaardt, The fate of pharmaceuticals and personal care products (PPCPs), endocrine disrupting contaminants (EDCs), metabolites and illicit drugs in a WWTW and environmental waters, Chemosphere. 174 (2017) 437-446. https://doi.org/10.1016/j.chemosphere.2017.01.101.

[11] S. Sauvé, M. Desrosiers, A review of what is an emerging contaminant, Chem. Cent. J. 8 (2014). https://doi.org/10.1186/1752-153X-8-15.

[12] T. Heberer, Occurrence, fate, and removal of pharmaceutical residues in the aquatic environment: a review of recent research data, Toxicol. Lett. 131 (2002) 5-17. https://doi.org/10.1016/S0378-4274(02)00041-3.

[13] M. Patel, R. Kumar, K. Kishor, T. Mlsna, C.U. Pittman, D. Mohan, Pharmaceuticals of emerging concern in aquatic systems: chemistry, occurrence, effects, and removal methods, Chem. Rev. 119 (2019) 3510-3673. https://doi.org/10.1021/acs.chemrev.8b00299.

[14] S.L. Kuchta, A.J. Cessna, Lincomycin and spectinomycin concentrations in liquid swine manure and their persistence during simulated manure storage, Arch. Environ. Contam. Toxicol. 57 (2009) 1-10. https://doi.org/10.1007/s00244-008-9229-z.

[15] P. Grenni, V. Ancona, A. Barra Caracciolo, Ecological effects of antibiotics on natural ecosystems: A review, Microchem. J. 136 (2018) 25-39. https://doi.org/10.1016/j.microc.2017.02.006.

[16] Q.-Q. Zhang, G.-G. Ying, C.-G. Pan, Y.-S. Liu, J.-L. Zhao, Comprehensive evaluation of antibiotics emission and fate in the river basins of China: source analysis, multimedia modeling, and linkage to bacterial resistance, Environ. Sci. Technol. 49 (2015) 6772-6782. https://doi.org/10.1021/acs.est.5b00729.

[17] E. Martínez-Carballo, C. González-Barreiro, S. Scharf, O. Gans, Environmental monitoring study of selected veterinary antibiotics in animal manure and soils in Austria, Environ. Pollut. 148 (2007) 570-579. https://doi.org/10.1016/j.envpol.2006.11.035.

[18] M. Pan, C.K.C. Wong, L.M. Chu, Distribution of antibiotics in wastewater-irrigated soils and their accumulation in vegetable crops in the Pearl River delta, Southern China, J. Agric. Food Chem. 62 (2014) 11062-11069. https://doi.org/10.1021/jf503850v.

[19] M. Pan, L.M. Chu, Transfer of antibiotics from wastewater or animal manure to soil and edible crops, Environ. Pollut. 231 (2017) 829-836. https://doi.org/10.1016/j.envpol.2017.08.051.

[20] M.R. Boleda, É. Alechaga, E. Moyano, M.T. Galceran, F. Ventura, Survey of the occurrence of pharmaceuticals in Spanish finished drinking waters, Environ. Sci. Pollut. Res. 21 (2014) 10917-10939. https://doi.org/10.1007/s11356-014-2885-9.

[21] H. Wang, N. Wang, B. Wang, Q. Zhao, H. Fang, C. Fu, C. Tang, F. Jiang, Y. Zhou, Y. Chen, Q. Jiang, Antibiotics in drinking water in shanghai and their contribution to antibiotic exposure of 
school children, Environ. Sci. Technol. 50 (2016) 2692-2699.

https://doi.org/10.1021/acs.est.5b05749.

[22] H. Wang, L. Ren, X. Yu, J. Hu, Y. Chen, G. He, Q. Jiang, Antibiotic residues in meat, milk and aquatic products in Shanghai and human exposure assessment, Food Control. 80 (2017) 217225. https://doi.org/10.1016/j.foodcont.2017.04.034.

[23] T. Yamaguchi, M. Okihashi, K. Harada, Y. Konishi, K. Uchida, M.H.N. Do, H.D.T. Bui, T.D. Nguyen, P.D. Nguyen, V.V. Chau, K.T.V. Dao, H.T.N. Nguyen, K. Kajimura, Y. Kumeda, C.T. Bui, M.Q. Vien, N.H. Le, K. Hirata, Y. Yamamoto, Antibiotic residue monitoring results for pork, chicken, and beef samples in Vietnam in 2012-2013, J. Agric. Food Chem. 63 (2015) 51415145. https://doi.org/10.1021/jf505254y.

[24] Y. Ben, C. Fu, M. Hu, L. Liu, M.H. Wong, C. Zheng, Human health risk assessment of antibiotic resistance associated with antibiotic residues in the environment: A review, Environ. Res. 169 (2019) 483-493. https://doi.org/10.1016/j.envres.2018.11.040.

[25] H.M.A. Asghar, S.N. Hussain, N.W. Brown, E.P.L. Roberts, Comparative adsorptionregeneration performance for newly developed carbonaceous adsorbent, J. Ind. Eng. Chem. 69 (2019) 90-98. https://doi.org/10.1016/j.jiec.2018.09.012.

[26] V. Homem, L. Santos, Degradation and removal methods of antibiotics from aqueous matrices - A review, J. Environ. Manage. 92 (2011) 2304-2347. https://doi.org/10.1016/j.jenvman.2011.05.023.

[27] F.R.P. Sales, R.B.G. Serra, G.J.A. de Figueirêdo, P.H.A. da Hora, A.C. de Sousa, Wastewater treatment using adsorption process in column for agricultural purposes, Ambiente E Agua Interdiscip. J. Appl. Sci. 14 (2019) 1. https://doi.org/10.4136/ambi-agua.2178.

[28] I. Ali, The quest for active carbon adsorbent substitutes: inexpensive sdsorbents for toxic metal ions removal from wastewater, Sep. Purif. Rev. 39 (2010) 95-171. https://doi.org/10.1080/15422119.2010.527802.

[29] D. Zhang, B. Pan, M. Wu, B. Wang, H. Zhang, H. Peng, D. Wu, P. Ning, Adsorption of sulfamethoxazole on functionalized carbon nanotubes as affected by cations and anions, Environ. Pollut. 159 (2011) 2616-2621. https://doi.org/10.1016/j.envpol.2011.05.036.

[30] D. Zhang, B. Pan, H. Zhang, P. Ning, B. Xing, Contribution of different sulfamethoxazole species to their overall adsorption on functionalized carbon nanotubes, Environ. Sci. Technol. 44 (2010) 3806-3811. https://doi.org/10.1021/es903851q.

[31] M. Nageeb, Adsorption technique for the removal of organic pollutants from water and wastewater, in: M.N. Rashed (Ed.), Org. Pollut. - Monit. Risk Treat., InTech, 2013. http://www.intechopen.com/books/organic-pollutants-monitoring-risk-andtreatment/adsorption-technique-for-the-removal-of-organic-pollutants-from-water-andwastewater (accessed August 23, 2019).

[32] M.B. Ahmed, J.L. Zhou, H.H. Ngo, W. Guo, Adsorptive removal of antibiotics from water and wastewater: Progress and challenges, Sci. Total Environ. 532 (2015) 112-126. https://doi.org/10.1016/j.scitotenv.2015.05.130.

[33] A.M. Aljeboree, A.N. Alshirif, Adsorption of pharmaceuticals as emerging contaminants from aqueous solutions on to friendly surfaces such as activated carbon: A review, J. Pharm. Sci. Res. 10 (2018) 2252-2257.

[34] G.Z. Kyzas, J. Fu, N.K. Lazaridis, D.N. Bikiaris, K.A. Matis, New approaches on the removal of pharmaceuticals from wastewaters with adsorbent materials, J. Mol. Liq. 209 (2015) 87-93. https://doi.org/10.1016/j.molliq.2015.05.025.

[35] V.K. Gupta, P.J.M. Carrott, M.M.L. Ribeiro Carrott, Suhas, Low-cost adsorbents: growing approach to wastewater treatment-a review, Crit. Rev. Environ. Sci. Technol. 39 (2009) $783-$ 842. https://doi.org/10.1080/10643380801977610.

[36] A. Gil, N. Taoufik, A.M. García, S.A. Korili, Comparative removal of emerging contaminants from aqueous solution by adsorption on an activated carbon, Environ. Technol. 40 (2019) 3017-3030. https://doi.org/10.1080/09593330.2018.1464066. 
[37] Z. Jeirani, C.H. Niu, J. Soltan, Adsorption of emerging pollutants on activated carbon, Rev. Chem. Eng. 33 (2017). https://doi.org/10.1515/revce-2016-0027.

[38] D. Mohan, K.P. Singh, Competitive Adsorption of Several Organics and Heavy Metals on Activated Carbon in Water, in: J.H. Lehr, J. Keeley (Eds.), Water Encycl., John Wiley \& Sons, Inc., Hoboken, NJ, USA, 2005: p. mw26. http://doi.wiley.com/10.1002/047147844X.mw26 (accessed April 20, 2020).

[39] M. Sulyman, J. Namiesnik, A. Gierak, Low-cost adsorbents derived from agricultural byproducts/wastes for enhancing contaminant uptakes from wastewater: a review, Pol. J. Environ. Stud. 26 (2017) 479-510. https://doi.org/10.15244/pjoes/66769.

[40] M.I. Inyang, B. Gao, Y. Yao, Y. Xue, A. Zimmerman, A. Mosa, P. Pullammanappallil, Y.S. Ok, X. Cao, A review of biochar as a low-cost adsorbent for aqueous heavy metal removal, Crit. Rev. Environ. Sci. Technol. 46 (2016) 406-433. https://doi.org/10.1080/10643389.2015.1096880.

[41] D. Mohan, A. Sarswat, Y.S. Ok, C.U. Pittman, Organic and inorganic contaminants removal from water with biochar, a renewable, low cost and sustainable adsorbent - A critical review, Bioresour. Technol. 160 (2014) 191-202. https://doi.org/10.1016/j.biortech.2014.01.120.

[42] A. Tytłak, P. Oleszczuk, R. Dobrowolski, Sorption and desorption of $\mathrm{Cr}(\mathrm{VI})$ ions from water by biochars in different environmental conditions, Environ. Sci. Pollut. Res. 22 (2015) 5985-5994. https://doi.org/10.1007/s11356-014-3752-4.

[43] F.L. Braghiroli, H. Bouafif, C.M. Neculita, A. Koubaa, Activated biochar as an effective sorbent for organic and inorganic contaminants in water, Water. Air. Soil Pollut. 229 (2018). https://doi.org/10.1007/s11270-018-3889-8.

[44] J. Lehmann, S. Joseph, Biochar for environmental management: science and technology, London: Earthscan, 2009.

[45] F.R. Oliveira, A.K. Patel, D.P. Jaisi, S. Adhikari, H. Lu, S.K. Khanal, Environmental application of biochar: current status and perspectives, Bioresour. Technol. 246 (2017) 110-122. https://doi.org/10.1016/j.biortech.2017.08.122.

[46] J. Zhao, X.-J. Shen, X. Domene, J.-M. Alcañiz, X. Liao, C. Palet, Comparison of biochars derived from different types of feedstock and their potential for heavy metal removal in multiplemetal solutions, Sci. Rep. 9 (2019). https://doi.org/10.1038/s41598-019-46234-4.

[47] K.A. Thompson, K.K. Shimabuku, J.P. Kearns, D.R.U. Knappe, R.S. Summers, S.M. Cook, Environmental comparison of biochar and activated carbon for tertiary wastewater treatment, Environ. Sci. Technol. 50 (2016) 11253-11262. https://doi.org/10.1021/acs.est.6b03239.

[48] D. Wei, B. Li, H. Huang, L. Luo, J. Zhang, Y. Yang, J. Guo, L. Tang, G. Zeng, Y. Zhou, Biocharbased functional materials in the purification of agricultural wastewater: Fabrication, application and future research needs, Chemosphere. 197 (2018) 165-180. https://doi.org/10.1016/j.chemosphere.2017.12.193.

[49] A.U. Rajapaksha, S.S. Chen, D.C.W. Tsang, M. Zhang, M. Vithanage, S. Mandal, B. Gao, N.S. Bolan, Y.S. Ok, Engineered/designer biochar for contaminant removal/immobilization from soil and water: potential and implication of biochar modification, Chemosphere. 148 (2016) 276-291. https://doi.org/10.1016/j.chemosphere.2016.01.043.

[50] T. Sizmur, T. Fresno, G. Akgül, H. Frost, E. Moreno-Jiménez, Biochar modification to enhance sorption of inorganics from water, Bioresour. Technol. 246 (2017) 34-47. https://doi.org/10.1016/j.biortech.2017.07.082.

[51] A.D. Igalavithana, S. Mandal, N.K. Niazi, M. Vithanage, S.J. Parikh, F.N.D. Mukome, M. Rizwan, P. Oleszczuk, M. Al-Wabel, N. Bolan, D.C.W. Tsang, K.-H. Kim, Y.S. Ok, Advances and future directions of biochar characterization methods and applications, Crit. Rev. Environ. Sci. Technol. 47 (2017) 2275-2330. https://doi.org/10.1080/10643389.2017.1421844.

[52] C. Peiris, S.R. Gunatilake, T.E. Mlsna, D. Mohan, M. Vithanage, Biochar based removal of antibiotic sulfonamides and tetracyclines in aquatic environments: a critical review, Bioresour. Technol. 246 (2017) 150-159. https://doi.org/10.1016/j.biortech.2017.07.150. 
[53] H. M. Aly, Biochar and its importance in adsorption of antibiotic and heavy metals from aqueous solutions, Ecol. Quest. 24 (2017) 75. https://doi.org/10.12775/EQ.2016.014.

[54] H. Zheng, Z. Wang, J. Zhao, S. Herbert, B. Xing, Sorption of antibiotic sulfamethoxazole varies with biochars produced at different temperatures, Environ. Pollut. 181 (2013) 60-67. https://doi.org/10.1016/j.envpol.2013.05.056.

[55] A. Ashiq, B. Sarkar, N. Adassooriya, J. Walpita, A.U. Rajapaksha, Y.S. Ok, M. Vithanage, Sorption process of municipal solid waste biochar-montmorillonite composite for ciprofloxacin removal in aqueous media, Chemosphere. 236 (2019) 124384. https://doi.org/10.1016/j.chemosphere.2019.124384.

[56] J. Clardy, M.A. Fischbach, C.R. Currie, The natural history of antibiotics, Curr. Biol. 19 (2009) R437-R441. https://doi.org/10.1016/j.cub.2009.04.001.

[57] E. Etebu, A. Ibemologi, Antibiotics: Classification and mechanisms of action with emphasis on molecular perspectives, Int. J. Appl. Microbiol. Biotechnol. Res. 4 (2016) 90-101.

[58] F. Khan, Antibiotics classification and visual target sites for bacterial inhibition, Adv. Pharmacol. Clin. Trials. 3 (2018). https://doi.org/10.23880/APCT-16000137.

[59] C. Walsh, Molecular mechanisms that confer antibacterial drug resistance, Nature. 406 (2000) 775-781. https://doi.org/10.1038/35021219.

[60] The nitroimidazole family of drugs., Br. J. Vener. Dis. 54 (1978) 69-71.

[61] J.B. Sauberan, J.S. Bradley, Antimicrobial agents, in: Princ. Pract. Pediatr. Infect. Dis., Elsevier, 2018: pp. 1499-1531.e3. https://linkinghub.elsevier.com/retrieve/pii/B9780323401814002929 (accessed August 27, 2019).

[62] S. Hanessian, ed., Natural products in medicinal chemistry, Wiley-VCH Verlag GmbH \& Co. KGaA, Weinheim, Germany, 2014. http://doi.wiley.com/10.1002/9783527676545 (accessed August 27, 2019).

[63] J. Bérdy, Thoughts and facts about antibiotics: where we are now and where we are heading, J. Antibiot. (Tokyo). 65 (2012) 385-395. https://doi.org/10.1038/ja.2012.27.

[64] Critically important antimicrobials for human medicine 6th. Revision 2018. Ranking of medically important antimicrobials for risk management of antimicrobial resistance due to non-human use., World Health Organization, 2019.

[65] T.P. Van Boeckel, S. Gandra, A. Ashok, Q. Caudron, B.T. Grenfell, S.A. Levin, R. Laxminarayan, Global antibiotic consumption 2000 to 2010: an analysis of national pharmaceutical sales data, Lancet Infect. Dis. 14 (2014) 742-750. https://doi.org/10.1016/S1473-3099(14)70780-7.

[66] E.Y. Klein, T.P. Van Boeckel, E.M. Martinez, S. Pant, S. Gandra, S.A. Levin, H. Goossens, R. Laxminarayan, Global increase and geographic convergence in antibiotic consumption between 2000 and 2015, Proc. Natl. Acad. Sci. 115 (2018) E3463-E3470. https://doi.org/10.1073/pnas.1717295115.

[67] H. Hao, G. Cheng, Z. Iqbal, X. Ai, H.I. Hussain, L. Huang, M. Dai, Y. Wang, Z. Liu, Z. Yuan, Benefits and risks of antimicrobial use in food-producing animals, Front. Microbiol. 5 (2014). https://doi.org/10.3389/fmicb.2014.00288.

[68] J.I.R. Castanon, History of the use of antibiotic as growth promoters in european poultry feeds, Poult. Sci. 86 (2007) 2466-2471. https://doi.org/10.3382/ps.2007-00249.

[69] C. Kirchhelle, Pharming animals: a global history of antibiotics in food production (19352017), Palgrave Commun. 4 (2018). https://doi.org/10.1057/s41599-018-0152-2.

[70] T.P. Van Boeckel, C. Brower, M. Gilbert, B.T. Grenfell, S.A. Levin, T.P. Robinson, A. Teillant, R. Laxminarayan, Global trends in antimicrobial use in food animals, Proc. Natl. Acad. Sci. 112 (2015) 5649-5654. https://doi.org/10.1073/pnas.1503141112.

[71] OIE. OIE Annual report on antimicrobial agents intended for use in animals (Third Report). (2018)., (n.d.). https://www.oie.int/fileadmin/Home/eng/Our_scientific_expertise/docs/pdf/AMR/Annual_R eport_AMR_3.pdf (accessed November 29, 2019). 
[72] R. Lulijwa, E.J. Rupia, A.C. Alfaro, Antibiotic use in aquaculture, policies and regulation, health and environmental risks: a review of the top 15 major producers, Rev. Aquac. (2019). https://doi.org/10.1111/raq.12344.

[73] X. Liu, J.C. Steele, X.-Z. Meng, Usage, residue, and human health risk of antibiotics in Chinese aquaculture: A review, Environ. Pollut. 223 (2017) 161-169. https://doi.org/10.1016/j.envpol.2017.01.003.

[74] Spraying diseased citrus orchards with antibiotics could backfire, Nature. 567 (2019) 283-283. https://doi.org/10.1038/d41586-019-00875-7.

[75] B. Kasprzyk-Hordern, Initiatives for addressing antimicrobial resistance in the environment: current situation and challenges: white paper. Wellcome Trust, 2018. https://wellcome.ac.uk/sites/default/files/ antimicrobial-resistance-environment -report.pdf.

[76] K.A. Tancos, K.D. Cox, Effects of consecutive streptomycin and kasugamycin applications on epiphytic bacteria in the apple phyllosphere, Plant Dis. 101 (2017) 158-164. https://doi.org/10.1094/PDIS-06-16-0794-RE.

[77] M. Zhang, L.-Y. He, Y.-S. Liu, J.-L. Zhao, W.-R. Liu, J.-N. Zhang, J. Chen, L.-K. He, Q.-Q. Zhang, G.G. Ying, Fate of veterinary antibiotics during animal manure composting, Sci. Total Environ. 650 (2019) 1363-1370. https://doi.org/10.1016/j.scitotenv.2018.09.147.

[78] S.I. Kwon, G. Owens, Y.S. Ok, D.B. Lee, W.-T. Jeon, J.G. Kim, K.-R. Kim, Applicability of the Charm II system for monitoring antibiotic residues in manure-based composts, Waste Manag. 31 (2011) 39-44. https://doi.org/10.1016/j.wasman.2010.08.018.

[79] M.G. Pikkemaat, H.J. Fels-Klerkx, B.J.A. Berendsen, H. Yassin, Antibiotic residues and resistance in the environment, RIKILT Wageningen UR, Wageningen, 2016. http://library.wur.nl/WebQuery/wurpubs/510717 (accessed September 5, 2019).

[80] K.-R. Kim, G. Owens, S.-I. Kwon, K.-H. So, D.-B. Lee, Y.S. Ok, Occurrence and environmental fate of veterinary antibiotics in the terrestrial environment, Water. Air. Soil Pollut. 214 (2011) 163-174. https://doi.org/10.1007/s11270-010-0412-2.

[81] R. Gothwal, T. Shashidhar, Antibiotic pollution in the environment: a review: antibiotic pollution in the environment, CLEAN - Soil Air Water. 43 (2015) 479-489. https://doi.org/10.1002/clen.201300989.

[82] W.C. Li, Occurrence, sources, and fate of pharmaceuticals in aquatic environment and soil, Environ. Pollut. 187 (2014) 193-201. https://doi.org/10.1016/j.envpol.2014.01.015.

[83] X.-W. Li, Y.-F. Xie, C.-L. Li, H.-N. Zhao, H. Zhao, N. Wang, J.-F. Wang, Investigation of residual fluoroquinolones in a soil-vegetable system in an intensive vegetable cultivation area in Northern China, Sci. Total Environ. 468-469 (2014) 258-264. https://doi.org/10.1016/j.scitotenv.2013.08.057.

[84] M.B.M. Ahmed, A.U. Rajapaksha, J.E. Lim, N.T. Vu, I.S. Kim, H.M. Kang, S.S. Lee, Y.S. Ok, Distribution and accumulative pattern of tetracyclines and sulfonamides in edible vegetables of cucumber, tomato, and lettuce, J. Agric. Food Chem. 63 (2015) 398-405. https://doi.org/10.1021/jf5034637.

[85] Y. Tao, G. Yu, D. Chen, Y. Pan, Z. Liu, H. Wei, D. Peng, L. Huang, Y. Wang, Z. Yuan, Determination of 17 macrolide antibiotics and avermectins residues in meat with accelerated solvent extraction by liquid chromatography-tandem mass spectrometry, J. Chromatogr. B. 897 (2012) 64-71. https://doi.org/10.1016/j.jchromb.2012.04.011.

[86] X. He, M. Deng, Q. Wang, Y. Yang, Y. Yang, X. Nie, Residues and health risk assessment of quinolones and sulfonamides in cultured fish from Pearl River Delta, China, Aquaculture. 458 (2016) 38-46. https://doi.org/10.1016/j.aquaculture.2016.02.006.

[87] L.M. Chiesa, M. Nobile, R. Malandra, S. Panseri, F. Arioli, Occurrence of antibiotics in mussels and clams from various FAO areas, Food Chem. 240 (2018) 16-23. https://doi.org/10.1016/j.foodchem.2017.07.072.

[88] N. Zheng, J. Wang, R. Han, X. Xu, Y. Zhen, X. Qu, P. Sun, S. Li, Z. Yu, Occurrence of several main antibiotic residues in raw milk in 10 provinces of China, Food Addit. Contam. Part B. 6 (2013) 84-89. https://doi.org/10.1080/19393210.2012.727189. 
[89] T. Yamaguchi, M. Okihashi, K. Harada, Y. Konishi, K. Uchida, M. Hoang Ngoc Do, L. Thi Bui, T.D. Nguyen, H.B. Phan, H. Dang Thien Bui, P.D. Nguyen, K. Kajimura, Y. Kumeda, C. Van Dang, K. Hirata, Y. Yamamoto, Detection of antibiotics in chicken eggs obtained from supermarkets in Ho Chi Minh City, Vietnam, J. Environ. Sci. Health Part B. 52 (2017) 430-433. https://doi.org/10.1080/03601234.2017.1293457.

[90] R. Collier, Swallowing the pharmaceutical waters, Can. Med. Assoc. J. 184 (2012) 163-164. https://doi.org/10.1503/cmaj.109-4086.

[91] Y.S. Ok, S.-C. Kim, K.-R. Kim, S.S. Lee, D.H. Moon, K.J. Lim, J.-K. Sung, S.-O. Hur, J.E. Yang, Monitoring of selected veterinary antibiotics in environmental compartments near a composting facility in Gangwon Province, Korea, Environ. Monit. Assess. 174 (2011) 693-701. https://doi.org/10.1007/s10661-010-1625-y.

[92] Y.M. Awad, S.-C. Kim, S.A.M. Abd El-Azeem, K.-H. Kim, K.-R. Kim, K. Kim, C. Jeon, S.S. Lee, Y.S. Ok, Veterinary antibiotics contamination in water, sediment, and soil near a swine manure composting facility, Environ. Earth Sci. 71 (2014) 1433-1440. https://doi.org/10.1007/s12665013-2548-z.

[93] K. Kumar, S. C. Gupta, Y. Chander, A.K. Singh, Antibiotic use in agriculture and its impact on the terrestrial environment, in: Adv. Agron., Elsevier, 2005: pp. 1-54. https://linkinghub.elsevier.com/retrieve/pii/S0065211305870014 (accessed September 12, 2019).

[94] K. Kummerer, Significance of antibiotics in the environment, J. Antimicrob. Chemother. 52 (2003) 5-7. https://doi.org/10.1093/jac/dkg293.

[95] S. Jechalke, H. Heuer, J. Siemens, W. Amelung, K. Smalla, Fate and effects of veterinary antibiotics in soil, Trends Microbiol. 22 (2014) 536-545. https://doi.org/10.1016/j.tim.2014.05.005.

[96] T. Shistar, C. Curle, Agricultural uses of antibiotics escalate bacterial resistance organic leads in prohibiting antibiotic use, Pestic. You. (2016). https://www.beyondpesticides.org/assets/media/documents/journal/bp-36.4-w17Antibiotics-Cited2.pdf.

[97] A.J. Ebele, M. Abou-Elwafa Abdallah, S. Harrad, Pharmaceuticals and personal care products (PPCPs) in the freshwater aquatic environment, Emerg. Contam. 3 (2017) 1-16. https://doi.org/10.1016/j.emcon.2016.12.004.

[98] P. Wu, S.T. Ata-Ul-Karim, B.P. Singh, H. Wang, T. Wu, C. Liu, G. Fang, D. Zhou, Y. Wang, W. Chen, A scientometric review of biochar research in the past 20 years (1998-2018), Biochar. 1 (2019) 23-43. https://doi.org/10.1007/s42773-019-00002-9.

[99] P. Oleszczuk, I. Jośko, M. Kuśmierz, Biochar properties regarding to contaminants content and ecotoxicological assessment, J. Hazard. Mater. 260 (2013) 375-382. https://doi.org/10.1016/j.jhazmat.2013.05.044.

[100] M. Hussain, M. Farooq, A. Nawaz, A.M. Al-Sadi, Z.M. Solaiman, S.S. Alghamdi, U. Ammara, Y.S. Ok, K.H.M. Siddique, Biochar for crop production: potential benefits and risks, J. Soils Sediments. 17 (2017) 685-716. https://doi.org/10.1007/s11368-016-1360-2.

[101] Y.S. Ok, S.X. Chang, B. Gao, H.-J. Chung, SMART biochar technology-a shifting paradigm towards advanced materials and healthcare research, Environ. Technol. Innov. 4 (2015) 206209. https://doi.org/10.1016/j.eti.2015.08.003.

[102] H. Jin, X. Wang, Z. Gu, J. Polin, Carbon materials from high ash biochar for supercapacitor and improvement of capacitance with HNO3 surface oxidation, J. Power Sources. 236 (2013) 285292. https://doi.org/10.1016/j.jpowsour.2013.02.088.

[103] T. Huggins, H. Wang, J. Kearns, P. Jenkins, Z.J. Ren, Biochar as a sustainable electrode material for electricity production in microbial fuel cells, Bioresour. Technol. 157 (2014) 114-119. https://doi.org/10.1016/j.biortech.2014.01.058.

[104] X. Li, L. Liu, X. Wang, Y.S. Ok, J.A.W. Elliott, S.X. Chang, H.-J. Chung, Flexible and Self-Healing Aqueous Supercapacitors for Low Temperature Applications: Polyampholyte Gel Electrolytes 
with Biochar Electrodes, Sci. Rep. 7 (2017) 1685. https://doi.org/10.1038/s41598-017-018733.

[105] H.-P. Schmidt, N. Hagemann, K. Draper, C. Kammann, The use of biochar in animal feeding, PeerJ. 7 (2019) e7373. https://doi.org/10.7717/peerj.7373.

[106] S. Gupta, H.W. Kua, Factors determining the potential of biochar as a carbon capturing and sequestering construction material: critical review, J. Mater. Civ. Eng. 29 (2017) 04017086. https://doi.org/10.1061/(ASCE)MT.1943-5533.0001924.

[107] G. Crini, E. Lichtfouse, Green adsorbents for pollutant removal: innovative materials, 2018. https://doi.org/10.1007/978-3-319-92162-4 (accessed September 11, 2019).

[108] T.M.E. Shareef, B. Zhao, Review paper: the fundamentals of biochar as a soil amendment tool and management in agriculture scope: an overview for farmers and gardeners, J. Agric. Chem. Environ. 06 (2017) 38-61. https://doi.org/10.4236/jacen.2017.61003.

[109] K.S.D. Premarathna, A.U. Rajapaksha, B. Sarkar, E.E. Kwon, A. Bhatnagar, Y.S. Ok, M. Vithanage, Biochar-based engineered composites for sorptive decontamination of water: a review, Chem. Eng. J. 372 (2019) 536-550. https://doi.org/10.1016/j.cej.2019.04.097.

[110] Y. Tong, P.J. McNamara, B.K. Mayer, Adsorption of organic micropollutants onto biochar: a review of relevant kinetics, mechanisms and equilibrium, Environ. Sci. Water Res. Technol. 5 (2019) 821-838. https://doi.org/10.1039/C8EW00938D.

[111] A. Delle Site, Factors affecting sorption of organic compounds in natural sorbent/water systems and sorption coefficients for selected pollutants. A review, J. Phys. Chem. Ref. Data. 30 (2001) 187-439. https://doi.org/10.1063/1.1347984.

[112] A. Bonilla-Petriciolet, D.I. Mendoza-Castillo, H.E. Reynel-Ávila, eds., Adsorption processes for water treatment and purification, Springer International Publishing, Cham, 2017. http://link.springer.com/10.1007/978-3-319-58136-1 (accessed September 12, 2019).

[113] M. Ahmad, A.U. Rajapaksha, J.E. Lim, M. Zhang, N. Bolan, D. Mohan, M. Vithanage, S.S. Lee, Y.S. Ok, Biochar as a sorbent for contaminant management in soil and water: A review, Chemosphere. 99 (2014) 19-33. https://doi.org/10.1016/j.chemosphere.2013.10.071.

[114] Y. Zhu, B. Yi, Q. Yuan, Y. Wu, M. Wang, S. Yan, Removal of methylene blue from aqueous solution by cattle manure-derived low temperature biochar, RSC Adv. 8 (2018) 19917-19929. https://doi.org/10.1039/C8RA03018A.

[115] M. Inyang, E. Dickenson, The potential role of biochar in the removal of organic and microbial contaminants from potable and reuse water: A review, Chemosphere. 134 (2015) 232-240. https://doi.org/10.1016/j.chemosphere.2015.03.072.

[116] X. Zhang, B. Gao, A.E. Creamer, C. Cao, Y. Li, Adsorption of VOCs onto engineered carbon materials: A review, J. Hazard. Mater. 338 (2017) 102-123. https://doi.org/10.1016/j.jhazmat.2017.05.013.

[117] J.J. Manyà, Pyrolysis for biochar purposes: a review to establish current knowledge gaps and research needs, Environ. Sci. Technol. 46 (2012) 7939-7954. https://doi.org/10.1021/es301029g.

[118] L. Xia, Y. Wang, J. Meng, W. Chen, Z. Zhang, The influencing factors of biochar's characteristics and the development of carbonization equipments: a review, in: F. Bian, Y. Xie (Eds.), GeoInform. Resour. Manag. Sustain. Ecosyst., Springer Berlin Heidelberg, 2016: pp. 760-769.

[119] X. Yang, S. Zhang, M. Ju, L. Liu, Preparation and modification of biochar materials and their application in soil remediation, Appl. Sci. 9 (2019) 1365. https://doi.org/10.3390/app9071365.

[120] M. Kończak, P. Oleszczuk, K. Różyło, Application of different carrying gases and ratio between sewage sludge and willow for engineered (smart) biochar production, J. CO2 Util. 29 (2019) 20-28. https://doi.org/10.1016/j.jcou.2018.10.019.

[121] L. Wang, Y.S. Ok, D.C.W. Tsang, D.S. Alessi, J. Rinklebe, H. Wang, O. Mašek, R. Hou, D. O'Connor, D. Hou, New trends in biochar pyrolysis and modification strategies: feedstock, pyrolysis conditions, sustainability concerns and implications for soil amendment, Soil Use Manag. (2020). https://doi.org/10.1111/sum.12592. 
[122] S. Yavari, A. Malakahmad, N.B. Sapari, S. Yavari, Sorption properties optimization of agricultural wastes-derived biochars using response surface methodology, Process Saf. Environ. Prot. 109 (2017) 509-519. https://doi.org/10.1016/j.psep.2017.05.002.

[123] J. Guo, A. Chong Lua, Characterization of chars pyrolyzed from oil palm stones for the preparation of activated carbons, J. Anal. Appl. Pyrolysis. 46 (1998) 113-125. https://doi.org/10.1016/S0165-2370(98)00074-6.

[124] M. Stefaniuk, P. Oleszczuk, Characterization of biochars produced from residues from biogas production, J. Anal. Appl. Pyrolysis. 115 (2015) 157-165. https://doi.org/10.1016/j.jaap.2015.07.011.

[125] X. He, Z. Liu, W. Niu, L. Yang, T. Zhou, D. Qin, Z. Niu, Q. Yuan, Effects of pyrolysis temperature on the physicochemical properties of gas and biochar obtained from pyrolysis of crop residues, Energy. 143 (2018) 746-756. https://doi.org/10.1016/j.energy.2017.11.062.

[126] K. Wang, N. Peng, G. Lu, Z. Dang, Effects of pyrolysis temperature and holding time on physicochemical properties of swine-manure-derived biochar, Waste Biomass Valorization. (2018). https://doi.org/10.1007/s12649-018-0435-2.

[127] K. Weber, P. Quicker, Properties of biochar, Fuel. 217 (2018) 240-261. https://doi.org/10.1016/j.fuel.2017.12.054.

[128] A. Zielińska, P. Oleszczuk, Evaluation of sewage sludge and slow pyrolyzed sewage sludgederived biochar for adsorption of phenanthrene and pyrene, Bioresour. Technol. 192 (2015) 618-626. https://doi.org/10.1016/j.biortech.2015.06.032.

[129] H. Wang, Y. Chu, C. Fang, F. Huang, Y. Song, X. Xue, Sorption of tetracycline on biochar derived from rice straw under different temperatures, PLOS ONE. 12 (2017) e0182776. https://doi.org/10.1371/journal.pone.0182776.

[130] Y. Dai, J. Li, D. Shan, Adsorption of tetracycline in aqueous solution by biochar derived from waste Auricularia auricula dregs, Chemosphere. 238 (2020) 124432. https://doi.org/10.1016/j.chemosphere.2019.124432.

[131] Z. Zeng, X. Tan, Y. Liu, S. Tian, G. Zeng, L. Jiang, S. Liu, J. Li, N. Liu, Z. Yin, Comprehensive adsorption studies of doxycycline and ciprofloxacin antibiotics by biochars prepared at different temperatures, Front. Chem. 6 (2018). https://doi.org/10.3389/fchem.2018.00080.

[132] T. Chen, L. Luo, S. Deng, G. Shi, S. Zhang, Y. Zhang, O. Deng, L. Wang, J. Zhang, L. Wei, Sorption of tetracycline on $\mathrm{H} 3 \mathrm{PO} 4$ modified biochar derived from rice straw and swine manure, Bioresour. Technol. 267 (2018) 431-437. https://doi.org/10.1016/j.biortech.2018.07.074.

[133] C. Li, X. Zhu, H. He, Y. Fang, H. Dong, J. Lü, J. Li, Y. Li, Adsorption of two antibiotics on biochar prepared in air-containing atmosphere: Influence of biochar porosity and molecular size of antibiotics, J. Mol. Liq. 274 (2019) 353-361. https://doi.org/10.1016/j.molliq.2018.10.142.

[134] H.M. Jang, E. Kan, A novel hay-derived biochar for removal of tetracyclines in water, Bioresour. Technol. 274 (2019) 162-172. https://doi.org/10.1016/j.biortech.2018.11.081.

[135] J.G. Shang, X.R. Kong, L.L. He, W.H. Li, Q.J.H. Liao, Low-cost biochar derived from herbal residue: characterization and application for ciprofloxacin adsorption, Int. J. Environ. Sci. Technol. 13 (2016) 2449-2458. https://doi.org/10.1007/s13762-016-1075-3.

[136] M. Xie, W. Chen, Z. Xu, S. Zheng, D. Zhu, Adsorption of sulfonamides to demineralized pine wood biochars prepared under different thermochemical conditions, Environ. Pollut. 186 (2014) 187-194. https://doi.org/10.1016/j.envpol.2013.11.022.

[137] Y. Lu, M. Jiang, C. Wang, Y. Wang, W. Yang, Impact of molecular size on two antibiotics adsorption by porous resins, J. Taiwan Inst. Chem. Eng. 45 (2014) 955-961. https://doi.org/10.1016/j.jtice.2013.09.009.

[138] A. Enders, K. Hanley, T. Whitman, S. Joseph, J. Lehmann, Characterization of biochars to evaluate recalcitrance and agronomic performance, Bioresour. Technol. 114 (2012) 644-653. https://doi.org/10.1016/j.biortech.2012.03.022.

[139] D. Mohan, C.U. Pittman, P.H. Steele, Pyrolysis of Wood/Biomass for Bio-oil: A Critical Review, Energy Fuels. 20 (2006) 848-889. https://doi.org/10.1021/ef0502397. 
[140] C.-H. Liu, Y.-H. Chuang, H. Li, B.J. Teppen, S.A. Boyd, J.M. Gonzalez, C.T. Johnston, J. Lehmann, W. Zhang, Sorption of lincomycin by manure-derived biochars from water, J. Environ. Qual. 45 (2016) 519. https://doi.org/10.2134/jeq2015.06.0320.

[141] L. Zhang, L. Tong, P. Zhu, P. Huang, Z. Tan, F. Qin, W. Shi, M. Wang, H. Nie, G. Yan, H. Huang, Adsorption of chlortetracycline onto biochar derived from corn cob and sugarcane bagasse, Water Sci. Technol. (2018). https://doi.org/10.2166/wst.2018.407.

[142] B. Wang, B. Gao, J. Fang, Recent advances in engineered biochar productions and applications, Crit. Rev. Environ. Sci. Technol. 47 (2017) 2158-2207. https://doi.org/10.1080/10643389.2017.1418580.

[143] S.Y. Foong, R.K. Liew, Y. Yang, Y.W. Cheng, P.N.Y. Yek, W.A. Wan Mahari, X.Y. Lee, C.S. Han, D.V.N. Vo, Q. Van Le, M. Aghbashlo, M. Tabatabaei, C. Sonne, W. Peng, S.S. Lam, Valorization of biomass waste to engineered activated biochar by microwave pyrolysis: Progress, challenges, and future directions, Chem. Eng. J. 389 (2020) 124401. https://doi.org/10.1016/j.cej.2020.124401.

[144] A.U. Rajapaksha, M. Vithanage, M. Zhang, M. Ahmad, D. Mohan, S.X. Chang, Y.S. Ok, Pyrolysis condition affected sulfamethazine sorption by tea waste biochars, Bioresour. Technol. 166 (2014) 303-308. https://doi.org/10.1016/j.biortech.2014.05.029.

[145] A.U. Rajapaksha, M. Vithanage, M. Ahmad, D.-C. Seo, J.-S. Cho, S.-E. Lee, S.S. Lee, Y.S. Ok, Enhanced sulfamethazine removal by steam-activated invasive plant-derived biochar, J. Hazard. Mater. 290 (2015) 43-50. https://doi.org/10.1016/j.jhazmat.2015.02.046.

[146] A.U. Rajapaksha, M. Vithanage, S.S. Lee, D.-C. Seo, D.C.W. Tsang, Y.S. Ok, Steam activation of biochars facilitates kinetics and $\mathrm{pH}$-resilience of sulfamethazine sorption, J. Soils Sediments. 16 (2016) 889-895. https://doi.org/10.1007/s11368-015-1325-x.

[147] X. Zhu, C. Li, J. Li, B. Xie, J. Lü, Y. Li, Thermal treatment of biochar in the air/nitrogen atmosphere for developed mesoporosity and enhanced adsorption to tetracycline, Bioresour. Technol. 263 (2018) 475-482. https://doi.org/10.1016/j.biortech.2018.05.041.

[148] S. Ge, S.Y. Foong, N.L. Ma, R.K. Liew, W.A. Wan Mahari, C. Xia, P.N.Y. Yek, W. Peng, W.L. Nam, X.Y. Lim, C.M. Liew, C.C. Chong, C. Sonne, S.S. Lam, Vacuum pyrolysis incorporating microwave heating and base mixture modification: An integrated approach to transform biowaste into eco-friendly bioenergy products, Renew. Sustain. Energy Rev. 127 (2020) 109871. https://doi.org/10.1016/j.rser.2020.109871.

[149] X. Yang, Y. Wan, Y. Zheng, F. He, Z. Yu, J. Huang, H. Wang, Y.S. Ok, Y. Jiang, B. Gao, Surface functional groups of carbon-based adsorbents and their roles in the removal of heavy metals from aqueous solutions: A critical review, Chem. Eng. J. 366 (2019) 608-621. https://doi.org/10.1016/j.cej.2019.02.119.

[150] P. Liu, W.-J. Liu, H. Jiang, J.-J. Chen, W.-W. Li, H.-Q. Yu, Modification of bio-char derived from fast pyrolysis of biomass and its application in removal of tetracycline from aqueous solution, Bioresour. Technol. 121 (2012) 235-240. https://doi.org/10.1016/j.biortech.2012.06.085.

[151] Y. Fan, B. Wang, S. Yuan, X. Wu, J. Chen, L. Wang, Adsorptive removal of chloramphenicol from wastewater by $\mathrm{NaOH}$ modified bamboo charcoal, Bioresour. Technol. 101 (2010) 76617664. https://doi.org/10.1016/j.biortech.2010.04.046.

[152] C.V. Gómez-Pacheco, J. Rivera-Utrilla, M. Sánchez-Polo, J.J. López-Peñalver, Optimization of the preparation process of biological sludge adsorbents for application in water treatment, J. Hazard. Mater. 217-218 (2012) 76-84. https://doi.org/10.1016/j.jhazmat.2012.02.067.

[153] H.M. Jang, S. Yoo, Y.-K. Choi, S. Park, E. Kan, Adsorption isotherm, kinetic modeling and mechanism of tetracycline on Pinus taeda-derived activated biochar, Bioresour. Technol. 259 (2018) 24-31. https://doi.org/10.1016/j.biortech.2018.03.013.

[154] H.M. Jang, S. Yoo, S. Park, E. Kan, Engineered biochar from pine wood: characterization and potential application for removal of sulfamethoxazole in water, Environ. Eng. Res. 24 (2018) 608-617. https://doi.org/10.4491/eer.2018.358. 
[155] H.M. Jang, E. Kan, Engineered biochar from agricultural waste for removal of tetracycline in water, Bioresour. Technol. 284 (2019) 437-447. https://doi.org/10.1016/j.biortech.2019.03.131.

[156] H. Huang, J. Tang, K. Gao, R. He, H. Zhao, D. Werner, Characterization of KOH modified biochars from different pyrolysis temperatures and enhanced adsorption of antibiotics, RSC Adv. 7 (2017) 14640-14648. https://doi.org/10.1039/C6RA27881G.

[157] X.-R. Jing, Y.-Y. Wang, W.-J. Liu, Y.-K. Wang, H. Jiang, Enhanced adsorption performance of tetracycline in aqueous solutions by methanol-modified biochar, Chem. Eng. J. 248 (2014) 168-174. https://doi.org/10.1016/j.cej.2014.03.006.

[158] J.L. Gardea-Torresdey, M.K. Becker-Hapak, J.M. Hosea, D.W. Darnall, Effect of chemical modification of algal carboxyl groups on metal ion binding, Environ. Sci. Technol. 24 (1990) 1372-1378. https://doi.org/10.1021/es00079a011.

[159] Z. Tan, X. Zhang, L. Wang, B. Gao, J. Luo, R. Fang, W. Zou, N. Meng, Sorption of tetracycline on $\mathrm{H}_{2} \mathrm{O}_{2}$-modified biochar derived from rape stalk, Environ. Pollut. Bioavailab. 31 (2019) 198207. https://doi.org/10.1080/26395940.2019.1607779.

[160] M. Nič, J. Jirát, B. Košata, A. Jenkins, A. McNaught, eds., IUPAC Compendium of Chemical Terminology: Gold Book, 2.1.0 ed., IUPAC, Research Triagle Park, NC, 2009. http://goldbook.iupac.org (accessed September 13, 2019).

[161] X. Tan, Y. Liu, Y. Gu, Y. Xu, G. Zeng, X. Hu, S. Liu, X. Wang, S. Liu, J. Li, Biochar-based nanocomposites for the decontamination of wastewater: A review, Bioresour. Technol. 212 (2016) 318-333. https://doi.org/10.1016/j.biortech.2016.04.093.

[162] P. Krasucka, R. Zaleski, K. Skrzypiec, J. Goworek, Amberlite XAD copolymers as an environment for silica deposition, Microporous Mesoporous Mater. 237 (2017) 210-221. https://doi.org/10.1016/j.micromeso.2016.09.019.

[163] M. M. Dawoud, H. M. Saleh, Introductory chapter: background on composite materials, in: H. El-Din M. Saleh, M. Koller (Eds.), Charact. Some Compos. Mater., IntechOpen, 2019. https://www.intechopen.com/books/characterizations-of-some-compositematerials/introductory-chapter-background-on-composite-materials (accessed October 2, 2019).

[164] A.M. Awad, S.M.R. Shaikh, R. Jalab, M.H. Gulied, M.S. Nasser, A. Benamor, S. Adham, Adsorption of organic pollutants by natural and modified clays: a comprehensive review, Sep. Purif. Technol. 228 (2019) 115719. https://doi.org/10.1016/j.seppur.2019.115719.

[165] R. Foroutan, R. Mohammadi, A.S. Adeleye, S. Farjadfard, Z. Esvandi, H. Arfaeinia, G.A. Sorial, B. Ramavandi, S. Sahebi, Efficient arsenic(V) removal from contaminated water using natural clay and clay composite adsorbents, Environ. Sci. Pollut. Res. 26 (2019) 29748-29762. https://doi.org/10.1007/s11356-019-06070-5.

[166] Y. Yao, B. Gao, J. Fang, M. Zhang, H. Chen, Y. Zhou, A.E. Creamer, Y. Sun, L. Yang, Characterization and environmental applications of clay-biochar composites, Chem. Eng. J. 242 (2014) 136-143. https://doi.org/10.1016/j.cej.2013.12.062.

[167] B. Sarkar, M. Megharaj, Y. Xi, R. Naidu, Surface charge characteristics of organo-palygorskites and adsorption of p-nitrophenol in flow-through reactor system, Chem. Eng. J. 185-186 (2012) 35-43. https://doi.org/10.1016/j.cej.2011.05.062.

[168] B. Sarkar, R. Rusmin, U.C. Ugochukwu, R. Mukhopadhyay, K.M. Manjaiah, Modified clay minerals for environmental applications, in: Modif. Clay Zeolite Nanocomposite Mater., Elsevier, 2019: pp. 113-127. https://linkinghub.elsevier.com/retrieve/pii/B9780128146170000037 (accessed April 5, 2020).

[169] M.M. Barbooti, B.D. Al-Dabbagh, R.H. Hilal, Preparation, characterization and utilization of polyacrylic acid-kaolin composite in the removal of heavy metals from water, Int. J. Environ. Sci. Technol. 16 (2019) 4571-4582. https://doi.org/10.1007/s13762-018-2067-2. 
[170] X. Wang, Y. Gu, X. Tan, Y. Liu, Y. Zhou, X. Hu, X. Cai, W. Xu, C. Zhang, S. Liu, Functionalized biochar/clay composites for reducing the bioavailable fraction of arsenic and cadmium in river sediment, Environ. Toxicol. Chem. 38 (2019) 2337-2347. https://doi.org/10.1002/etc.4542.

[171] J.R. Ray, I.A. Shabtai, M. Teixidó, Y.G. Mishael, D.L. Sedlak, Polymer-clay composite geomedia for sorptive removal of trace organic compounds and metals in urban stormwater, Water Res. 157 (2019) 454-462. https://doi.org/10.1016/j.watres.2019.03.097.

[172] R. Mukhopadhyay, D. Bhaduri, B. Sarkar, R. Rusmin, D. Hou, R. Khanam, S. Sarkar, J. Kumar Biswas, M. Vithanage, A. Bhatnagar, Y.S. Ok, Clay-polymer nanocomposites: progress and challenges for use in sustainable water treatment, J. Hazard. Mater. 383 (2020) 121125. https://doi.org/10.1016/j.jhazmat.2019.121125.

[173] K.S.D. Premarathna, A.U. Rajapaksha, N. Adassoriya, B. Sarkar, N.M.S. Sirimuthu, A. Cooray, Y.S. Ok, M. Vithanage, Clay-biochar composites for sorptive removal of tetracycline antibiotic in aqueous media, J. Environ. Manage. 238 (2019) 315-322. https://doi.org/10.1016/j.jenvman.2019.02.069.

[174] J. Zhang, M. Lu, J. Wan, Y. Sun, H. Lan, X. Deng, Effects of pH, dissolved humic acid and Cu 2+ on the adsorption of norfloxacin on montmorillonite-biochar composite derived from wheat straw, Biochem. Eng. J. 130 (2018) 104-112. https://doi.org/10.1016/j.bej.2017.11.018.

[175] A. Ashiq, N.M. Adassooriya, B. Sarkar, A.U. Rajapaksha, Y.S. Ok, M. Vithanage, Municipal solid waste biochar-bentonite composite for the removal of antibiotic ciprofloxacin from aqueous media, J. Environ. Manage. 236 (2019) 428-435. https://doi.org/10.1016/j.jenvman.2019.02.006.

[176] J. Tang, H. Lv, Y. Gong, Y. Huang, Preparation and characterization of a novel graphene/biochar composite for aqueous phenanthrene and mercury removal, Bioresour. Technol. 196 (2015) 355-363. https://doi.org/10.1016/j.biortech.2015.07.047.

[177] T. Liu, B. Gao, J. Fang, B. Wang, X. Cao, Biochar-supported carbon nanotube and graphene oxide nanocomposites for $\mathrm{Pb}$ (II) and Cd( II ) removal, RSC Adv. 6 (2016) 24314-24319. https://doi.org/10.1039/C6RA01895E.

[178] B. Sarkar, S. Mandal, Y.F. Tsang, P. Kumar, K.-H. Kim, Y.S. Ok, Designer carbon nanotubes for contaminant removal in water and wastewater: A critical review, Sci. Total Environ. 612 (2018) 561-581. https://doi.org/10.1016/j.scitotenv.2017.08.132.

[179] S. Chuanyu, W. Yu, Synthesis and characterization of graphene oxide composite with Fe304, Mater. Sci.-Pol. 33 (2015) 488-490. https://doi.org/10.1515/msp-2015-0068.

[180] M. Inyang, B. Gao, A. Zimmerman, M. Zhang, H. Chen, Synthesis, characterization, and dye sorption ability of carbon nanotube-biochar nanocomposites, Chem. Eng. J. 236 (2014) 39-46. https://doi.org/10.1016/j.cej.2013.09.074.

[181] T.J.M. Fraga, M.N. Carvalho, M.G. Ghislandi, M.A. da Motta Sobrinho, Functionalized graphene-based materials as innovative adsorbents of organic pollutants: a concise overview, Braz. J. Chem. Eng. 36 (2019) 1-31. https://doi.org/10.1590/0104-6632.20190361s20180283.

[182] Y. Zhang, B. Cao, L. Zhao, L. Sun, Y. Gao, J. Li, F. Yang, Biochar-supported reduced graphene oxide composite for adsorption and coadsorption of atrazine and lead ions, Appl. Surf. Sci. 427 (2018) 147-155. https://doi.org/10.1016/j.apsusc.2017.07.237.

[183] D. Huang, X. Wang, C. Zhang, G. Zeng, Z. Peng, J. Zhou, M. Cheng, R. Wang, Z. Hu, X. Qin, Sorptive removal of ionizable antibiotic sulfamethazine from aqueous solution by graphene oxide-coated biochar nanocomposites: influencing factors and mechanism, Chemosphere. 186 (2017) 414-421. https://doi.org/10.1016/j.chemosphere.2017.07.154.

[184] M. Inyang, B. Gao, A. Zimmerman, Y. Zhou, X. Cao, Sorption and cosorption of lead and sulfapyridine on carbon nanotube-modified biochars, Environ. Sci. Pollut. Res. 22 (2015) 1868-1876. https://doi.org/10.1007/s11356-014-2740-z.

[185] F. Cheng, X. Li, Preparation and application of biochar-based catalysts for biofuel production, Catalysts. 8 (2018) 346. https://doi.org/10.3390/catal8090346.

[186] R. Li, J.J. Wang, L.A. Gaston, B. Zhou, M. Li, R. Xiao, Q. Wang, Z. Zhang, H. Huang, W. Liang, H. Huang, X. Zhang, An overview of carbothermal synthesis of metal-biochar composites for the 
removal of oxyanion contaminants from aqueous solution, Carbon. 129 (2018) 674-687. https://doi.org/10.1016/j.carbon.2017.12.070.

[187] R. Li, J.J. Wang, B. Zhou, M.K. Awasthi, A. Ali, Z. Zhang, A.H. Lahori, A. Mahar, Recovery of phosphate from aqueous solution by magnesium oxide decorated magnetic biochar and its potential as phosphate-based fertilizer substitute, Bioresour. Technol. 215 (2016) 209-214. https://doi.org/10.1016/j.biortech.2016.02.125.

[188] D.-W. Cho, K. Yoon, Y. Ahn, Y. Sun, D.C.W. Tsang, D. Hou, Y.S. Ok, H. Song, Fabrication and environmental applications of multifunctional mixed metal-biochar composites (MMBC) from red mud and lignin wastes, J. Hazard. Mater. 374 (2019) 412-419. https://doi.org/10.1016/j.jhazmat.2019.04.071.

[189] S. Wang, B. Gao, Y. Li, A. Mosa, A.R. Zimmerman, L.Q. Ma, W.G. Harris, K.W. Migliaccio, Manganese oxide-modified biochars: preparation, characterization, and sorption of arsenate and lead, Bioresour. Technol. 181 (2015) 13-17. https://doi.org/10.1016/j.biortech.2015.01.044.

[190] C. Li, L. Zhang, Y. Gao, A. Li, Facile synthesis of nano ZnO/ZnS modified biochar by directly pyrolyzing of zinc contaminated corn stover for $\mathrm{Pb}(\mathrm{II}), \mathrm{Cu}(\mathrm{II})$ and $\mathrm{Cr}(\mathrm{VI})$ removals, Waste Manag. 79 (2018) 625-637. https://doi.org/10.1016/j.wasman.2018.08.035.

[191] S. Wang, M. Zhao, M. Zhou, Y.C. Li, J. Wang, B. Gao, S. Sato, K. Feng, W. Yin, A.D. Igalavithana, P. Oleszczuk, X. Wang, Y.S. Ok, Biochar-supported nZVI (nZVI/BC) for contaminant removal from soil and water: a critical review, J. Hazard. Mater. 373 (2019) 820-834. https://doi.org/10.1016/j.jhazmat.2019.03.080.

[192] I.K.M. Yu, X. Xiong, D.C.W. Tsang, L. Wang, A.J. Hunt, H. Song, J. Shang, Y.S. Ok, C.S. Poon, Aluminium-biochar composites as sustainable heterogeneous catalysts for glucose isomerisation in a biorefinery, Green Chem. 21 (2019) 1267-1281. https://doi.org/10.1039/C8GC02466A.

[193] X. Yang, G. Xu, H. Yu, Z. Zhang, Preparation of ferric-activated sludge-based adsorbent from biological sludge for tetracycline removal, Bioresour. Technol. 211 (2016) 566-573. https://doi.org/10.1016/j.biortech.2016.03.140.

[194] Y. Zhou, X. Liu, Y. Xiang, P. Wang, J. Zhang, F. Zhang, J. Wei, L. Luo, M. Lei, L. Tang, Modification of biochar derived from sawdust and its application in removal of tetracycline and copper from aqueous solution: adsorption mechanism and modelling, Bioresour. Technol. 245 (2017) 266-273. https://doi.org/10.1016/j.biortech.2017.08.178.

[195] Y. Chen, J. Shi, Q. Du, H. Zhang, Y. Cui, Antibiotic removal by agricultural waste biochars with different forms of iron oxide, RSC Adv. 9 (2019) 14143-14153. https://doi.org/10.1039/C9RA01271K.

[196] R. Li, Z. Wang, X. Zhao, X. Li, X. Xie, Magnetic biochar-based manganese oxide composite for enhanced fluoroquinolone antibiotic removal from water, Environ. Sci. Pollut. Res. 25 (2018) 31136-31148. https://doi.org/10.1007/s11356-018-3064-1.

[197] X. Tan, S. Liu, Y. Liu, Y. Gu, G. Zeng, X. Cai, Z. Yan, C. Yang, X. Hu, B. Chen, One-pot synthesis of carbon supported calcined-Mg/Al layered double hydroxides for antibiotic removal by slow pyrolysis of biomass waste, Sci. Rep. 6 (2016). https://doi.org/10.1038/srep39691.

[198] J. Heo, Y. Yoon, G. Lee, Y. Kim, J. Han, C.M. Park, Enhanced adsorption of bisphenol A and sulfamethoxazole by a novel magnetic CuZnFe2O4-biochar composite, Bioresour. Technol. 281 (2019) 179-187. https://doi.org/10.1016/j.biortech.2019.02.091.

[199] H. Zhang, Z. Wang, R. Li, J. Guo, Y. Li, J. Zhu, X. Xie, TiO2 supported on reed straw biochar as an adsorptive and photocatalytic composite for the efficient degradation of sulfamethoxazole in aqueous matrices, Chemosphere. 185 (2017) 351-360. https://doi.org/10.1016/j.chemosphere.2017.07.025.

[200] D. Fu, Z. Chen, D. Xia, L. Shen, Y. Wang, Q. Li, A novel solid digestate-derived biochar-Cu NP composite activating $\mathrm{H} 2 \mathrm{O} 2$ system for simultaneous adsorption and degradation of tetracycline, Environ. Pollut. 221 (2017) 301-310. https://doi.org/10.1016/j.envpol.2016.11.078. 
[201] J. Deng, H. Dong, C. Zhang, Z. Jiang, Y. Cheng, K. Hou, L. Zhang, C. Fan, Nanoscale zero-valent iron/biochar composite as an activator for Fenton-like removal of sulfamethazine, Sep. Purif. Technol. 202 (2018) 130-137. https://doi.org/10.1016/j.seppur.2018.03.048.

[202] V.-T. Nguyen, C.-M. Hung, T.-B. Nguyen, J.-H. Chang, T.-H. Wang, C.-H. Wu, Y.-L. Lin, C.-W. Chen, C.-D. Dong, Efficient heterogeneous activation of persulfate by iron-modified biochar for removal of antibiotic from aqueous solution: a case study of tetracycline removal, Catalysts. 9 (2019) 49. https://doi.org/10.3390/catal9010049.

[203] J. Xu, X. Zhang, C. Sun, J. Wan, H. He, F. Wang, Y. Dai, S. Yang, Y. Lin, X. Zhan, Insights into removal of tetracycline by persulfate activation with peanut shell biochar coupled with amorphous $\mathrm{Cu}$-doped $\mathrm{FeOOH}$ composite in aqueous solution, Environ. Sci. Pollut. Res. 26 (2019) 2820-2834. https://doi.org/10.1007/s11356-018-3777-1.

[204] D. Harikishore Kumar Reddy, K. Vijayaraghavan, J.A. Kim, Y.-S. Yun, Valorisation of postsorption materials: Opportunities, strategies, and challenges, Adv. Colloid Interface Sci. 242 (2017) 35-58. https://doi.org/10.1016/j.cis.2016.12.002.

[205] J. Gómez-Pastora, E. Bringas, I. Ortiz, Recent progress and future challenges on the use of high performance magnetic nano-adsorbents in environmental applications, Chem. Eng. J. 256 (2014) 187-204. https://doi.org/10.1016/j.cej.2014.06.119.

[206] D. Bhagawan, S. Poodari, G. Ravi kumar, S. Golla, C. Anand, K.S. Banda, V. Himabindu, S. Vidyavathi, Reactivation and recycling of spent carbon using solvent desorption followed by thermal treatment (TR), J. Mater. Cycles Waste Manag. 17 (2015) 185-193. https://doi.org/10.1007/s10163-014-0237-y.

[207] Y. Dai, N. Zhang, C. Xing, Q. Cui, Q. Sun, The adsorption, regeneration and engineering applications of biochar for removal organic pollutants: A review, Chemosphere. 223 (2019) 12-27. https://doi.org/10.1016/j.chemosphere.2019.01.161.

[208] R.S. de Lima, C.L. de Paiva e Silva Zanta, L. Meili, P.V. dos Santos Lins, G.E. de Souza dos Santos, J. Tonholo, Fenton-based processes for the regeneration of biochar from Syagrus coronata biomass used as dye adsorbent, DESALINATION WATER Treat. 162 (2019) 391-398. https://doi.org/10.5004/dwt.2019.24343.

[209] J.U. Ani, K.G. Akpomie, U.C. Okoro, L.E. Aneke, O.D. Onukwuli, O.T. Ujam, Potentials of activated carbon produced from biomass materials for sequestration of dyes, heavy metals, and crude oil components from aqueous environment, Appl. Water Sci. 10 (2020). https://doi.org/10.1007/s13201-020-1149-8.

[210] Y. Yao, B. Gao, J. Chen, L. Yang, Engineered Biochar Reclaiming Phosphate from Aqueous Solutions: Mechanisms and Potential Application as a Slow-Release Fertilizer, Environ. Sci. Technol. 47 (2013) 8700-8708. https://doi.org/10.1021/es4012977.

[211] M. Waqas, A.S. Aburiazaiza, R. Miandad, M. Rehan, M.A. Barakat, A.S. Nizami, Development of biochar as fuel and catalyst in energy recovery technologies, J. Clean. Prod. 188 (2018) 477488. https://doi.org/10.1016/j.jclepro.2018.04.017.

[212] H. Abdullah, H. Wu, Biochar as a Fuel: 1. Properties and Grindability of Biochars Produced from the Pyrolysis of Mallee Wood under Slow-Heating Conditions, Energy Fuels. 23 (2009) 4174-4181. https://doi.org/10.1021/ef900494t.

[213] Dudek, Świechowski, Manczarski, Koziel, Białowiec, The Effect of Biochar Addition on the Biogas Production Kinetics from the Anaerobic Digestion of Brewers' Spent Grain, Energies. 12 (2019) 1518. https://doi.org/10.3390/en12081518.

[214] C.W. Wambugu, E.R. Rene, J. van de Vossenberg, C. Dupont, E.D. van Hullebusch, Role of Biochar in Anaerobic Digestion Based Biorefinery for Food Waste, Front. Energy Res. 7 (2019). https://doi.org/10.3389/fenrg.2019.00014.

[215] S. Shackley, J. Hammond, J. Gaunt, R. Ibarrola, The feasibility and costs of biochar deployment in the UK, Carbon Manag. 2 (2011) 335-356. https://doi.org/10.4155/cmt.11.22.

[216] M.B. Ahmed, J.L. Zhou, H.H. Ngo, W. Guo, Insight into biochar properties and its cost analysis, Biomass Bioenergy. 84 (2016) 76-86. https://doi.org/10.1016/j.biombioe.2015.11.002. 
[217] B.A. Oni, O. Oziegbe, O.O. Olawole, Significance of biochar application to the environment and economy, Ann. Agric. Sci. 64 (2019) 222-236. https://doi.org/10.1016/j.aoas.2019.12.006.

[218] Transforming our world : the 2030 Agenda for Sustainable Development, (2015). https://www.refworld.org/docid/57b6e3e44.html (accessed April 22, 2020).

[219] C. Zhang, G. Zeng, D. Huang, C. Lai, M. Chen, M. Cheng, W. Tang, L. Tang, H. Dong, B. Huang, X. Tan, R. Wang, Biochar for environmental management: Mitigating greenhouse gas emissions, contaminant treatment, and potential negative impacts, Chem. Eng. J. 373 (2019) 902-922. https://doi.org/10.1016/j.cej.2019.05.139.

[220] W.-J. Liu, H. Jiang, H.-Q. Yu, Development of Biochar-Based Functional Materials: Toward a Sustainable Platform Carbon Material, Chem. Rev. 115 (2015) 12251-12285. https://doi.org/10.1021/acs.chemrev.5b00195.

[221] S.P. Galinato, J.K. Yoder, D. Granatstein, The economic value of biochar in crop production and carbon sequestration, Energy Policy. 39 (2011) 6344-6350. https://doi.org/10.1016/j.enpol.2011.07.035.

[222] https://standards.iteh.ai/catalog/standards/cen/ec6fa589-b01e-41cc-958d-a8ff4e9ef892/en12915-1-2009, (n.d.).

[223] S. Meyer, L. Genesio, I. Vogel, H.-P. Schmidt, G. Soja, E. Someus, S. Shackley, F.G.A. Verheijen, B. Glaser, BIOCHAR STANDARDIZATION AND LEGISLATION HARMONIZATION, J. Environ. Eng. Landsc. Manag. 25 (2017) 175-191. https://doi.org/10.3846/16486897.2016.1254640.

[224] B. Saletnik, G. Zaguła, M. Bajcar, M. Tarapatskyy, G. Bobula, C. Puchalski, Biochar as a Multifunctional Component of the Environment-A Review, Appl. Sci. 9 (2019) 1139. https://doi.org/10.3390/app9061139. 
Table 1 Classification of antibiotics according to chemical structure, including examples of compounds (structure figures are taken from ChemSpider http://www.chemspider.com) and mechanisms of action [5,13,15,57,60-62].

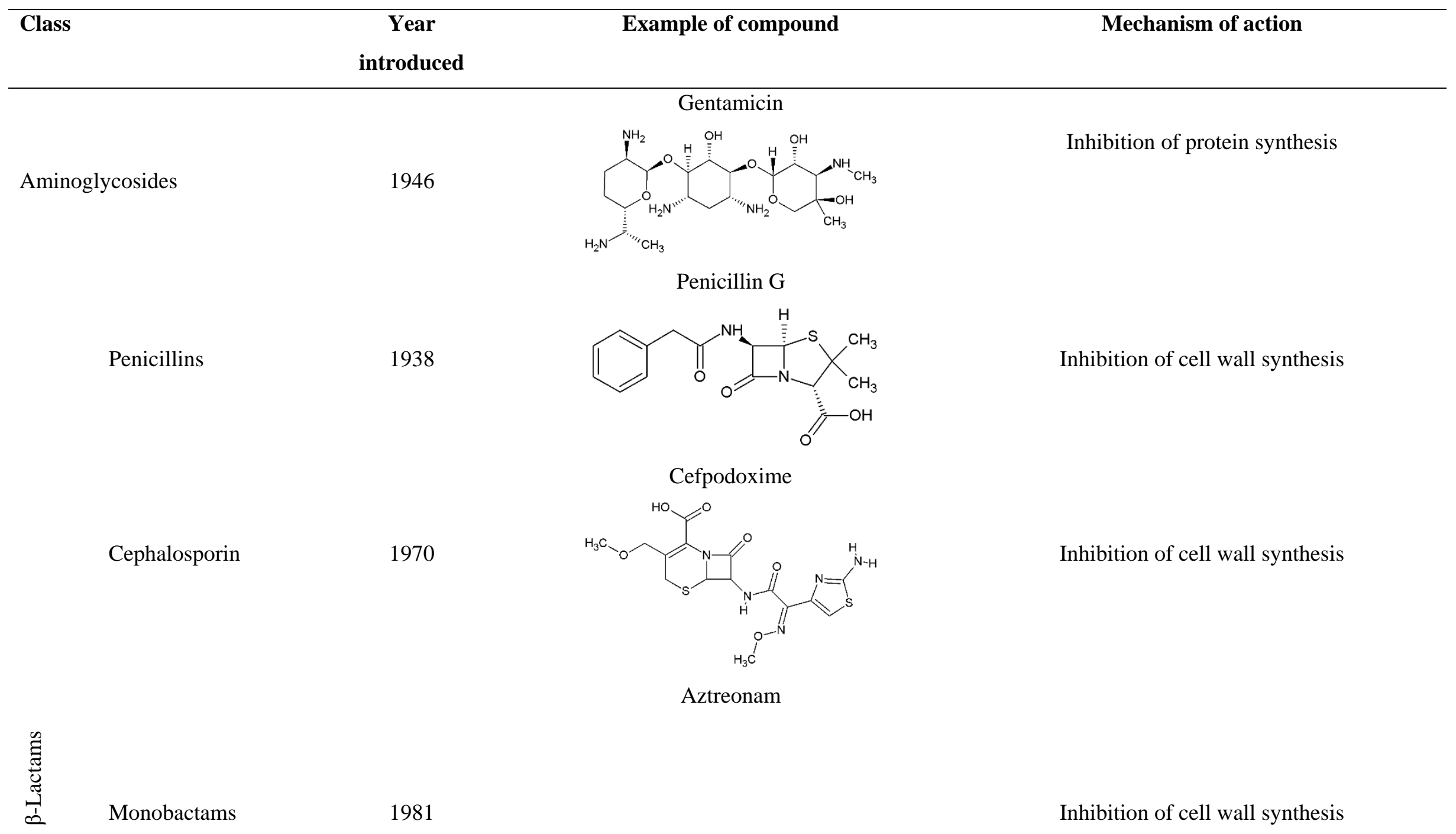


Carbapenems

1985

Chloramphenicols

1948

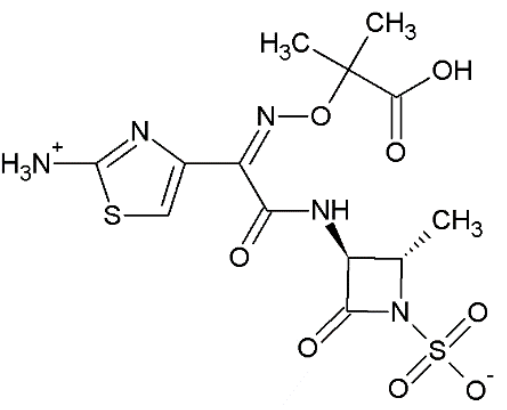

Meropenem

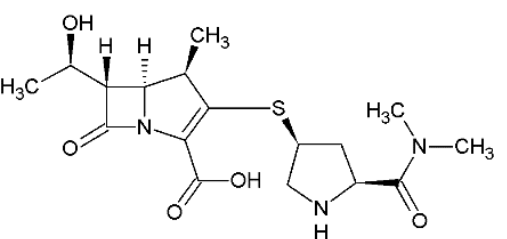

Chloramphenicol

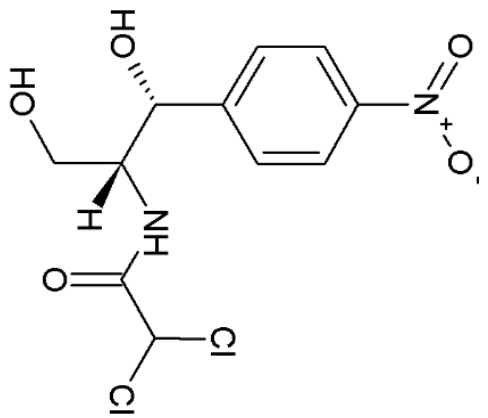

Vancomycin
Inhibition of cell wall synthesis

Inhibition of protein synthesis

Inhibition of cell wall synthesis 
Lincosamides

Macrolides/

Ketolides

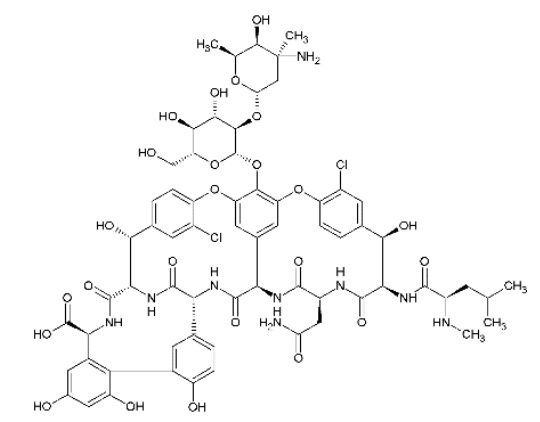

Lincomycin

1952

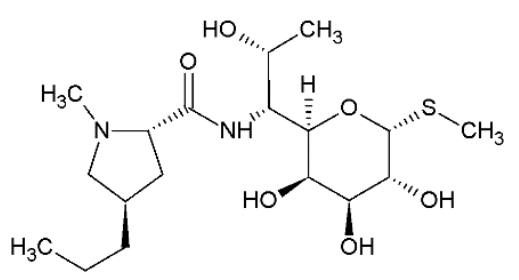

Erythromycin

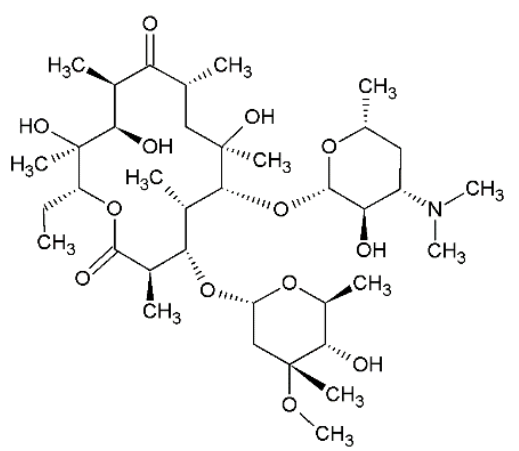

/Telithromycin
$1951 /$

2007
Inhibition of protein synthesis

Inhibition of protein synthesis 


\section{Nitroimidazole}

1960

Oxazolidinones

Polymyxins

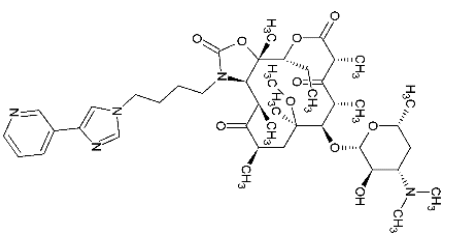

Metronidazole

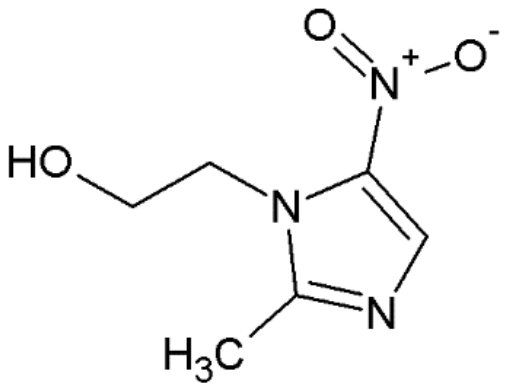

Linezolid

2000

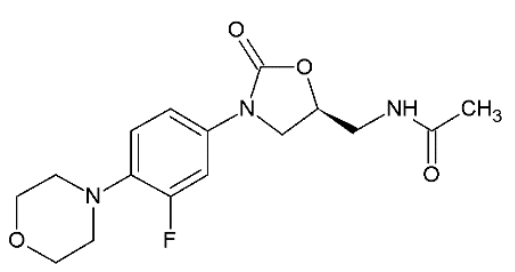

\section{Colistin}

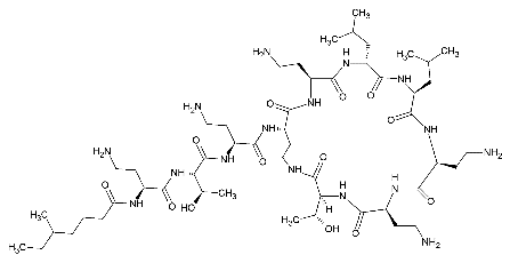

Rifampicin
Inhibition of nucleic acid synthesis

Inhibition of protein synthesis

\section{Breaking up the cell membrane}

Inhibition of nucleic acids synthesis 
Rifamycins

1958

Sulphonamides

1936

Tetracyclines

1952

Quinolones

1968

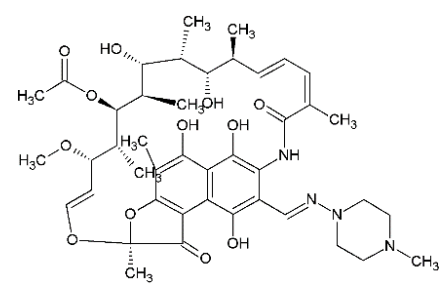

Sulfadimidine

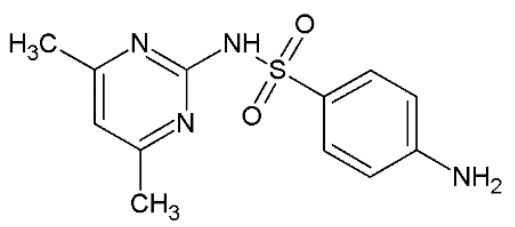

Tetracycline
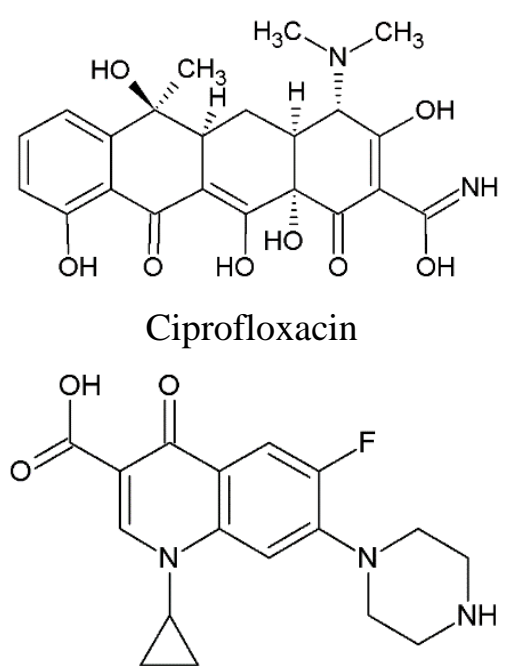

Blockage of folic acid metabolism

Inhibition of protein synthesis

Inhibition of nucleic acid synthesis 
Table 2. Antibiotic adsorption capacities on pristine BCs derived from different feedstocks at various conditions.

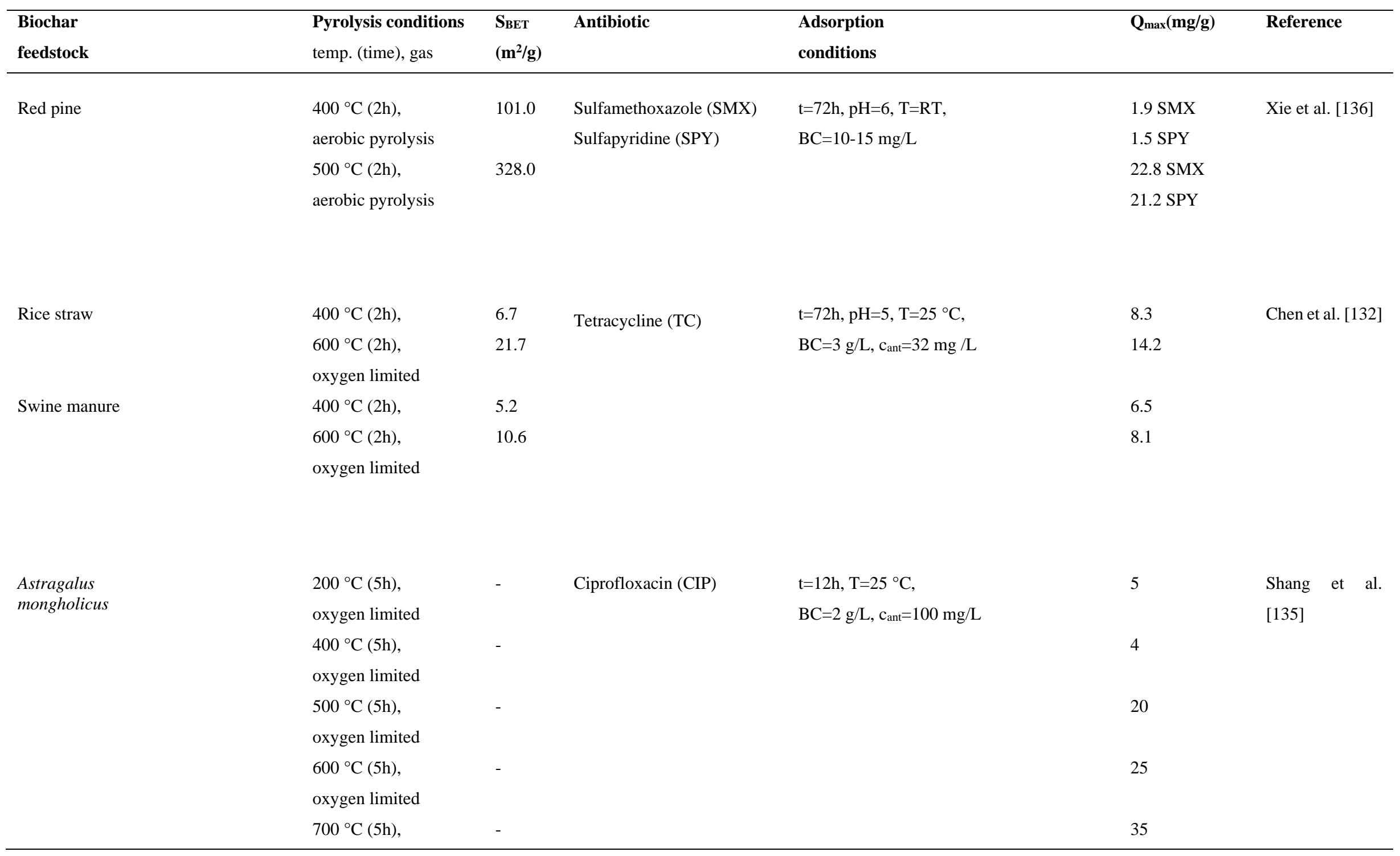




\begin{tabular}{|c|c|c|c|c|c|c|}
\hline \multirow[b]{3}{*}{ Bull manure } & \multicolumn{6}{|l|}{ oxygen limited } \\
\hline & $\begin{array}{l}800{ }^{\circ} \mathrm{C}(5 \mathrm{~h}) \\
\text { oxygen limited }\end{array}$ & \multicolumn{3}{|l|}{176.0} & \multicolumn{2}{|l|}{38} \\
\hline & $600^{\circ} \mathrm{C}, \mathrm{N}_{2}$ & 250.0 & Lincomycin (LIN) & $\begin{array}{l}\mathrm{t}=48 \mathrm{~h}, \mathrm{pH}=10, \mathrm{~T}=25^{\circ} \mathrm{C} \\
\mathrm{BC}=1 \mathrm{~g} / \mathrm{L}, \mathrm{c}_{\mathrm{ant}}=1 \mathrm{mg} / \mathrm{L}\end{array}$ & 0.30 & Liu et al. [140] \\
\hline Dairy manure & $600^{\circ} \mathrm{C}, \mathrm{N}_{2}$ & 229.0 & & & 0.37 & \\
\hline Poultry manure & $600^{\circ} \mathrm{C}, \mathrm{N}_{2}$ & 37.0 & & & 0.43 & \\
\hline Pinewood & $600{ }^{\circ} \mathrm{C}(3 \mathrm{~h}), \mathrm{N}_{2}$ & 337.0 & Tetracycline (TC) & $\mathrm{t}=48 \mathrm{~h}, \mathrm{~T}=25^{\circ} \mathrm{C}$, & TC 5.53 & Li et al. [133] \\
\hline \multirow{15}{*}{ Pinus radiata } & & & Sulfadiazine (SD) & $\mathrm{BC}=0.08-0.5 \mathrm{~g} / \mathrm{L}, \mathrm{c}_{\mathrm{ant}}=6-48 \mathrm{mg} / \mathrm{L}$ & SD 1.27 & \\
\hline & $600^{\circ} \mathrm{C}(3 \mathrm{~h})$ & 391.0 & & & TC 6.42 & \\
\hline & Air: $\mathrm{N}_{2} 1: 5$ & & & & SD 2.20 & \\
\hline & $700{ }^{\circ} \mathrm{C}(3 \mathrm{~h}), \mathrm{N}_{2}$ & 369.0 & & & TC 7.38 & \\
\hline & & & & & SD 2.84 & \\
\hline & $700^{\circ} \mathrm{C}(3 \mathrm{~h})$ & 454.0 & & & TC 17.5 & \\
\hline & Air: $\mathrm{N}_{2} 1: 10$ & & & & SD 9.32 & \\
\hline & $700{ }^{\circ} \mathrm{C}(3 \mathrm{~h})$ & 541.0 & & & TC 101 & \\
\hline & Air: $\mathrm{N}_{2} 1: 5$ & & & & SD 123 & \\
\hline & $800^{\circ} \mathrm{C}(3 \mathrm{~h}), \mathrm{N}_{2}$ & 431.0 & & & TC 8.66 & \\
\hline & & & & & SD 4.94 & \\
\hline & $800^{\circ} \mathrm{C}(3 \mathrm{~h})$ & 483.0 & & & TC 26.6 & \\
\hline & Air: $\mathrm{N}_{2} 1: 10$ & & & & SD 11.4 & \\
\hline & $800{ }^{\circ} \mathrm{C}(3 \mathrm{~h})$ & 738.0 & & & TC 261 & \\
\hline & Air: $\mathrm{N}_{2} 1: 5$ & & & & SD 163 & \\
\hline
\end{tabular}




\begin{tabular}{|c|c|c|c|c|c|c|}
\hline Alfalfa Medicago sativa $L$. & $500{ }^{\circ} \mathrm{C}(0.5 \mathrm{~h}), \mathrm{N}_{2}$ & 31.1 & Tetracycline (TC) & $\begin{array}{l}\mathrm{t}=5 \mathrm{~d}, \mathrm{pH}=5, \mathrm{~T}=25^{\circ} \mathrm{C} \\
\mathrm{BC}=0.1 \mathrm{~g} / \mathrm{L}, \mathrm{c}_{\text {ant }}=10-100 \mathrm{mg} / \mathrm{L}\end{array}$ & 372.31 & $\begin{array}{l}\text { Jang \& Kan } \\
{[134]}\end{array}$ \\
\hline Bermudagrass Cynodon dactylon & $500{ }^{\circ} \mathrm{C}(0.5 \mathrm{~h}), \mathrm{N}_{2}$ & 34.7 & & & 44.24 & \\
\hline \multirow[t]{4}{*}{ Waste Auricularia auricula dregs } & $300{ }^{\circ} \mathrm{C}(2 \mathrm{~h}), \mathrm{N}_{2}$ & 2.6 & Tetracycline (TC) & $\mathrm{t}=12 \mathrm{~h}, \mathrm{~T}=\mathrm{RT}$ & 7.22 & Dai et al. [130] \\
\hline & & & & $\mathrm{BC}=0.8-4 \mathrm{~g} / \mathrm{L}, \mathrm{c}_{\mathrm{ant}}=10-25 \mathrm{mg} / \mathrm{L}$ & & \\
\hline & $500{ }^{\circ} \mathrm{C}(2 \mathrm{~h}), \mathrm{N}_{2}$ & 19.0 & & & 9.90 & \\
\hline & $700{ }^{\circ} \mathrm{C}(2 \mathrm{~h}), \mathrm{N}_{2}$ & 46.6 & & & 11.90 & \\
\hline \multirow[t]{3}{*}{ Rice straw } & $300^{\circ} \mathrm{C}(2 \mathrm{~h})$ & 2.5 & Tetracycline (TC) & $\begin{array}{l}\mathrm{t}=24 \mathrm{~h}, \mathrm{~T}=25^{\circ} \mathrm{C}, \\
\mathrm{BC}=3 \mathrm{~g} / \mathrm{L}, \mathrm{c}_{\mathrm{ant}}=0.5-32 \mathrm{mg} / \mathrm{L}\end{array}$ & 4136 & $\begin{array}{l}\text { Wang et al. } \\
{[129]}\end{array}$ \\
\hline & $500^{\circ} \mathrm{C}(2 \mathrm{~h})$ & 10.2 & & & 8756 & \\
\hline & $700^{\circ} \mathrm{C}(2 \mathrm{~h})$ & 27.7 & & & 14157 & \\
\hline Corn cob & $\begin{array}{l}500{ }^{\circ} \mathrm{C}(24 \mathrm{~h}) \\
\text { oxygen limited }\end{array}$ & 2.9 & Chlortetracycline (CTC) & $\begin{array}{l}\mathrm{t}=24 \mathrm{~h}, \mathrm{pH}=5, \mathrm{~T}=25^{\circ} \mathrm{C}, \\
\mathrm{BC}=10 \mathrm{~g} / \mathrm{L}, \mathrm{c}_{\text {ant }}=200 \mathrm{mg} / \mathrm{L}\end{array}$ & 12.39 & $\begin{array}{l}\text { Zhang et al. } \\
{[141]}\end{array}$ \\
\hline Sugarcane bagasse & $\begin{array}{l}500^{\circ} \mathrm{C}(24 \mathrm{~h}), \\
\text { oxygen limited }\end{array}$ & 248.1 & & & 16.96 & \\
\hline
\end{tabular}

Where: $\mathrm{S}_{\mathrm{BET}}-$ the specific surface area determined from $\mathrm{N}_{2}$ sorption measurements according to the BET equation, $\mathrm{t}-\mathrm{adsorption}$ time, $\mathrm{pH}-$ adsorption $\mathrm{pH}$, $\mathrm{T}$ - adsorption temperature, $\mathrm{BC}$-adsorbent dose, $\mathrm{c}_{\mathrm{ant}}-$ initial antibiotic concentration, $\mathrm{Q}_{\max }-$ the maximum adsorption capacity 
Table 3. Antibiotic adsorption on modified BCs.

\begin{tabular}{|c|c|c|c|c|c|c|c|}
\hline $\begin{array}{l}\text { Biochar } \\
\text { feedstock }\end{array}$ & $\begin{array}{l}\text { Pyrolysis } \\
\text { conditions } \\
\text { temp. (time), gas }\end{array}$ & $\begin{array}{l}\text { Sorbents/ } \\
\text { Modificated sorbents }\end{array}$ & $\begin{array}{l}\text { SBET } \\
\left(\mathrm{m}^{2} / \mathrm{g}\right)\end{array}$ & Antibiotic & Adsorption condition & $\begin{array}{l}\text { max } \\
(\mathrm{mg} / \mathrm{g})\end{array}$ & Reference \\
\hline $\begin{array}{l}\text { Burcucumber } \\
\text { Sicyos } \\
\text { angulatus L. }\end{array}$ & $\begin{array}{l}700 \quad{ }^{\circ} \mathrm{C} \quad(2 \mathrm{~h}), \\
\text { oxygen limited }\end{array}$ & $\begin{array}{l}\text { Pristine } \mathrm{BC} \\
\text { Steam activated } \mathrm{BC} \\
\left(5 \mathrm{~mL} / \mathrm{min}, 45 \mathrm{~min}, 700^{\circ} \mathrm{C}\right)\end{array}$ & $\begin{array}{l}2.3 \\
7.1\end{array}$ & $\begin{array}{l}\text { Sulfamethazine } \\
\text { (SMT) }\end{array}$ & $\begin{array}{l}\mathrm{t}=72 \mathrm{~h}, \mathrm{pH}=3, \mathrm{~T}=25^{\circ} \mathrm{C}, \\
\mathrm{BC}=1 \mathrm{~g} / \mathrm{L}, \mathrm{c}_{a n t}=2.5-50 \mathrm{mg} / \mathrm{L},\end{array}$ & $\begin{array}{l}20.56 \\
37.73\end{array}$ & $\begin{array}{l}\text { Rajapaksha et al. } \\
\text { [145] }\end{array}$ \\
\hline Tea waste & $\begin{array}{l}700 \quad{ }^{\circ} \mathrm{C} \quad(2 \mathrm{~h}), \\
\text { oxygen limited }\end{array}$ & $\begin{array}{l}\text { Pristine } \mathrm{BC} \\
\text { Steam activated } \mathrm{BC} \\
\left(5 \mathrm{~mL} / \mathrm{min}, 45 \mathrm{~min}, 700^{\circ} \mathrm{C}\right)\end{array}$ & $\begin{array}{l}342.2 \\
576.1\end{array}$ & $\begin{array}{l}\text { Sulfamethazine } \\
\text { (SMT) }\end{array}$ & $\begin{array}{l}\mathrm{t}=72 \mathrm{~h}, \mathrm{pH}=3, \mathrm{~T}=25^{\circ} \mathrm{C}, \\
\mathrm{BC}=1 \mathrm{~g} / \mathrm{L}, \mathrm{c}_{a n t}=2.5-50 \mathrm{mg} / \mathrm{L},\end{array}$ & $\begin{array}{l}7.12 \\
33.81\end{array}$ & $\begin{array}{l}\text { Rajapaksha et al. } \\
\text { [144] }\end{array}$ \\
\hline $\begin{array}{l}\text { Pinus Radiata } \\
\text { sawdust }\end{array}$ & $400^{\circ} \mathrm{C}(2 \mathrm{~h}), \mathrm{N}_{2}$ & $\begin{array}{l}\text { Air activated BCs } \\
\left(3 \mathrm{~h}, 700{ }^{\circ} \mathrm{C}\right) \\
\mathrm{N}_{2} 200 \mathrm{ml} / \mathrm{min}+\text { air flux } \mathrm{ml} / \mathrm{min}:\end{array}$ & & Tetracycline (TC) & $\begin{array}{l}\mathrm{t}=48 \mathrm{~h}, \mathrm{pH}=6.8, \mathrm{~T}=25^{\circ} \mathrm{C}, \\
\mathrm{BC}=1 \mathrm{~g} / \mathrm{L}, \mathrm{c}_{\text {ant }}=25-500 \mathrm{mg} / \mathrm{L},\end{array}$ & & Zhu et al. [147] \\
\hline & & $\begin{array}{l}0 \\
30 \\
50 \\
70\end{array}$ & $\begin{array}{l}359.0 \\
457.0 \\
587.0 \\
601.0\end{array}$ & & & $\begin{array}{l}10.4 \\
55.3 \\
90.4 \\
96.1\end{array}$ & \\
\hline Rice straw & $\begin{array}{l}700 \quad{ }^{\circ} \mathrm{C} \quad(2 \mathrm{~h}), \\
\text { oxygen limited }\end{array}$ & $\begin{array}{l}\text { Pristine } \mathrm{BC} \\
\text { Post-synthesis modif. BCs by immersion } \\
\left(24 \mathrm{~h}, 25^{\circ} \mathrm{C}\right) \text { in } 14 \% \mathrm{H}_{3} \mathrm{PO}_{4}\end{array}$ & $\begin{array}{l}369.3 \\
372.2\end{array}$ & Tetracycline (TC) & $\begin{array}{l}\mathrm{t}=216 \mathrm{~h}, \mathrm{~T}=25^{\circ} \mathrm{C} \\
\mathrm{BC}=0.16-0.33 \mathrm{~g} / \mathrm{L}, \mathrm{c}_{\text {ant }}=120 \mathrm{mg} / \mathrm{L}\end{array}$ & $\begin{array}{l}150.2 \\
166.3\end{array}$ & Chen et al. [132] \\
\hline Swine manure & & $\begin{array}{l}\text { Pristine BC } \\
\text { Modified }\end{array}$ & $\begin{array}{l}227.6 \\
319.0\end{array}$ & & & $\begin{array}{l}127.8 \\
159.7\end{array}$ & \\
\hline Rice-husk & $500-550{ }^{\circ} \mathrm{C}$ & Pristine BC & 34.4 & $\begin{array}{l}\text { Tetracycline (TC) } \\
82\end{array}$ & $\mathrm{~T}=30^{\circ} \mathrm{C}$ & 16.95 & Liu et al. [150] \\
\hline
\end{tabular}


Post-synthesis modif. by stirring

$\left(1 \mathrm{~h}, 60-70{ }^{\circ} \mathrm{C}\right)$ in

$10 \% \mathrm{H}_{2} \mathrm{SO}_{4}(\mathrm{v} / \mathrm{v})$

$3 \mathrm{~mol} / \mathrm{L} \mathrm{KOH}$

Pristine BC

Post-synthesis modif. by stirring

$\left(6 \mathrm{~h}, 60^{\circ} \mathrm{C}\right)$ in

$10 \% \mathrm{H}_{2} \mathrm{SO}_{4}(\mathrm{v} / \mathrm{v})$

$10 \% \mathrm{KOH}$

Treatment plant $700{ }^{\circ} \mathrm{C}$

sludge

Pinus taeda

$300^{\circ} \mathrm{C}, \mathrm{N}_{2}$

Pristine BC

Pre-synthesis modif. impregantion

sludge in $\mathrm{NaOH}(50 \mathrm{~g} / 100 \mathrm{~g} \mathrm{w} / \mathrm{w})$

Post-synthesis modif. by mixing BC with

$4 \mathrm{M} \mathrm{NaOH}$ solution for $2 \mathrm{~h}$ and

carbonized $\left(800^{\circ} \mathrm{C}, 2 \mathrm{~h}\right)$

Pristine BC

Pristine $\mathrm{BC}$ carbonized at $800{ }^{\circ} \mathrm{C}$ for $2 \mathrm{~h}$

Alfalfa hays

$300^{\circ} \mathrm{C}, \mathrm{N}$

$\mathrm{BC}=5 \mathrm{~g} / \mathrm{L}, \mathrm{c}_{\mathrm{ant}}=0.5-1 \mathrm{~g} / \mathrm{L}$

Post-synthesis modif. by mixing $\mathrm{BC}$ with
0.7

46.8

117.8

$<1$

Chloramphenicol

(CAP)

$=0.5 \mathrm{~h}, \mathrm{~T}=25^{\circ} \mathrm{C}$,

$\mathrm{BC}=8 \mathrm{~g} / \mathrm{L}, \mathrm{c}_{\mathrm{ant}}=20 \mathrm{mg} / \mathrm{L}$

31.4

Tetracycline (TC)

$\mathrm{t}=8 \mathrm{~d}, \mathrm{~T}=25^{\circ} \mathrm{C}$

1.4

959.9

Sulfamethoxazole

(SMX)

Tetracycline (TC)

$\mathrm{t}=5 \mathrm{~d}, \mathrm{pH}=5, \mathrm{~T}=20^{\circ} \mathrm{C}$,

$\mathrm{BC}=0.1 \mathrm{~g} / \mathrm{L} \mathrm{c}_{\text {ant }}=10-100 \mathrm{mg} / \mathrm{L}$,

55.62

302.37
Tetracycline (TC)

$4 \mathrm{M} \mathrm{NaOH}$ solution for $2 \mathrm{~h}$ and

carbonizated $\left(800^{\circ} \mathrm{C}, 2 \mathrm{~h}\right)$
30.70 


\begin{tabular}{|c|c|c|c|c|c|c|c|}
\hline \multirow[t]{6}{*}{ Poplar sawdust } & $300{ }^{\circ} \mathrm{C}(6 \mathrm{~h})$ & Pristine $\mathrm{BC}$ & - & Tetracycline (TC) & $\mathrm{t}=72 \mathrm{~h}, \mathrm{~T}=25^{\circ} \mathrm{C}$, & 4.3 & Huang et al. [156] \\
\hline & & $\begin{array}{l}\text { Post-synthesis modif. by stirring } \\
\left(5 \mathrm{~h}, 65^{\circ} \mathrm{C}\right) \text { in } 2 \mathrm{M} \mathrm{KOH}\end{array}$ & 1.6 & & $c_{\text {ant }}=10-90 \mathrm{mg} / \mathrm{L}$ & 21.17 & \\
\hline & $500{ }^{\circ} \mathrm{C}(6 \mathrm{~h})$ & & 12.3 & & & 7.37 & \\
\hline & & & 106.8 & & & 4.97 & \\
\hline & $700{ }^{\circ} \mathrm{C}(6 \mathrm{~h})$ & & 111.4 & & & 11.63 & \\
\hline & & & 337.8 & & & 7.13 & \\
\hline \multirow[t]{2}{*}{ Rice-husk } & $500-550 \quad{ }^{\circ} \mathrm{C}$ & Pristine $\mathrm{BC}$ & 51.7 & Tetracycline (TC) & $\mathrm{t}=312 \mathrm{~h}, \mathrm{~T}=20^{\circ} \mathrm{C}$ & 81 & Jing et al. [157] \\
\hline & oxygen limited & Post-synthesis modif. with acid $\mathrm{MeOH}$ & 66.0 & & $\mathrm{BC}=1 \mathrm{~g} / \mathrm{L}, \mathrm{c}_{\text {ant }}=100 \mathrm{mg} / \mathrm{L}$ & 95 & \\
\hline \multirow[t]{6}{*}{ Rape stalk } & $300{ }^{\circ} \mathrm{C}(4 \mathrm{~h}) \mathrm{N}_{2}$ & Pristine $\mathrm{BC}$ & 3.9 & Tetracycline (TC) & $\mathrm{t}=48 \mathrm{~d}, \mathrm{~T}=25^{\circ} \mathrm{C}$ & 35.9 & Tan et al. [159] \\
\hline & & $\begin{array}{l}\text { Post-synthesis modif. by stirring ( } 24 \mathrm{~h} \text {, } \\
25^{\circ} \mathrm{C} \text { ) in } 30 \% \mathrm{H}_{2} \mathrm{O}_{2}\end{array}$ & 1.8 & & $\mathrm{BC}=0.1 \mathrm{~g} / \mathrm{L} c_{\mathrm{ant}}=1-15 \mathrm{mg} / \mathrm{L}$ & 34.0 & \\
\hline & $450{ }^{\circ} \mathrm{C}(4 \mathrm{~h}) \mathrm{N}_{2}$ & & 6.8 & & & 26.33 & \\
\hline & & & 4.2 & & & 32.83 & \\
\hline & $600^{\circ} \mathrm{C}(4 \mathrm{~h}) \mathrm{N}_{2}$ & & 112.4 & & & 32.0 & \\
\hline & & & 117.1 & & & 42.45 & \\
\hline
\end{tabular}

Where: $\mathrm{S}_{\mathrm{BET}}-$ the specific surface area determined from $\mathrm{N}_{2}$ sorption measurements according to the BET equation, $\mathrm{t}-\mathrm{adsorption}$ time, $\mathrm{pH}-$ adsorption $\mathrm{pH}$, $\mathrm{T}$ - adsorption temperature, $\mathrm{BC}$-adsorbent dose, $\mathrm{c}_{\mathrm{ant}}$ - initial antibiotic concentration, $\mathrm{Q}_{\max }-$ the maximum adsorption capacity 
Table 4. Antibiotic adsorption/degradation on biochar composites.

\begin{tabular}{|c|c|c|c|c|c|c|c|}
\hline $\begin{array}{l}\text { Biochar } \\
\text { feedstock }\end{array}$ & Composite preparation & Sorbent & $\begin{array}{l}\text { S }_{\text {BET }} \\
\left(\mathbf{m}^{2} / \mathbf{g}\right)\end{array}$ & Antibiotic & $\begin{array}{l}\text { Adsorption/ } \\
\text { degradation condition }\end{array}$ & $\begin{array}{l}Q_{\max }(\mathbf{m g} / \mathrm{g}) \\
\text { or } \\
\text { \%removal }\end{array}$ & Reference \\
\hline $\begin{array}{l}\text { Municipal solid } \\
\text { waste }\end{array}$ & $\begin{array}{l}\text { Pre-treatment biomass with } \\
\text { clays } \\
\text { Montmorillonite (MMT) and } \\
\text { Red earth clay }(\mathrm{RE}) \\
\text { Pyrolysis }\left(500^{\circ} \mathrm{C}, 0.5 \mathrm{~h}\right)\end{array}$ & $\begin{array}{l}\text { Pristine BC } \\
\text { BC-MMT } \\
\text { BC-RE }\end{array}$ & $\begin{array}{l}4.3 \\
8.7 \\
8.4\end{array}$ & Tetracycline (TC) & $\begin{array}{l}\mathrm{t}=12 \mathrm{~h}, \mathrm{pH}=3-9 \\
\mathrm{BC}=2 \mathrm{~g} / \mathrm{L}, \mathrm{c}_{\text {ant }}=20 \mathrm{mg} / \mathrm{L},\end{array}$ & $\begin{array}{l}3.9 \\
4.2 \\
77.9\end{array}$ & $\begin{array}{l}\text { Premarathna et al. } \\
{[173]}\end{array}$ \\
\hline Wheat straw & $\begin{array}{l}\text { Pre-treatment biomass with } \\
\text { Montmorillonite suspension } \\
\text { Pyrolysis }\left(400^{\circ} \mathrm{C}, 6 \mathrm{~h}\right)\end{array}$ & $\begin{array}{l}\text { Pristine BC } \\
\text { BC-MMT }\end{array}$ & $\begin{array}{l}20.1 \\
112.6\end{array}$ & Norfloxacin (NOR) & $\begin{array}{l}\mathrm{t}=48 \mathrm{~h}, \mathrm{pH}=3-11, \mathrm{~T}=25^{\circ} \mathrm{C}, \\
\mathrm{BC}=1.25 \mathrm{~g} / \mathrm{L}, \\
\mathrm{c}_{\text {ant }}=10 \mathrm{mg} / \mathrm{L},\end{array}$ & $\begin{array}{l}10.6 \\
25.5\end{array}$ & Zhang et al. [174] \\
\hline $\begin{array}{l}\text { Municipal solid } \\
\text { waste }\end{array}$ & $\begin{array}{l}\text { Pre-treatment biomass with } \\
\text { Bentonite (BT) suspension } \\
\text { Pyrolysis }\left(450^{\circ} \mathrm{C}, 0.5 \mathrm{~h}\right)\end{array}$ & $\begin{array}{l}\text { Pristine BC } \\
\text { BC-BT }\end{array}$ & $\begin{array}{l}167.6 \\
286.6\end{array}$ & Ciprofloxacin (CPX) & $\begin{array}{l}\mathrm{t}=12 \mathrm{~h}, \mathrm{pH}=6-7, \mathrm{~T}=25^{\circ} \mathrm{C}, \\
\mathrm{BC}=1 \mathrm{~g} / \mathrm{L} \\
\mathrm{c}_{\mathrm{ant}}=10-250 \mathrm{mg} / \mathrm{L}\end{array}$ & $\begin{array}{l}114.0 \\
190.0\end{array}$ & Ashiq et al. [175] \\
\hline Bamboo sawdust & $\begin{array}{lll}\text { Pre-treatment } & \text { biomass } & \text { with } \\
\text { Graphene } & \text { oxide } & (\mathrm{GO}) \\
\text { suspension } & & \end{array}$ & $\begin{array}{l}\text { Pristine BC } \\
\text { BC-GO }\end{array}$ & $\begin{array}{l}184.9 \\
348.2\end{array}$ & Sulfamethazine (SMT) & $\begin{array}{l}\mathrm{t}=48 \mathrm{~h}, \mathrm{pH}=3-9, \mathrm{~T}=25^{\circ} \mathrm{C} \\
\mathrm{BC}=1 \mathrm{~g} / \mathrm{L}, \mathrm{c}_{\text {ant }}=10 \mathrm{~g} / \mathrm{L}\end{array}$ & $\begin{array}{l}3.0 \\
6.5\end{array}$ & Huang et al. [183] \\
\hline
\end{tabular}




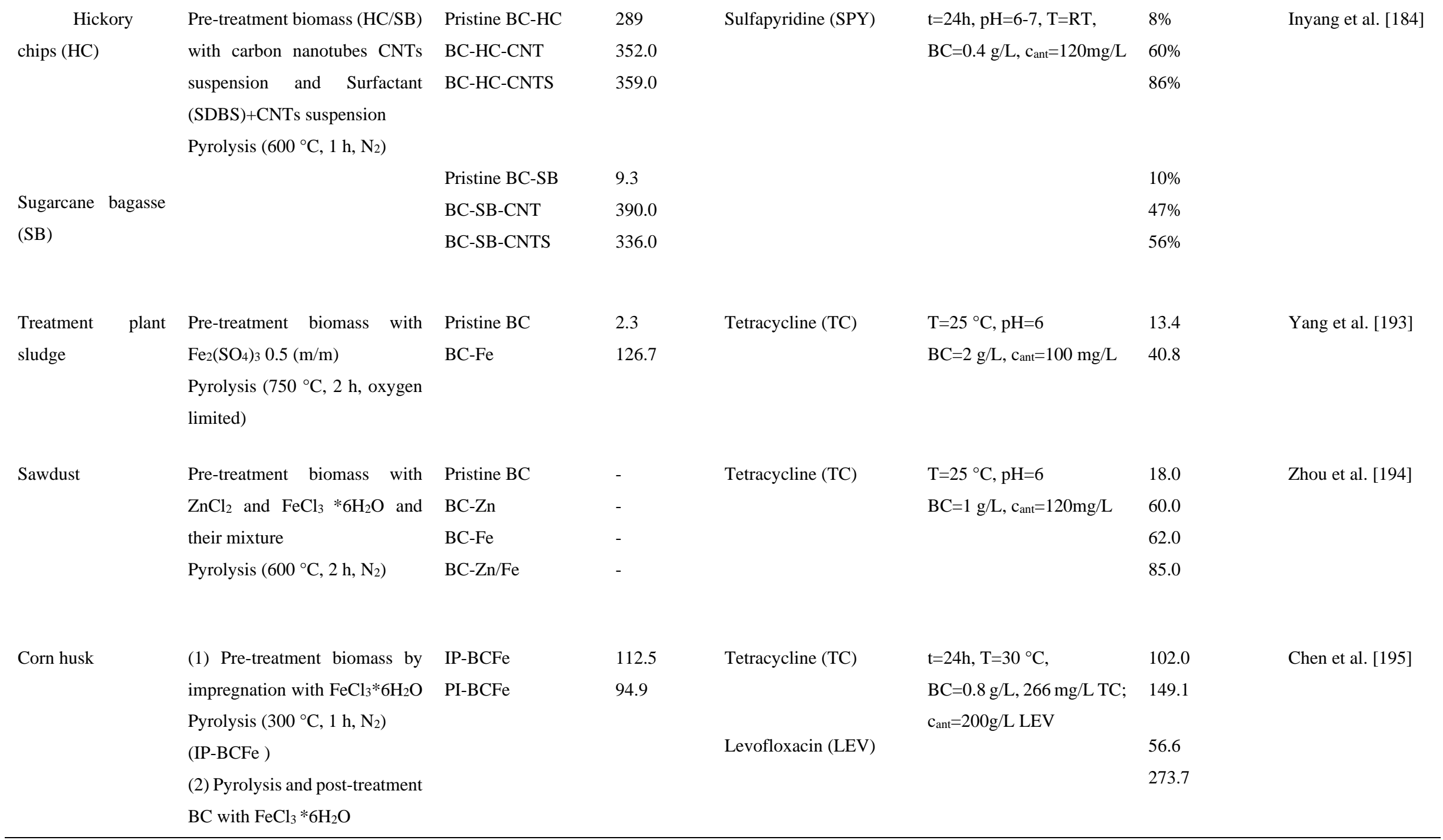




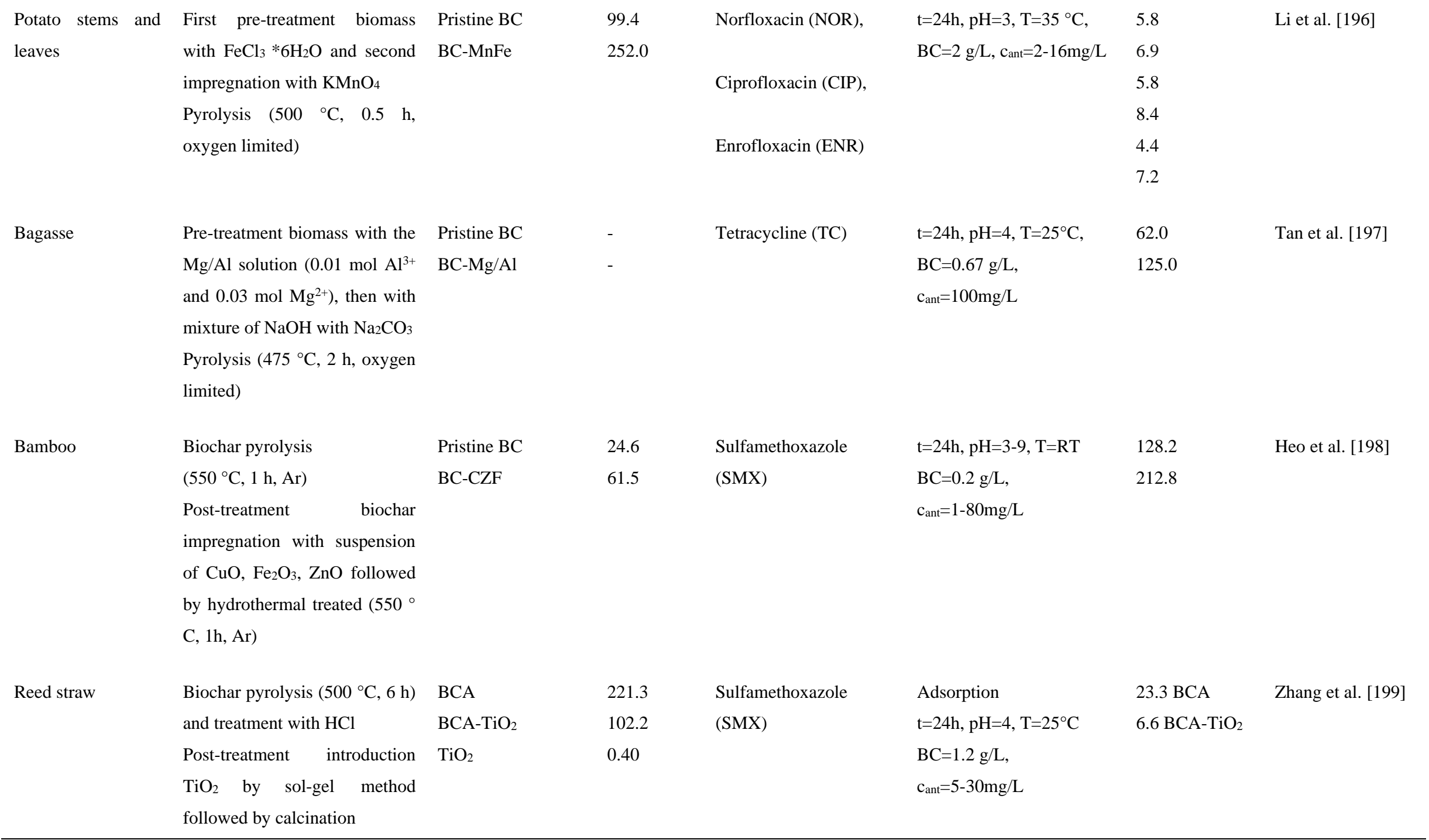




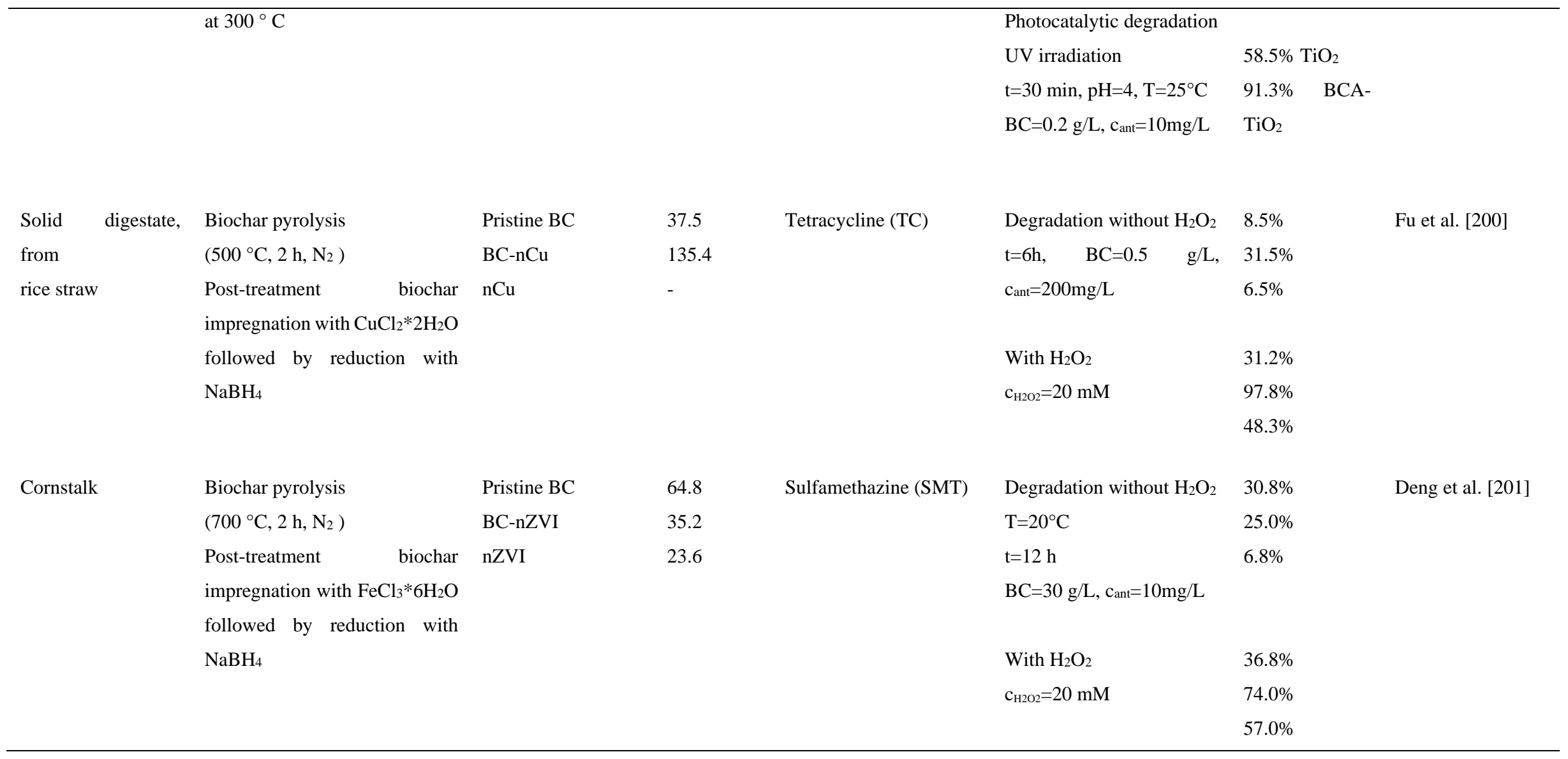

Where: $\mathrm{S}_{\mathrm{BET}}-$ the specific surface area determined from $\mathrm{N}_{2}$ sorption measurements according to the BET equation, $\mathrm{t}-$ adsorption time, $\mathrm{pH}-$ adsorption $\mathrm{pH}, \mathrm{T}-$ adsorption temperature, $\mathrm{BC}$ - adsorbent dose, $c_{\text {ant }}$-initial antibiotic concentration, $\mathrm{c}_{\mathrm{H} 2 \mathrm{O} 2}-\mathrm{H}_{2} \mathrm{O}_{2}$ concentration, $\mathrm{Q}_{\max }-$ the maximum adsorption capacity, \%removal - the maximum percentage of antibiotic removal 